Original Research Paper

\title{
Stability, Stress and Strain Analysis of Very Slender Pinned Thin-Walled Box Columns according to FEM, Euler and TSTh
}

\author{
${ }^{1 *}$ Krzysztof Murawski and ${ }^{2}$ Alexandre de Macêdo Wahrhaftig \\ ${ }^{1}$ Independent Researcher, Poland \\ ${ }^{2}$ Department of Construction and Structures (DCE), Polytechnic School, Federal University of Bahia (UFBA), \\ Rua Aristides Novís, 02, $5^{\circ}$ Andar, Federação, Salvador - BA, Brazil, CEP: 40210-910
}

Article history

Received: 21-03-2021

Revised: $16-04-2021$

Accepted: 22-04-2021

Corresponding Author:

Krzysztof Murawski

Independent Researcher,

Poland

Email: k.murawski@interia.pl

\begin{abstract}
In this study, a Finite Element Method (FEM) analysis is presented for the loss of stability in elastic states of very slender pinned without friction box-section thin-walled column axially compressed. From the FEM buckling linear stress analyses are determined the compressing critical forces for 36 cases, presented in tables and as the surface functions in dependence on the slenderness ratio and cross-section. Also are presented graphs obtained from the FEM post-buckling linear stress analysis for the elastic central line, slope, deflection and states of the stresses and strains of the box-section column $20 \times 28 \times 1 \times 2500 \mathrm{~mm}$ made of steel, by the assumption that a maximal deflection equals the half of a side dimension. The obtained from the FEM computing function and surface graphs are compared and then discussed with graphs corresponding to Euler's and Technical Stability Theory (TSTh) results. Finally are compared graphs of the stresses and strains of box-section thin-walled column $20 \times 28 \times 1 \times 2500$ obtained from FEM and TSTh, but under compressing critical force determined according to TSTh.
\end{abstract}

Keywords: Stability, Elastic States, Slenderness, Thin-Walled, Box-Section, Rectangular, Column, Steel

\section{Introduction}

The question of stability of structures has a very wide way of meaning and is meant in many ways.

The problem of the stability is searched and analyzed with a focus on many other relevant aspects, like buckling of columns, rods, beams, boxes, arches, plates, panels, shells, membranes, cones, pales, poles, pillars, pipes, tubes, tanks and silos, as well as stability of connections, joints or of wooden, plywood, bamboo, bones, auxetic, composite, rubber, foam and laminate, sandwich, layered and Functionally Graded Material (FGM) structures, nanostructures, structures under their own weight or seismic load ... and many others.

When is considered the application of thin-walled elements in load-bearing structures, accordingly, the first issue to analyze is their load capacity to sustain axial loads, i.e., their stability and susceptibility to potential buckling collapse mechanisms. In the case of very slender, thin-walled columns, this refers to the problem of stability in elastic states.

\section{Stability Analysis According to Euler}

The basic theory of slender rods losing stability in elastic states, as known, has been originally formulated by (Euler, $1744 ; 1759)$. He first introduced the concept of critical load $P_{c r}$ and presented, according to his theory, the differential equation of an elastic deflected central line:

$$
E J \frac{d^{2} y}{d x^{2}}=-P_{c r} y,
$$

Where:

$E$ : The Young's modulus of elasticity of the column

$J$ : Moment of inertia of the cross-section area

$y$ : Distance from the undeformed central line from the $\mathrm{y}$-axis

He had assumed a displacement $y(x)$ of the column axis as a part of a sine curve:

$$
y(x)=\sin \left(n \cdot \frac{\pi}{L} x\right),
$$


Where:

$n$ : The coefficient of the sine curve part and depends on boundaries $(n=1$ for a pinned column, $n=2$ for a column fixed at one end, $n=1 / 2$ for a column fixed by a pinned end and a vertically slide for the second end, $n=0.7$ for a column with a pinned end and a pinned vertical slide at the second end)

$L$ : length of the column

and he has obtained the formula for a critical stress $\sigma_{c r}$ of an axially compressed column by force as follows:

$$
\sigma_{c r}^{\text {Euler }}=\frac{P_{c r}}{A}=\left(\frac{\pi}{n \cdot \lambda}\right)^{2} \cdot E .
$$

Where:

$A$ : The transverse cross-section area of the column

$\lambda$ : Slenderness ratio of the column, i.e., the ratio of the length of a column and the least radius of gyration of its cross section

The problem of the stability was later searched and analyzed further with a focus on many other relevant aspects for various engineering applications, like buckling of columns composed of various constructional materials (Gupta et al., 2001; Oleiwi et al., 2014; Schnabl et al., 2013; Kalamar et al., 2016; Thermou et al., 2018; Zhou et al., 2017; Ye et al., 2018; Osmani and Meftah, 2018; Wang et al., 2018; Naderpour et al., 2019; Qi et al., 2019), as well as beams (Ascione and Grimaldi, 1983; Di Sarno and Manfredi, 2012; Li et al., 2015; Ozbasaran et al., 2015; Monsalve-Cano and Aristizábal-Ochoa, 2016; Nguyen et al., 2018; Toufik et al., 2018) or nanobeams (Rahmani et al., 2017; Mohammadi et al., 2019).

Single-layer graphene sheets have been examined in (Genoese et al., 2019), while polymer-confined concrete columns have been discussed in (Liang et al., 2012) and hyperelastic tubes are analyzed by (Liu, 2018).

Many other research contributions have been then related to the stability issues of a multitude of loadbearing systems and members can be found in the literature, including plates (Sabouri-Ghomi et al., 2008; Rao and Ra, 2009; Xu et al., 2013; Moradi-Dastjerdi and Malek-Mohammadi, 2017; Riahi et al., 2018; Vu et al., 2019) and nanoplates (Malikan et al., 2018), bracing systems (Rahnavard et al., 2018), tubes (Nouri et al., 2015; Mozafari et al., 2018; Ahmed et al., 2017; Sadath et al., 2017; Sun et al., 2018), frames (Marante et al., 2012; Slimani et al., 2018), pipes (Lolov and Lilkova-Markova, 2005; Melissianos et al., 2017; Moustabchir et al., 2018; Psyrras et al., 2019), or Functionally Graded Material (FGM) structures (Moita et al., 2018; Singh and Harsha, 2019), etc.

\section{Literature Review}

The problem of the stability of columns was later searched and analyzed further with a focus on many other relevant aspects for various engineering applications.

Yiotis et al. (1982) presented a solution methodology for investigating the stability of rectangular box-shaped structures subjected to transverse uniformly distributed compressive loading. This investigation was concerned with the two-dimensional behavior of box-shaped structures of finite length which required an analysis of four interconnected plates.

Abdel-Lateef et al. (2001) presented the elastic stability of a column with variable cross-section subjected to distributed and concentrated axial load.

Seyranian and Privalova (2003) dealt with the optimization and post-buckling behavior of columns elastically supported at both ends.

Milašinović et al. (2003) dealt with the buckling problem of steel columns using by RheologicalDynamical Analogy (RDA).

Alvarenga and Silveira (2006) presented a study about the steel plane frames (portals) and the numerical formulation based on the finite element model of a Bernoulli-Euler beam-column member using the called "slice technique".

D'Aniello et al. (2006) executed two full-scale experimental tests on the lateral load-displacement response of a restrained column structure seismically retrofitted by buckling restrained braces which were first summarized and then compared to numerical modeling.

Lolov and Lilkova-Markova (2006) dealt with the dynamic stability of a curved pipe bent in the arc of a circle on hinge supports at the ends. The methods of the numerical solution of the dynamic stability of a pipe in its plane were developed.

Fraldi et al. (2008) aimed at deriving assessment and design formulae for determining the response and the ultimate compressive strength of circular concrete columns confined by Fiber Reinforced Polymers.

Sanchez and Corte's Salas (2008) searched deformation of steel straight pipes with internal pressure under axial compression and bending load by seismic action.

Wahrhaftig et al. (2008) evaluated a buckling critical load of bars subjected to their self-weight. Wahrhaftig et al. (2016) executed a calculation of the natural frequency of vibration and the stability verification of a slender column including the reducing effects of stiffness both of axial force and creep. Wahrhaftig et al. (2019) executed an analytical determination of the vibration frequencies and buckling loads of slender reinforced concrete towers. Wahrhaftig et al. (2020a) evaluated a limit state of stress and strain of free-fixed columns with variable geometry. Wahrhaftig et al. (2020b) did an evaluation of 
mathematical solutions for the determination of buckling of columns under self-weight. Wahrhaftig (2020c) did a time-dependent analysis of slender, tapered reinforced concrete columns. Wahrhaftig et al. (2021) made a stress assessment in reinforcement for columns with concrete creep.

Ismail (2011) evaluated the dynamical behavior and stability of pipes conveying fluid.

Abed et al. (2013) presented finite-element analysis to study the axial load capacity of pretwisted steel bars of rectangular cross sections.

Andreev and Tsybin (2015) gave the solution to the problem of the stability of a compressed rod with a variable cross-section.

Kambe et al. (2013) developed the sandwich panel with plywood and steel member for a new structural member. Then, they studied the compressive performance of that whole member.

Hedayati et al. (2015) executed a critical buckling load analysis of a truck chassis with an arc-length method and the effect of replacing conventional steel with stainless steel in a critical point of the truck chassis.

Al-Kamal (2016) presented the possible collapse mechanisms initiated by a precast flexural member dropping on a lower member.

Jakab et al. (2016) focused on load-bearing glass columns and also on the design, the load-bearing capacity and the stability issues of fins. In Fig. 4 they presented the graph of strains at mid-length of a slender glass column measured by strain gouges similarly like in Fig. 4a in the book of (Murawski, 2011a) and in Fig. 4 in the paper of (Murawski and Kłos, 2007) and in the doctor's thesis of (Murawski, 1999) as well as in Rys. 2 in the paper of (Murawski, 1992). They described this as: “...Fig. 4 indicates the loading force vs. strains on the glass surface. At the beginning both outer surfaces of the glass column is in compression after that, the compression starts to decrease at one outer glass surface and tensile stresses develop. The buckling process starts during this phenomenon", i.e., is according to the Technical Stability Theory (TSTh).

Kalamar et al. (2016) executed an experimental investigation for the structural performance assessment of square hollow glass columns.

Li et al. (2016) presented a novel scrimber composite. The attempts were made through theoretical analysis to predict the buckling stress of the column specimens under both elastic and inelastic buckling. In Fig. 9e they presented the graph of strains at mid-length of a slender column and measured by strain gouges similarly like in Fig. 4a in the book of (Murawski, 2011a) and in Fig. 4 in the paper of (Murawski and Kłos, 2007) and in the doctor's thesis of (Murawski, 1999) as well as in Rys.2 in the paper of (Murawski, 1992).
Łukowicz et al. (2016) dealt with cold-formed steel sections as extensively affected the modern steel construction industry.

Megahed (2016) dealt with an experimental and theoretical analysis of concrete-encased cold-formed steel composite column.

Abbas and Awazli (2017) developed a numerical model in a three-dimensional nonlinear finite element and then validated it against experimental results reported in the literature, to investigate the behavior of conventionally RC columns subjected to axial load and lateral reversal cyclic loading.

Ammash (2017) dealt with shape optimization of innovated cold-formed steel columns under uniaxial compressive loading.

Atteya et al. (2017) dealt with an axial load capacity and the stiffness of a rectangular Hollow Structural Section (HSS) of the steel tube. In Fig. 19 they presented the graphs of strains at mid-length measured by strain gouges similarly like in Fig. 4a in the book of (Murawski, 2011a) and in Fig. 4 in the paper of (Murawski and Kłos, 2007) and in the doctor's thesis of (Murawski, 1999) as well as in Rys. 2 in the study of (Murawski, 1992). Those graphs showed the way of losing stability in accordance with the Technical Stability Theory.

Baru (2017) dealt with buckling, as the most prominent failure mode of steel column stability as well as the structural stability of steel structures.

Bedon and Amadio (2017) did a unified approach for the buckling verification of structural glass elements. Bedon and Amadio (2018) made a buckling analysis and design proposal for 2-side supported double Insulated Glass Units (IGUs) in compression.

Brasil and Wahrhaftig (2017) did an experimental evaluation of the effect of geometric nonlinearities on structural resonances.

Johnson et al. (2017) reported the results of a numerical and theoretical study of buckling in elastic columns containing a line of holes.

Oliveira et al. (2017) studied the shear effect on the buckling of columns embedded in an elastic medium, evidencing the interaction of the column with the foundation.

Abdel-Karim et al. (2018) proposed a model for the strength analysis of High-Strength Concrete (HSC) columns subjected to eccentric loading.

Abdulazeez et al. (2019) presented a numerical study on the behavior of Hollow-Core Fiber reinforced polymer-Concrete-Steel (HC-FCS) columns under combined axial compression and lateral loadings.

Isleem et al. (2018) presented results of experimental tests on 28 larger-sized rectangular plain and reinforced concrete columns confined with carbon fiber-reinforced polymer wraps. 
Razdolsky (2018) focused on elastic stability analysis of battened columns and laced columns with crosswise, fir-shaped and serpentine lattices.

Slimani et al. (2018) dealt with the concept of the effective length factor of columns representing an important parameter with regard to the elastic buckling analysis.

Thumrongvut and Tiwjantuk (2018) analysed strength and axial behavior of cellular lightweight concrete-filled steel rectangular tube columns under axial compression.

Anuntasena et al. (2019) presented the 3D finite element analysis of the concrete-encased steel columns subjected to concentric or eccentric loadings.

Ivanov (2019a) did a theoretical study of small vibrations of two rigid bodies with damping and next Ivanov (2019b) analyzed vibrations of a shaft caused by inertial excitations.

Kudryavtsev (2019) presented the study of behavior of axially loaded columns that consisted of two flanges and a thin triangularly corrugated web, connected by automatic welding.

Nazarimofrad and Shokrgozar (2019) dealt with a seismic performance of steel braced frames with selfcentering buckling-restrained brace utilizing superelastic shape memory alloys.

Qi et al. (2019) dealt with the innovative pultruded fiber reinforced polymer. Axial compression tests with both ends pinned were employed to investigate the columns under concentric load. The courses of the values of the longitudinal strains in Fig. 10 correspond to the graph in Fig. 4 in the paper of (Murawski and Kłos, 2007) and in Fig. 4a of (Murawski, 2011a) - what confirms qualitatively the correctness of the presented Technical Stability Theory.

Roy et al. (2019) dealt with a built-up box-section popular for column members in cold-formed steel. The authors presented an experimental investigation on an axial capacity. Tests were conducted for different values of slenderness.

Zhou et al. (2019) introduced the effective length factor and imperfection factor to the current stability factor formula to calculate the ultimate load of the lattice boom accurately.

Abedini et al. (2020) focused on investigating blast load parameters to design reinforced concretes columns to withstand blast detonation.

Ahiwale et al. (2020) tested the twelve concrete-filled tubular columns under axial compression. The behaviour of CFT columns has been studied in terms of axial loadcarrying capacity, deflection, and buckling effects and compared the behaviour with numerical results determined using Eurocode 4 and AISC 360-10.

Alomarah et al. (2020) presented a combined experimental and numerical investigation of the out-ofplane and in-plane performances of an auxetic structure, re-entrant chiral auxetic, under quasi-static uniaxial compression.

Avci-Karatas (2020) considered the need for suitable analysis and design of mid-rise reinforced concrete buildings in hilly regions subjected to earthquake and wind.

Doan et al. (2020) provided an investigation based on a numerical study of the effects of the section dimensions, thickness ratio and slenderness ratio on the critical buckling load of a thin-walled composite strut under uniaxial compression.

Goroshko et al. (2020) proposed a method of preventing the loss of Euler stability by thin rods.

Kiss (2020a) investigated the planar stability of fixedfixed shallow circular arches. Later Kiss (2020b) aimed to find the buckling loads for pinned-rotationally restrained shallow circular arches in terms of the rotational end stiffness, geometry and material distribution.

Naseri et al. (2020) presented an experimental study into the buckling behaviour of glass fabric-reinforced polymer cylindrical shells subjected to axial compression load.

Qays and Al-Zuhairi (2020) dealt with a structural performance of slender columns with cross and squareshaped under compression load.

Rajkannu and Jayachandran (2020) presented the details of an experimental and numerical study on the effect of warping on the flexural-torsional buckling behavior of axially loaded cold-formed steel lipped channel members.

Saberi et al. (2020) studied the cooperation of steel and concrete in composite columns.

Saingam et al. (2020) dealt with composite behavior in buildings retrofitted using buckling-restrained braces with elastic steel frames.

Zucco et al. (2020) tested a $750 \times 640 \times 240 \mathrm{~mm}$ variable-stiffness unitized integrated-stiffener out-ofautoclave thermoplastic composite wing-box for a combined shear-bending-torsion induced buckling load. The experimental test results of the wing-box were also compared with the predictions made by a numerical study performed.

Mehrabi et al. (2021) dealt with a seismic response prediction of fiber-reinforced concrete columns rectangular columns using intelligent fuzzy-based hybrid metaheuristic techniques.

\section{Stability Analysis According to TSTh}

This research study herein discussed also Technical Stability Theory (TSTh) method of analysis for the column stability in elastic states that the stress and strain state in a critical transverse cross-section (after losing stability and before losing its carrying capacity) appears as a result of a sum of pure compression phenomena and bending effects (Fig. 1 and also Murawski, 1992; 2002; 
2003a; 2003b; 2003c; 2003d; 2004a; 2004b; 2004c; 2004d; 2005; 2007; 2011b; 2017a; 2017b; 2018; 2020b).

The method is thus developed on a basic simplification for very slender columns, that is the beginning of the loadcarrying capacity lost (i.e., the maximum achieved value of force, on a force $P$-shortening $\Delta L$ graph) in an elastic state follows the exceedance of the force line from a critical transverse cross-section.

According to the TSTh the fibre extension $\varepsilon$ at the distance $y$ from the undeformed central line and the corresponding stress $\sigma_{n}$ were in fact given by (Fig. 1):

$$
\begin{gathered}
\varepsilon=\frac{ \pm(\rho+y) \cdot \theta-\rho \cdot \theta}{\rho \cdot \theta}= \pm \frac{y}{\rho}, \\
\sigma_{n}=\sigma_{g}-\sigma_{c}= \pm \frac{y}{\rho} \cdot E-\frac{P}{A},
\end{gathered}
$$

Where:

$\rho$ : The radius of the curved central line

$\theta$. Angle of the central line slope in relation to the force line

$y: \quad$ Defined in Eq. (1)

$\sigma_{n}:$ Normal stress

$\sigma_{g}$ : Bending stress

$\sigma_{c}:$ Compressive stress

\section{$E: \quad$ Defined in Eq. (1) \\ $P$ : Imposed axial force \\ A: Defined in Eq. (3)}

Due to the force equilibrium, it is:

$$
d P=\left(\sigma_{g}+\sigma_{c}\right) \cdot d A=\left( \pm \frac{y}{\rho} \cdot E-\frac{P}{A}\right) \cdot d A
$$

moreover, unlike Euler, it was assumed that the displacement of the column axis was determined by taking into account the conditions of the small deformation theory, as a function of the curvature radius, that is:

$\frac{1}{\rho} \cong \frac{d^{2} y}{d x^{2}}$,

and the reference boundary conditions: $d y / d x=0$ for $x=$ $L / 2$ and $y=0$ for $x=0$.

The governing differential equations for the curved central line $d^{2} y / d x^{2}$ and its slope $d y / d x$, as well as the equation of the central line $y(x)$ for a pinned without friction axially compressed column, were like Eqs. (59), (60), (61) in (Murawski, 2011c), or Eqs. (2.7), (2.8), (2.9) in (Murawski, 2018).

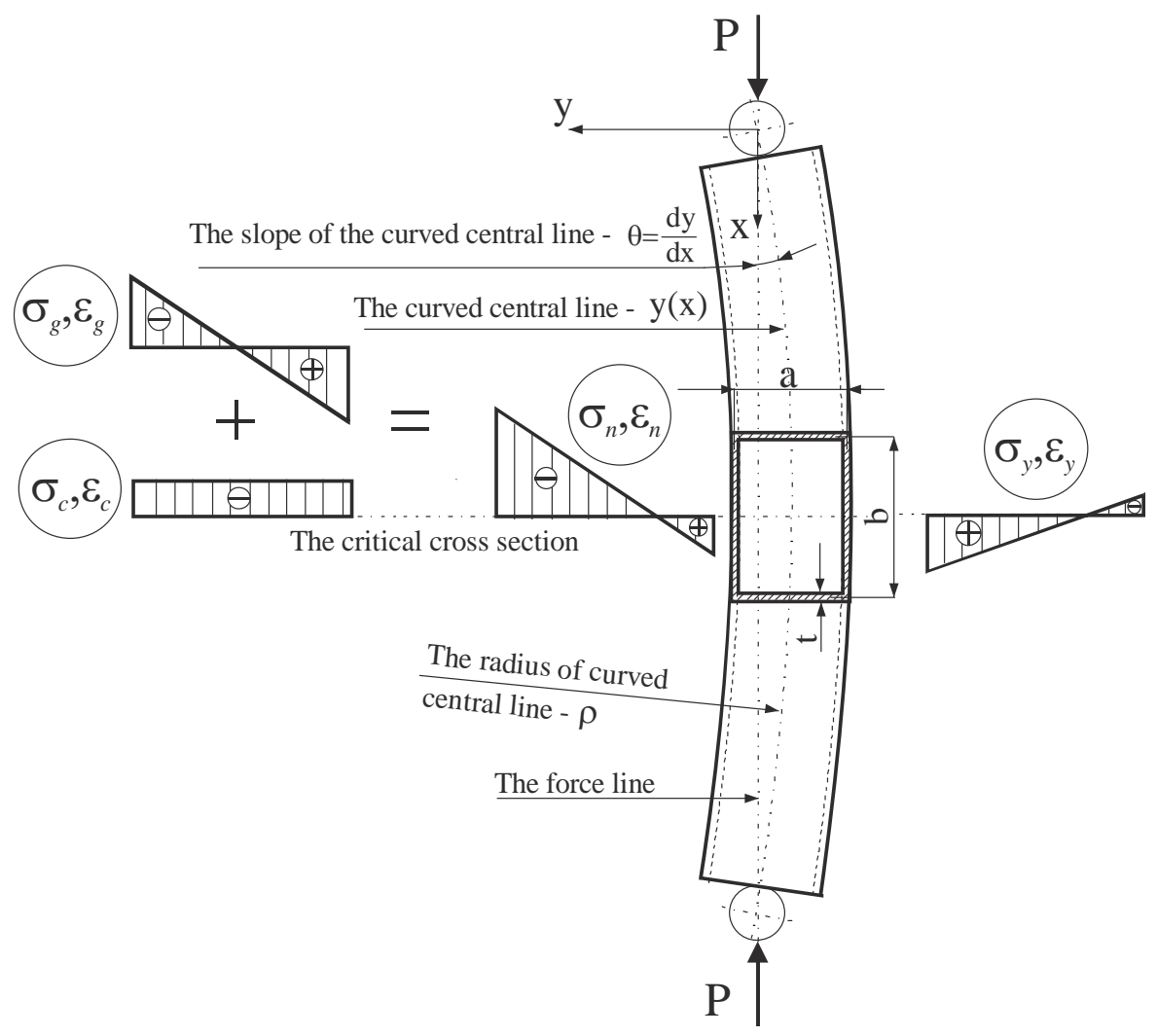

Fig. 1: Stresses and strains in the critical transverse cross-section of a pinned box-section column axially compressed by force according to TSTh 
From the assumption that the loss of carrying capacity follows the force line exceeding the critical transverse cross-section $\left(y_{x=L / 2}=y_{c r}\right)$, moreover, the critical compressive stress $\sigma_{c r}$ for axially compressed columns under the force through ball-and-socket joints was like Eq. (65) in (Murawski, 2011c), or Eq. (2.13) in (Murawski, 2018).

In the paper (Murawski, 2020c), according to the TSTh as a theoretical example, was analyzed the rectangular column made of steel with dimensions: The shorter median side $a=20 \mathrm{~mm}$, longer median side $b=28$ $\mathrm{mm}$, thickness $t=1 \mathrm{~mm}$, length $L=2500 \mathrm{~mm}$ and slenderness ratio $\lambda=314.8$. From the stability analysis were obtained the graphs of the elastic line $y(x)$, its slope $d y / d x$, the function $y_{L / 2}(P)$ and compressive critical stresses $\sigma_{c r}$. From the stress and strain analysis were obtained the graphs of the shell stress and strain states.

The same case is also computed in this study using the Finite Element Method and Euler's theory.

\section{Finite Element Method (FEM)}

According to (Wikipedia, 2021), the FEM is a method for solving differential equations arising in mathematical modeling. It is a general numerical method for solving partial differential equations in two or three space variables. To solve a problem, the FEM subdivides a large system into smaller, simpler parts that are called finite elements. This is achieved by a particular space discretization in the space dimensions, which is implemented by the construction of a mesh of the object: The numerical domain for the solution, which has a finite number of points. The FEM formulation of a boundary value problem finally results in a system of algebraic equations. The method approximates the unknown function over the domain. The simple equations that model these finite elements are then assembled into a larger system of equations that models the entire problem. The FEM then uses variational methods from the calculus of variations to approximate a solution by minimizing an associated error function.

\section{Finite Element Analysis (FEA)}

According to (Algor $\AA, 2001)$, the FEA is a computerized method for predicting how a real-world object will react to forces, heat, vibration, etc., in terms of whether it will break, wear out, or work the way it was designed.

The FEA works by breaking a real object down into a large number (1000 to $100,000 \mathrm{~s}$ or more) of elements, such as little cubes. The behavior of each little element, which is regular in shape, is readily predicted by set mathematical equations. The computer then adds up all of the individual behaviors to predict the behavior of the actual object.

\section{FEA Theory}

Hooke (1678) set down the basis for modern finite element stress analysis with Hooke's Law. Simply, an elastic body stretches (strain) in proportion to the force (stress) on it. Mathematically:

$P=k \cdot x$,

Where:

$k$ : The proportional constant

$x$ : Distance of stretching

Hooke proved the equation by using weights to stretch wires hanging from the ceiling. Each element has corners, i.e., nodes. Every node will move because all materials have some elasticity. That movement would be described by Eq. (8) for that element except that other elements are in the way or are tending to hold it back. As the force is transmitted through the first element, it spreads out to other nodes.

According to (Algor®, 2001) in the FEA occurs a step called element stiffness formulation. The $k$ is created for the relationship between every node on each element. Thus, every node is connected to every other node on each element by a spring. After the analysis, a step known as processing is done, i.e., a value for each $x$ and $P$ is determined for each node by the Eq. (8) and $x$ and $P$ are vectors as each has a value and a direction.

In the final step, which is called post-processing, the stresses are determined by knowing the $P$ at each node and the geometry of each element.

A node is a coordinate location in space where the Degrees Of Freedom (DOF) are defined. The DOF for this point represent the possible movement of this point due to the loading of the structure. The DOF also represents which forces and moments are transferred from one element to the next. Also, results of an FEA (deflections and stresses) are usually given at the nodes.

In the real world, a point can move in 6 different directions, translation in $T_{x}, T_{y}$ and $T_{z}$ and rotation about $R_{x}, R_{y}$ and $R_{z}$. In the FEA, a node may be limited in the calculated motions for a variety of reasons. For example, there is no need to calculate the out-of-plane translation on a 2-D element; it would not be a 2-D element if its nodes were allowed to move out of a plane.

The DOF of a node (which is based on the element type) also relates what types of forces and restraints are transmitted through the node to the element. A force (axial or shear) is equivalent to a DOF translation. A moment is equivalent to a DOF rotational. Thus, to transfer a moment about a certain axis, the node must 
have that DOF. If a node does not have that rotational DOF, then applying a moment to the node will have no effect on the analysis. Likewise, restraining that node with a rotational boundary condition will have no effect; the node does not "know" how to transmit the moment.

An element is the basic building block of the FEA. There are several basic types of elements. Which type of element for the FEA is used depends on the type of object that is to be modeled for the FEA and the type of analysis that is going to be performed.

An element is a mathematical relation that defines how the degrees of freedom of a node related to the next. These elements can be lines (beams), areas (2-D or 3-D plates), or solids (bricks). It also relates to how the deflections create stress.

Buckling is a geometric instability due to compression: Common in thin-walled cases and slender structural members.

\section{Linear Critical Buckling (LCB)}

A thin-walled column pressed down by a gradually increased force, at some point will suddenly squash. This sudden phenomenon of scrunching is known as buckling.

In the normal use of most products, buckling can be catastrophic if it occurs. The failure is not one of stress, but of geometric stability. Once the geometry of the part starts to deform, it can no longer support even a fraction of the force initially applied.

The worst part about buckling for engineers is that buckling usually occurs at relatively low-stress values compared to what the material can withstand. So they have to make a separate check to see if a product or part thereof is okay with respect to buckling.

Buckling almost always involves compression. In civil engineering, buckling is to be avoided when designing support columns, load bearing walls and sections of bridges which may flex under load. In mechanical engineering, designs involving thin parts in flexible structures like airplanes and automobiles are susceptible to buckling. Even if the stress is very low, buckling of local areas can cause the whole structure to collapse by a rapid progression of propagated buckling.

For nonlinear situations, buckling can be determined as part of nonlinear stress analysis.

The (Algor®, 2001) requires determining of the element formulation, i.e., to select by an user what type of formulation is used when calculating the shape functions for the stiffness matrix. There are formulations as follows:

- Veubeke - uses the theory by B. Fraeijs de Veubeke for plate formulation for displaced and equilibrium models

- $\quad$ Reduced shear - uses the Constant Linear Strain Triangle (CLST) with reduced shear integration and Hsieh, Clough and Tocher (HCT) plate bending element theories

- Linear strain - uses the Constant Linear Strain Triangle (CLST) without reduced shear integration and Hsieh, Clough and Tocher (HCT) plate bending element theories

- Constant strain - uses the Constant Strain Triangle (CST) and Hsieh, Clough and Tocher (HCT) plate bending element theories

\section{FEM Model}

For the FEM the stability analysis was used the computer program Algor® (2001). The Linear Critical Buckling Load analysis was applied. The column was modelled as made of steel R35 (Murawski 2003a, 2004b, 2017a, 2017b, 2020a, 2020b, 2020c).

The model (Fig. 2 and 3) of every box-section column with different lengths $L$ was built from the plate elements with four nodes in 140 levels with 16 nodes what caused certain numerical instabilities because of the changing the element height/side/thickness ratio. The square plate elements would be ideal for every box-section column.

The material of the model elements was defined as isotropic. The thickness $\mathrm{t}$ of the analyzed columns was $0.2,0.4,0.6,0.8,1.0$ and $1.2 \mathrm{~mm}$ (Table 1).

The mass density of the steel R35 was: $8000 \mathrm{~kg} / \mathrm{m}^{3}$. The value of the elasticity modulus was $E=166600 \mathrm{MPa}$ like in the works (Murawski 2003a; 2004b; 2017a; 2017b; 2020a; 2020b; 2020c).

The assumed Poisson's ratio was $v=0.3$.

The model was built as a column with dimensions: $a-b-L$ and $t$ (Table 1 ).

The column was loaded with the force of $1 \mathrm{~N}$.

The force compressing by disks, made of steel with $20 \mathrm{~mm}$ of thickness, was applied to the central node of the upper disk. The influence of them on the surface graphs of the $\sigma_{n}$ and $\varepsilon_{n}$ was reduced using the option: Hide elements.

This node had degrees of freedom: $T_{z}, R_{x}$, whereas the bottom disk has: $R_{x}$.

\section{FEM Stability Analysis}

In the program extensions in the own question of the FEM with the tolerance of convergence were normalized. For the computing, the value predefined by the program was applied: 0.00001 .

The maximum number of iterations predefined by the program was 32 . For the sake of verifying the results obtained from the computing for available in ALGOR @ Element Formulation the obtained results were compared:

- Veubeke: $1823.57 \mathrm{~N}$

- Reduced shear: $1846.93 \mathrm{~N}$ 
Krzysztof Murawski and Alexandre de Macêdo Wahrhaftig / American Journal of Engineering and Applied Sciences 2021,14 (2): 214.257 DOI: 10.3844/ajeassp.2021.214.257

- $\quad$ Linear strain: $1849.06 \mathrm{~N}$
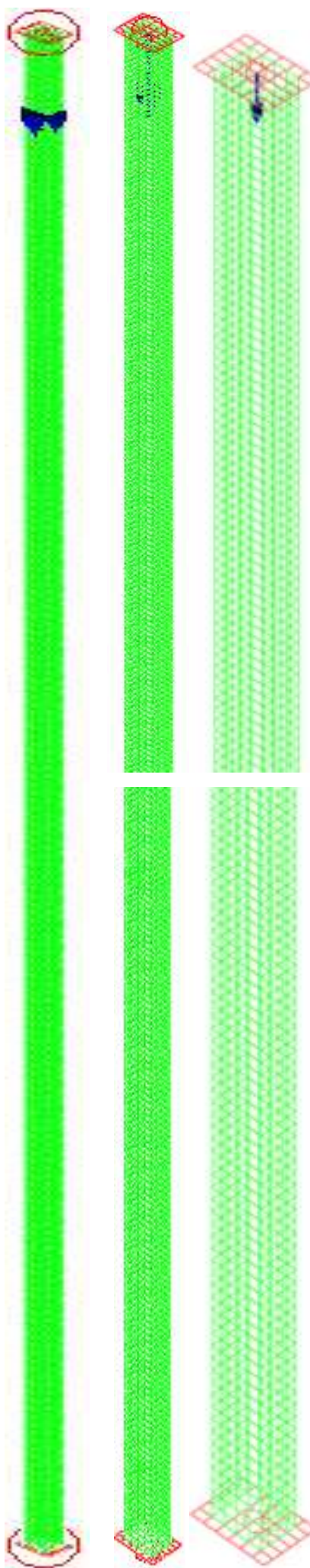
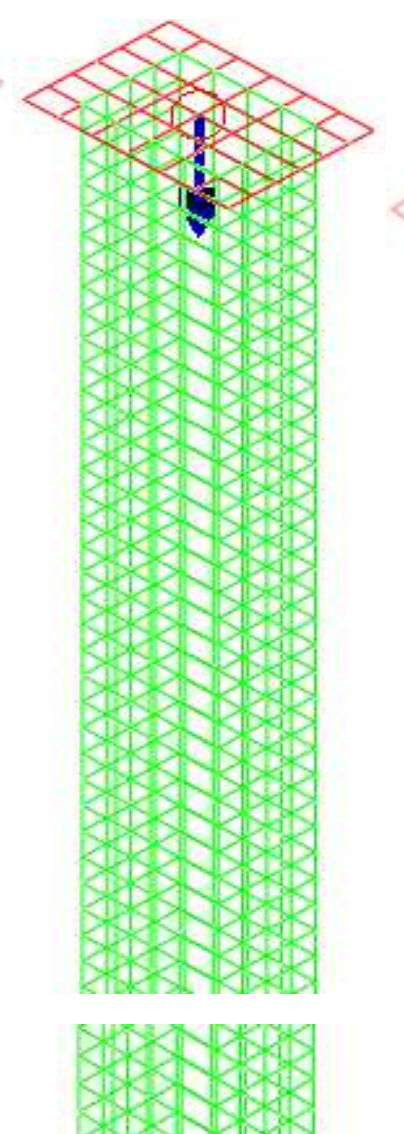

- $\quad$ Constant strain: $1846.93 \mathrm{~N}$
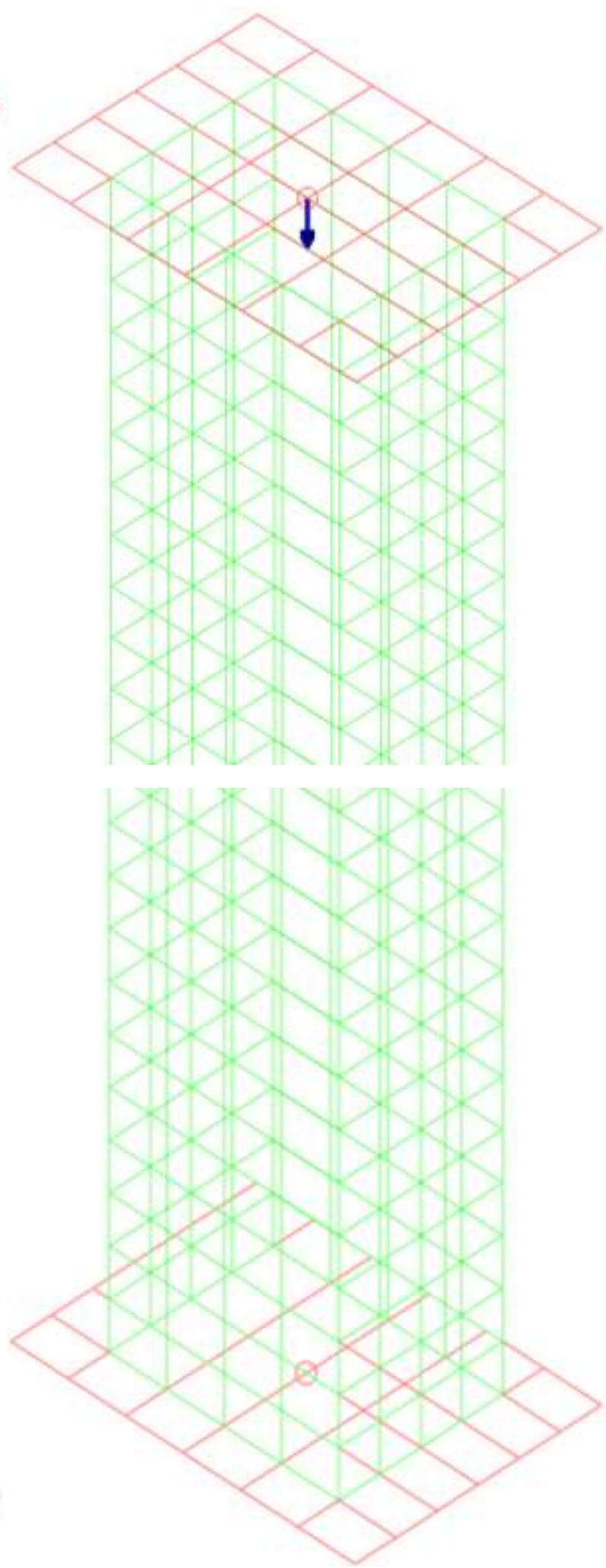

Fig. 2: FEM mesh model of the disks and box-section column: Elements and the way of loading. The ends are in the enlargements 
Krzysztof Murawski and Alexandre de Macêdo Wahrhaftig / American Journal of Engineering and Applied Sciences 2021,14 (2): 214.257 DOI: 10.3844/ajeassp.2021.214.257

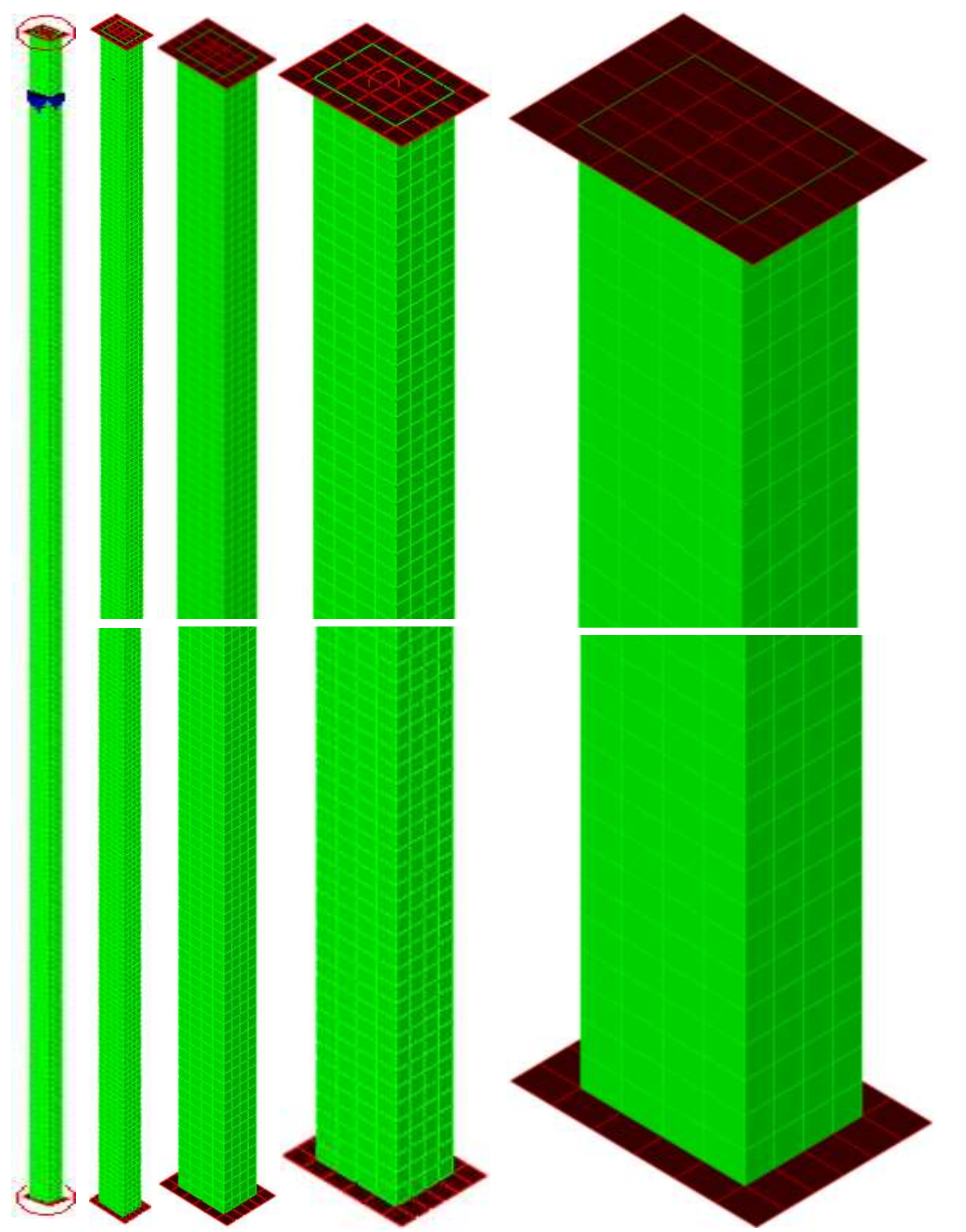

Fig. 3: FEM shell model of the disks and box-section column: elements and the way of loading. The ends are in the enlargements 

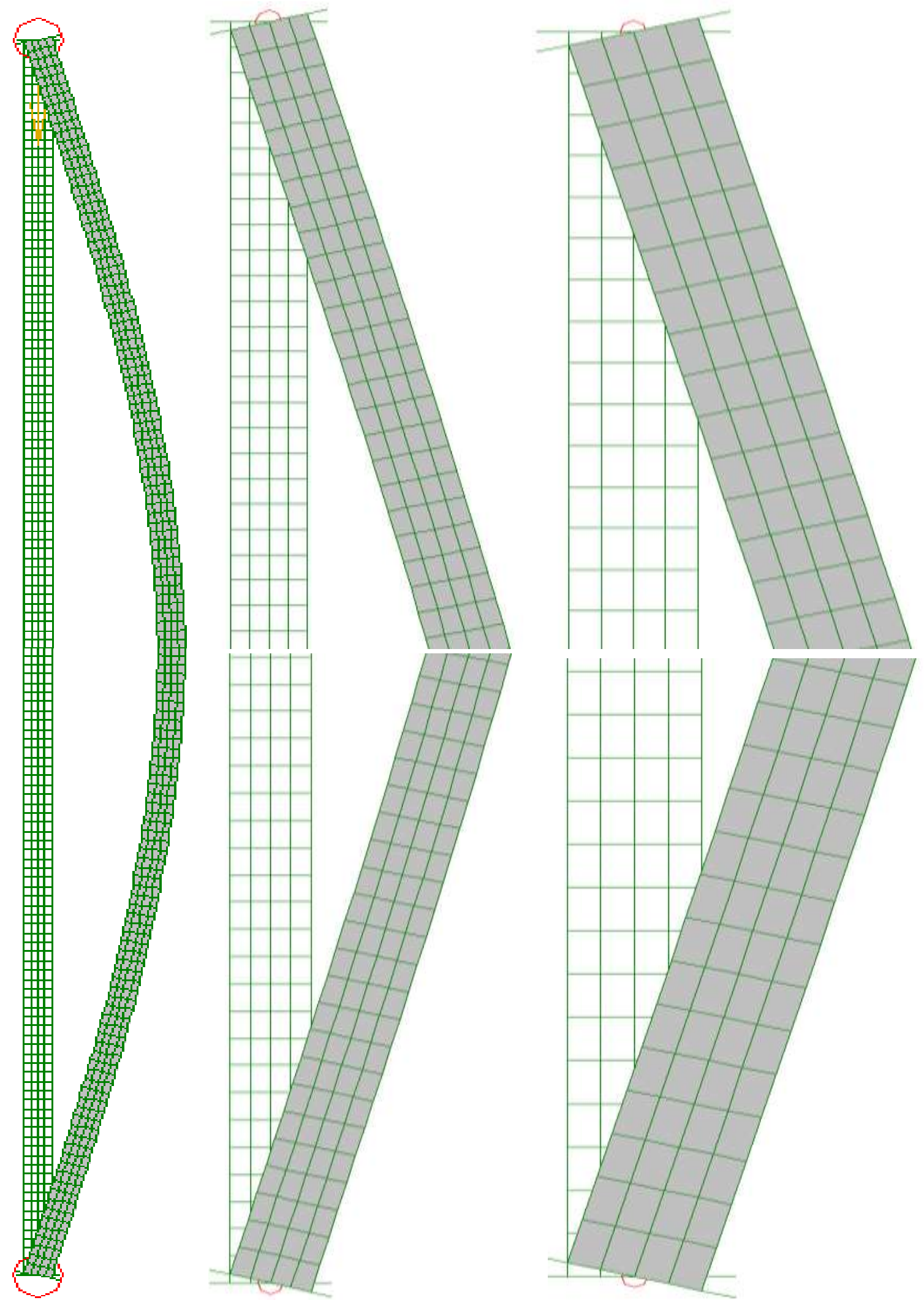

Fig. 4: Deformed FEM model of the box-section column with the ends in the enlargements 

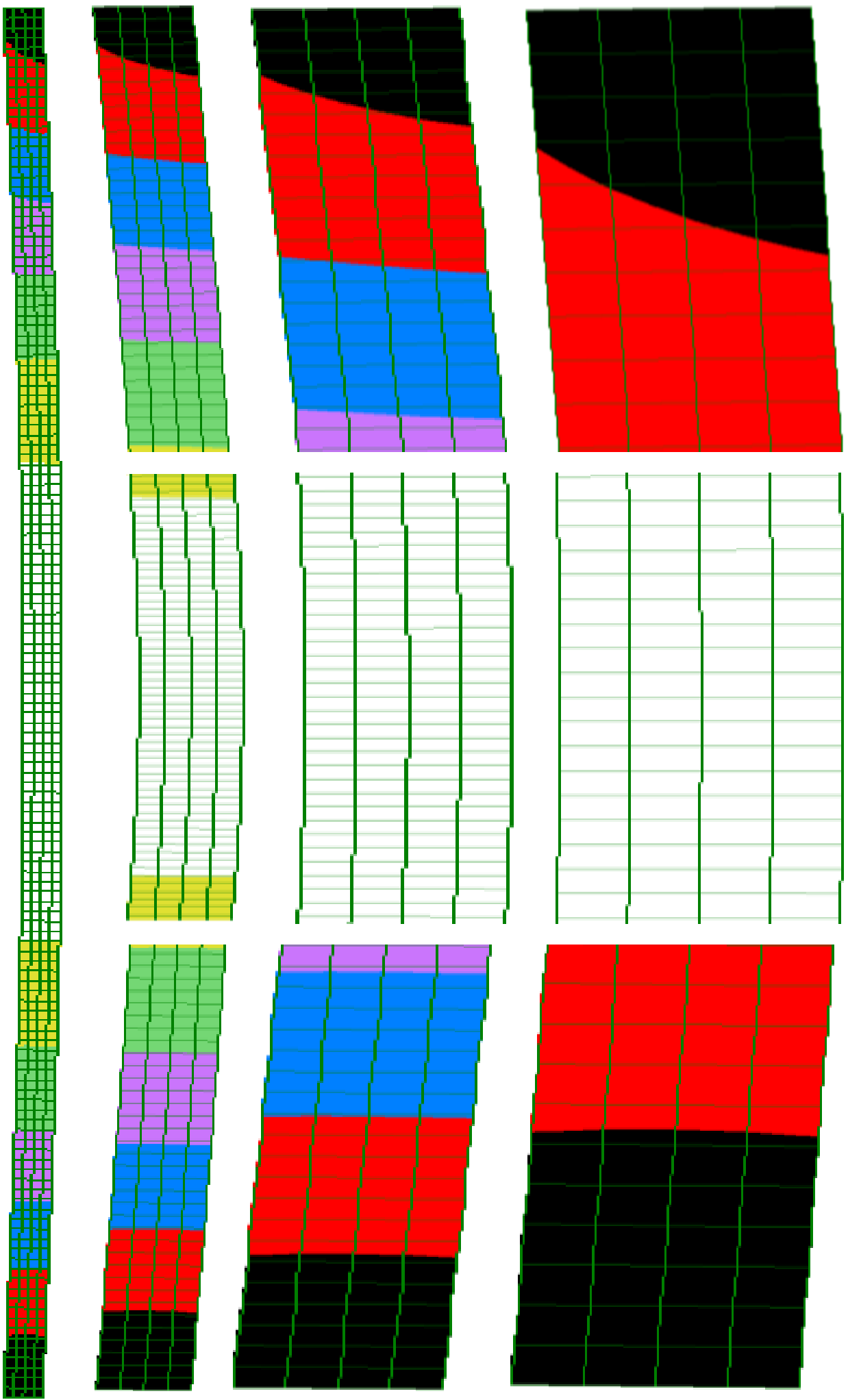

Displacement
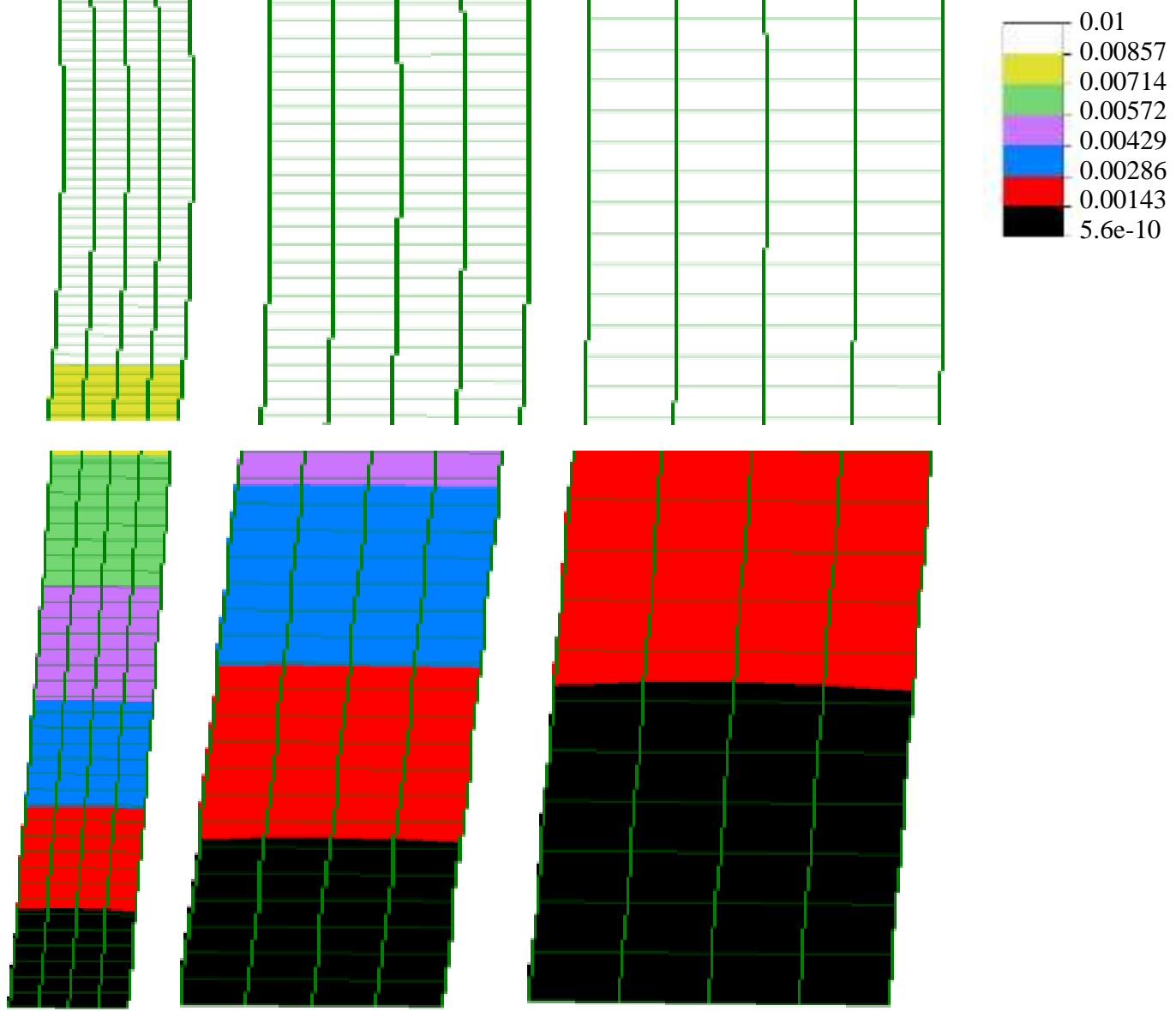

Fig. 5: Surface graphs of the displacements of the pinned box-section column with dimensions $a=20 \mathrm{~mm}, b=28 \mathrm{~mm}, t=1 \mathrm{~mm}, L=$ $2500 \mathrm{~mm}$ under axially compressing load, according to the FEM post-buckling linear stress analysis, by the assumption that a maximal deflection equals the half of a side dimension $(a / 2=10 \mathrm{~mm})$, like in the TSTh, where the exit of a force line from a critical transverse section follows a loss of the stability 


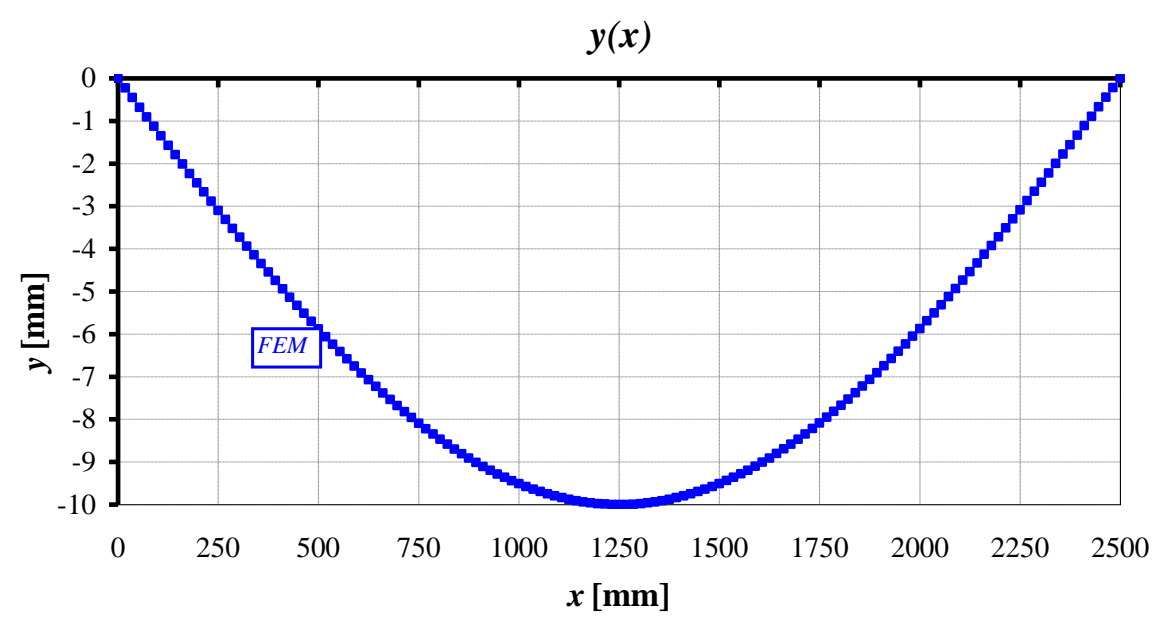

(a)

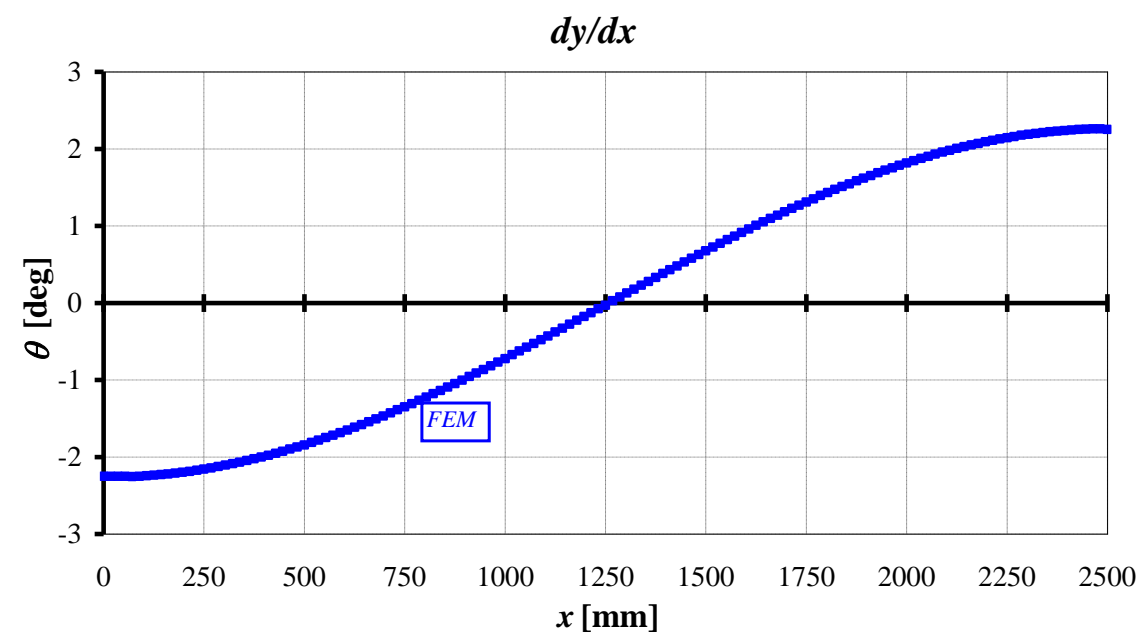

(b)

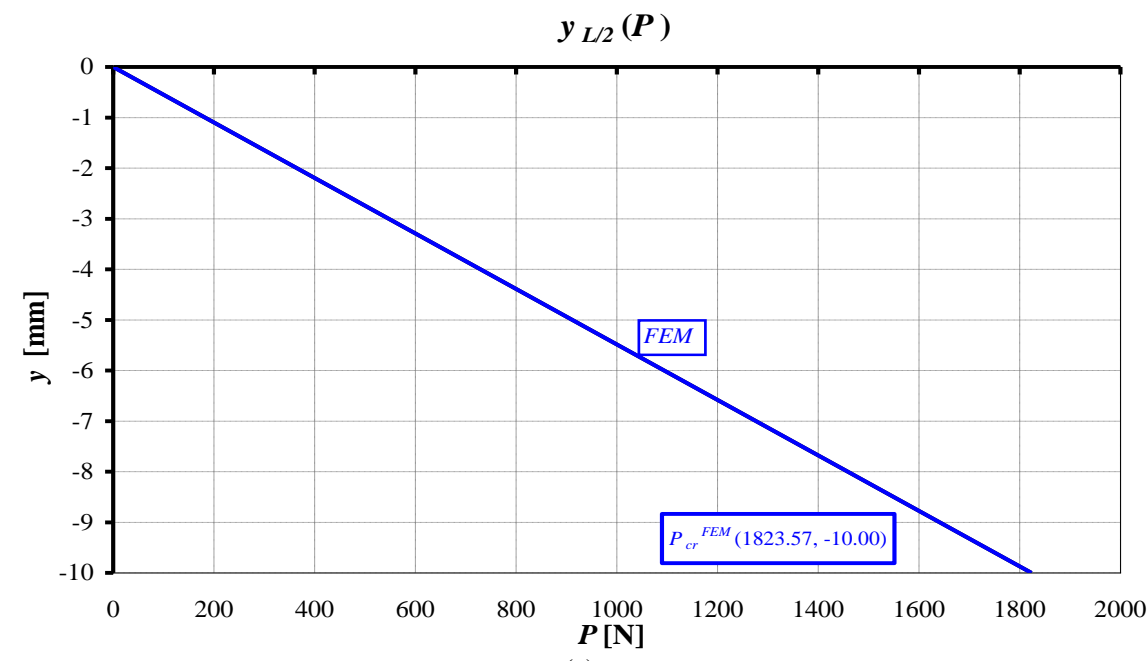

(c)

Fig. 6: Evolution of (a) elastic line $y(x)$, (b) elastic line slope $d y / d x$ and (c) function $y_{L}(P)$ for the compressed pinned box-section steel column with dimensions: $a=20 \mathrm{~mm}, b=28 \mathrm{~mm}, t=1 \mathrm{~mm}, L=2500 \mathrm{~mm}$, according to the results obtained from the FEM computing by the assumption that a maximal deflection equals the half of a side dimension $(a / 2=10 \mathrm{~mm})$, like in the TSTh, where the exit of a force line from a critical transverse section follows a loss of the stability 


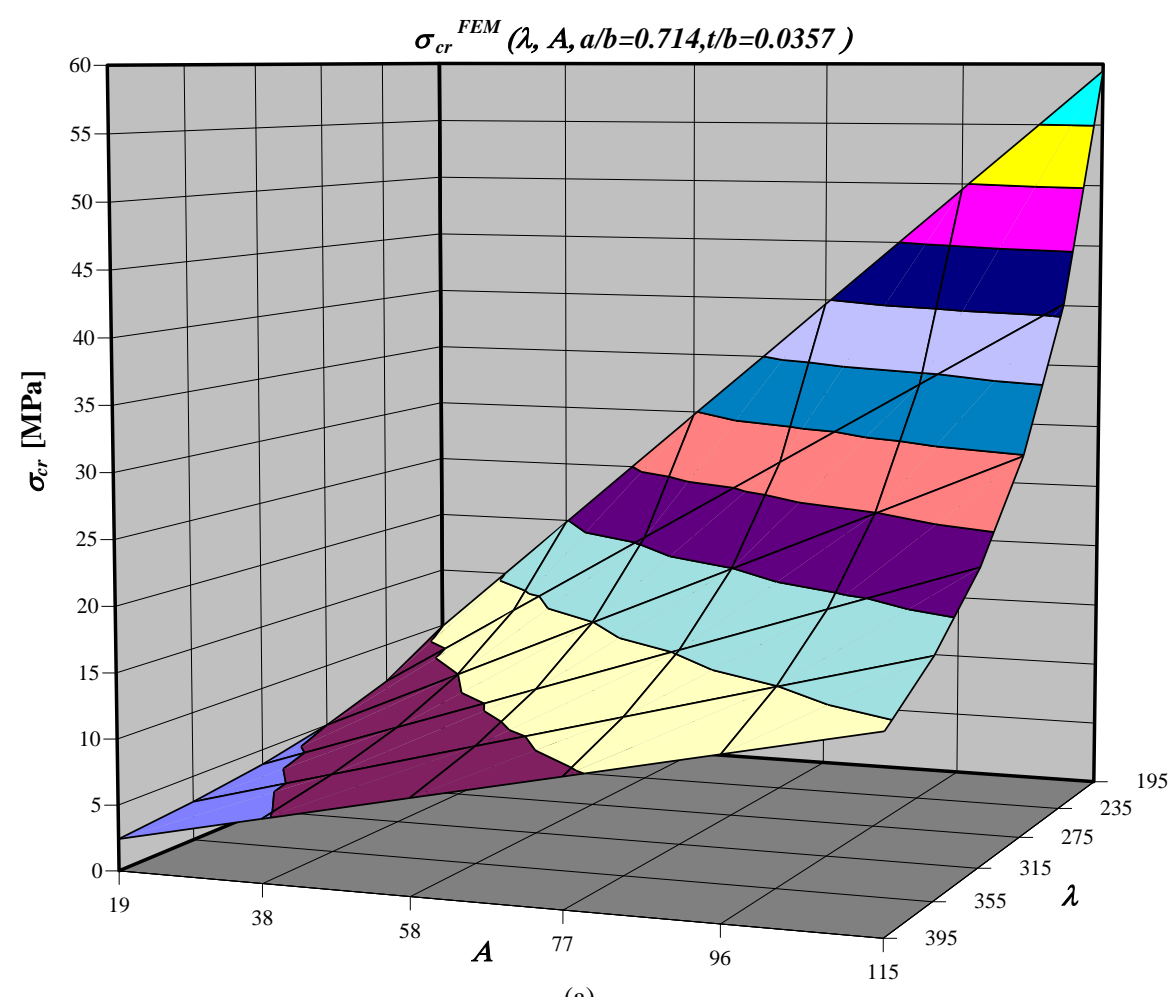

(a)

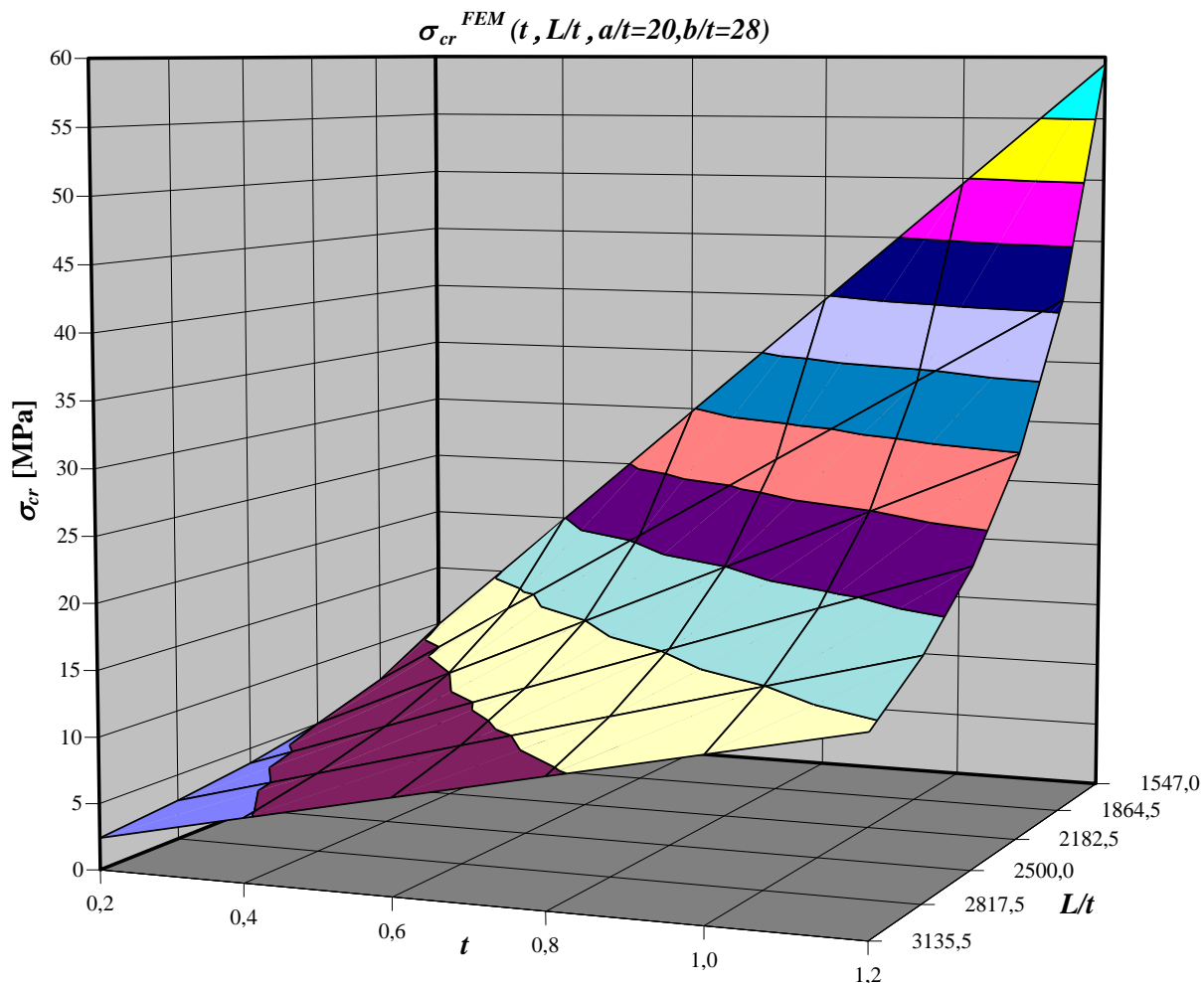

(b)

Fig. 7: Surface functions of critical compressive stresses: (a) $\sigma_{c r}{ }^{F E M}(\lambda, A, a / b=0.714, t / b=0.0357)$, (b) $\sigma_{c r}{ }^{F E M}(t, L / t, a / t=20, b / t=$ 28) for pinned without friction box-section columns made of steel and axially compressed by force, according to the results obtained from the FEM buckling linear stress computing 
Krzysztof Murawski and Alexandre de Macêdo Wahrhaftig / American Journal of Engineering and Applied Sciences 2021,14 (2): 214.257 DOI: 10.3844/ajeassp.2021.214.257

Table 1: Dimensions $a-b-L, t$, slenderness ratio $\lambda$ and cross-section area $A$ of the columns used for computing

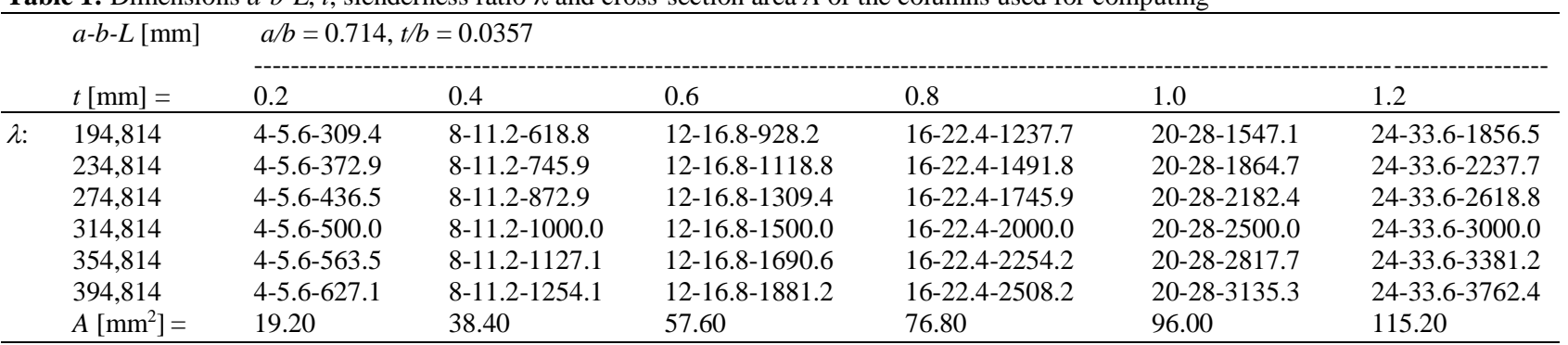

Table 2: Critical compressive forces $P_{c r}{ }^{F E M}$ obtained from the FEM computing

\begin{tabular}{|c|c|c|c|c|c|c|c|}
\hline \multirow{2}{*}{\multicolumn{2}{|c|}{$\begin{array}{l}P_{c r}{ }^{F E M}[\mathrm{~N}] \\
t[\mathrm{~mm}]=\end{array}$}} & \multicolumn{6}{|c|}{$a / b=0.714, t / b=0.0357$} \\
\hline & & 0.2 & 0.4 & 0.6 & 0.8 & 1.0 & 1.2 \\
\hline \multirow[t]{7}{*}{$\lambda:$} & 194,814 & 190,20 & 760,79 & 1711,87 & 3042,85 & 4754,53 & 6846,85 \\
\hline & 234,814 & 131,04 & 524,01 & 1179,19 & 2096,11 & 3275,34 & 4716,36 \\
\hline & 274,814 & 95,68 & 382,79 & 861,26 & 1531,07 & 2392,24 & 3445,13 \\
\hline & 314,814 & 72,94 & 291,76 & 656,48 & 1167,08 & 1823,57 & 2625,99 \\
\hline & 354,814 & 57,44 & 229,71 & 516,91 & 918,89 & 1435,81 & 2067,67 \\
\hline & 394,814 & 46,38 & 185,57 & 417,53 & 742,31 & 1159,82 & 1670,14 \\
\hline & $A\left[\mathrm{~mm}^{2}\right]=$ & 19.20 & 38.40 & 57.60 & 76.80 & 96.00 & 115.20 \\
\hline
\end{tabular}

Table 3: Critical compressive stresses $\sigma_{c r}{ }^{F E M}$ obtained from the FEM computing

\begin{tabular}{|c|c|c|c|c|c|c|c|}
\hline & \multirow{2}{*}{$\begin{array}{l}\sigma_{c r}^{F E M}[\mathrm{MPa}] \\
t[\mathrm{~mm}]=\end{array}$} & \multicolumn{6}{|c|}{$a / b=0.714, t / b=0.0357$} \\
\hline & & 0.2 & 0.4 & 0.6 & 0.8 & 1.0 & 1.2 \\
\hline \multirow[t]{7}{*}{$\lambda:$} & 194,814 & 9,91 & 19,81 & 29,72 & 39,62 & 49,53 & 59,43 \\
\hline & 234,814 & 6,82 & 13,65 & 20,47 & 27,29 & 34,12 & 40,94 \\
\hline & 274,814 & 4,98 & 9,97 & 14,95 & 19,94 & 24,92 & 29,91 \\
\hline & 314,814 & 3,80 & 7,60 & 11,40 & 15,20 & 19,00 & 22,80 \\
\hline & 354,814 & 2,99 & 5,98 & 8,97 & 11,96 & 14,96 & 17,95 \\
\hline & 394,814 & 2,42 & 4,83 & 7,25 & 9,67 & 12,08 & 14,50 \\
\hline & $\mathrm{A}\left[\mathrm{mm}^{2}\right]=$ & 19.20 & 38.40 & 57.60 & 76.80 & 96.00 & 115.20 \\
\hline
\end{tabular}

As the formula of the applied elements, i.e. the type of the formulation used for calculating the shape functions for the stiffness matrix, was used the default Element Formulation: Veubeke, which gave the lowest values.

The results as the graphs of the Deformed FEM model (Fig. 4), displacements (Fig. 5), elastic line $y(x)$ (Fig. 6a), elastic line slope $d y / d x$ (Fig. 6b) and function $y_{L}(P)$ (Fig. 6c) were obtained.

There were calculated 36 samples using the FEM (Table 1) taking under account the slenderness ratio $\lambda$, transverse critical transverse section $A$ and thickness t. The results, i.e., the critical compressive forces $P_{c r} F E M$, were obtained from the FEM computing as the buckling load multipliers (Table 2).

The critical compressive stresses $\sigma_{c r}{ }^{F E M}$ obtained from the FEM computing are presented in Table 3 and as the surface function in dependence on the slenderness ratio $\lambda$ and transverse critical cross-section $A$ in Fig. 7a $\sigma_{c r}{ }^{F E M}(\lambda, A, a / b=0.714, t / b=0.0357)$, as well as in the dependence on the thickness $t$ and $L / t$ ratio in Fig. 7b $\sigma_{c r}{ }^{F E M}(t, L / t, a / t=20, b / t=28)$.

\section{FEM Stress and Strain Analysis}

The buckled column with the elastic line $y(x)$ like in (Fig. 6a and 8), i.e., according to the TSTh (the loss of stability of the columns follows the exceedance of the force line from a critical cross-section) was next analyzed using the Linear Static Stresses Analysis. As a theoretical example, the graphs of the FEM stresses and strains are presented in Figs. 9-13 for a box-section column made of steel R35 with the Young's modulus $E$ $=166600 \mathrm{MPa}$ and nominal dimensions $a=20 \mathrm{~mm}, b=$ $28 \mathrm{~mm}$ and $t=1 \mathrm{~mm}$ and length $L=2500 \mathrm{~mm}(\lambda=314.8$ the slenderness, when the limiting slenderness $\lambda_{\text {el-lt }}=$ 102.7) and the column is compressed by ball-and-socket joints without friction. The same column was searched according to TSTh in the paper of (Murawski, 2020c). Figure 9-11 show the surface graphs of the stresses $\sigma_{n}$ and strains $\varepsilon_{n}$, obtained from the FEM post-buckling linear stress analysis. Figure 12-13 show the graphs of the FEM values of the $\sigma_{n}, \sigma_{y}(x, y), \varepsilon_{n}, \varepsilon_{y}(x, y)$ and $\Delta L, \Delta a(x, y)$ for $x$ $=0 \div L$ and $y= \pm a / 2, \pm a / 4,0.0$ in the longitudinal and transverse cross-sections. 


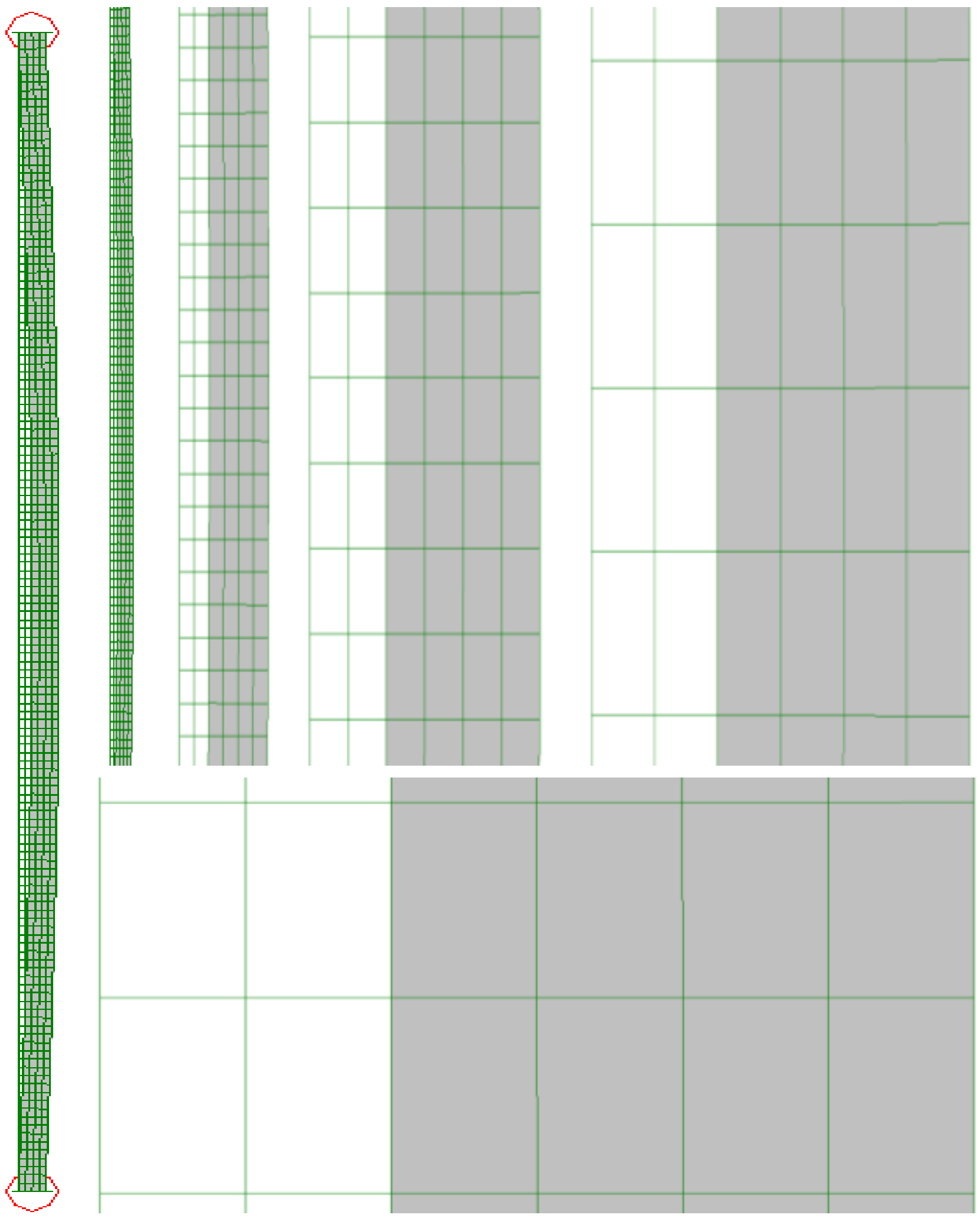

Fig. 8: Deformed FEM shell model and the undeformed FEM mesh model for the post-buckling linear stress analysis of the pinned boxsection column while the force line is getting out the critical transverse cross-section, like in the TSTh, where the exit of a force line from a critical transverse section follows a loss of the stability. The middle part of the column is shown in enlargements 


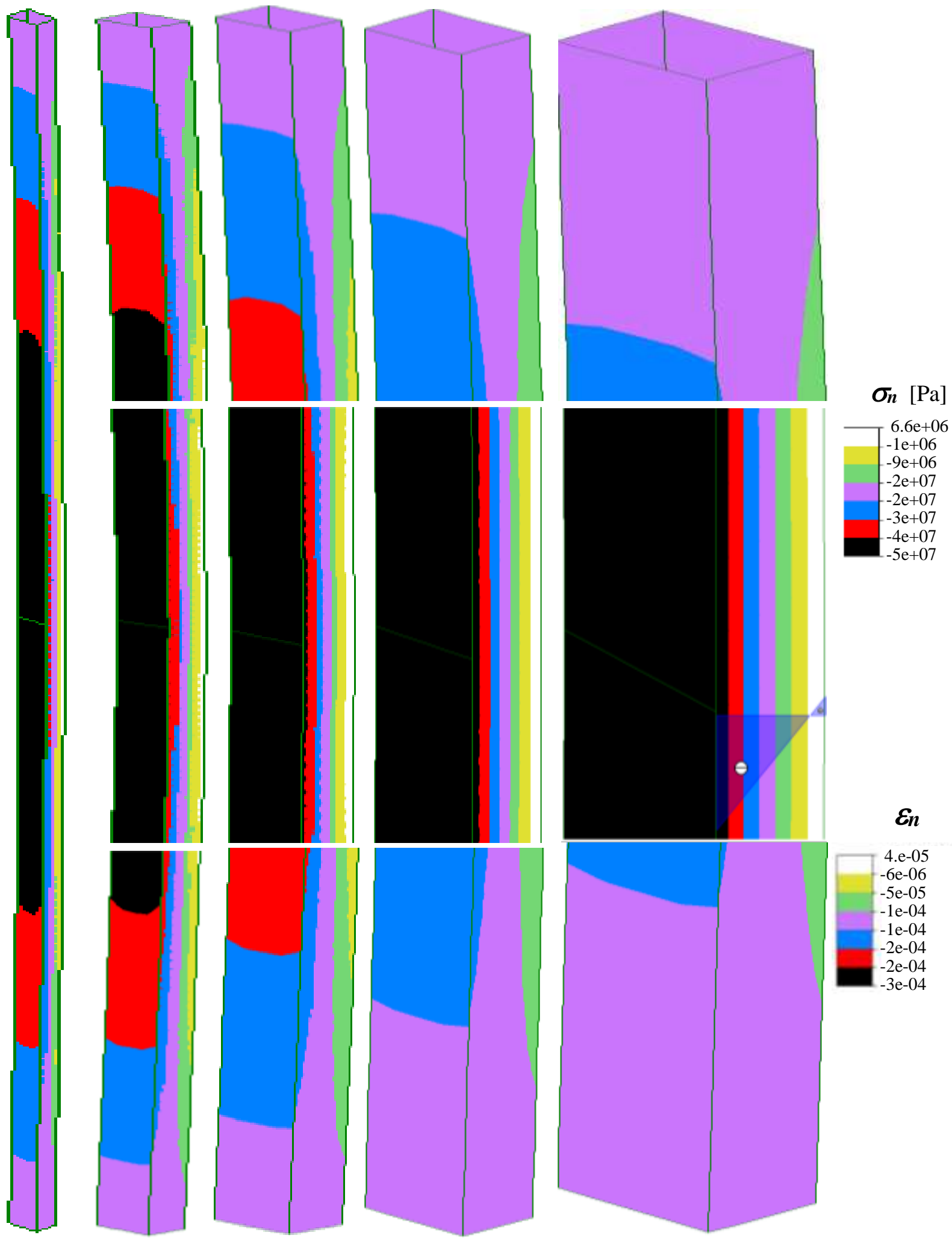

Fig. 9: Surface graphs of the $\sigma_{n}$ and $\varepsilon_{n}$ obtained from the post-buckling linear stress FEM analysis of the box-section column axially compressed by force through ball-and-socket without friction, with the dimensions $a=20 \mathrm{~mm}, b=28 \mathrm{~mm}, t=1 \mathrm{~mm}, L=2500$ $\mathrm{mm}$ made of steel R35 while the force line is getting out the critical cross-section. View on the concave wall. The top, middle and bottom parts of the column are shown in the enlargements 


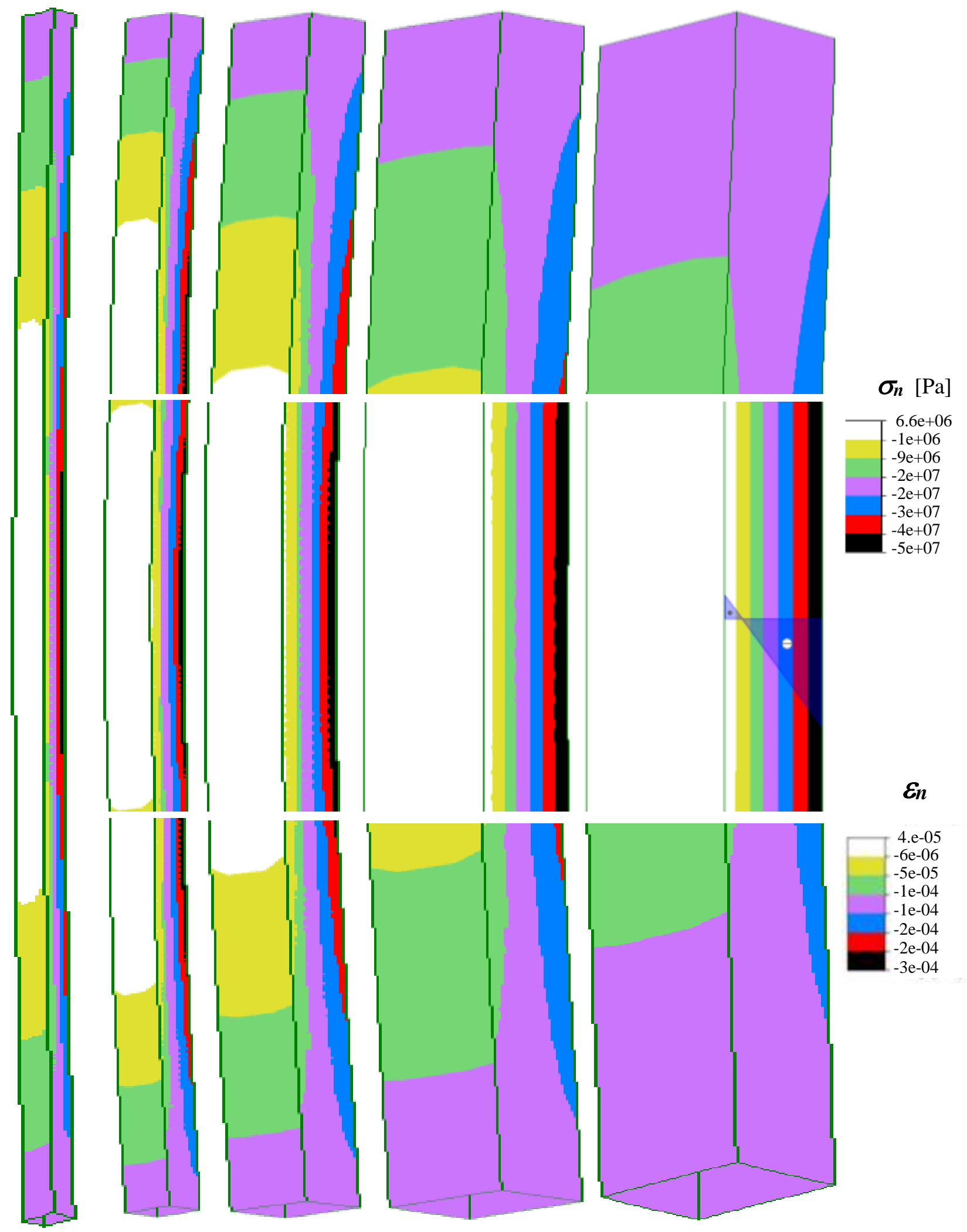

Fig. 10: Surface graphs of the $\sigma_{n}$ and $\varepsilon_{n}$ obtained from the post-buckling linear stress FEM analysis of the pinned box-section column with the dimensions $a=20 \mathrm{~mm}, b=28 \mathrm{~mm}, t=1 \mathrm{~mm}, L=2500 \mathrm{~mm}$ while the force line is getting out the critical transverse section. View on the convex wall. The top, middle and bottom parts of the column are shown in the enlargements 

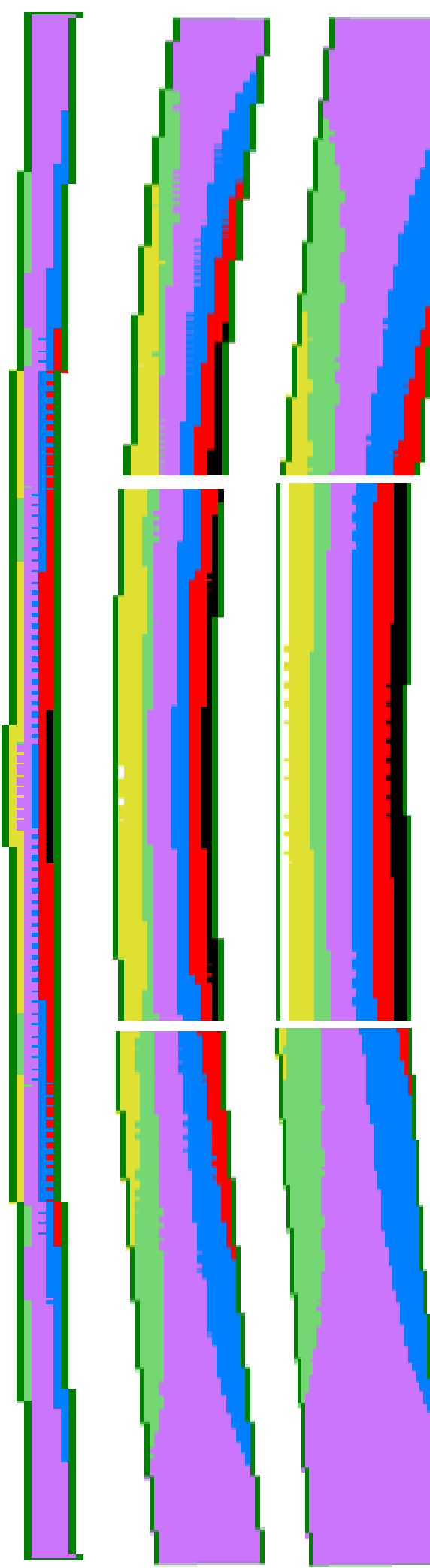
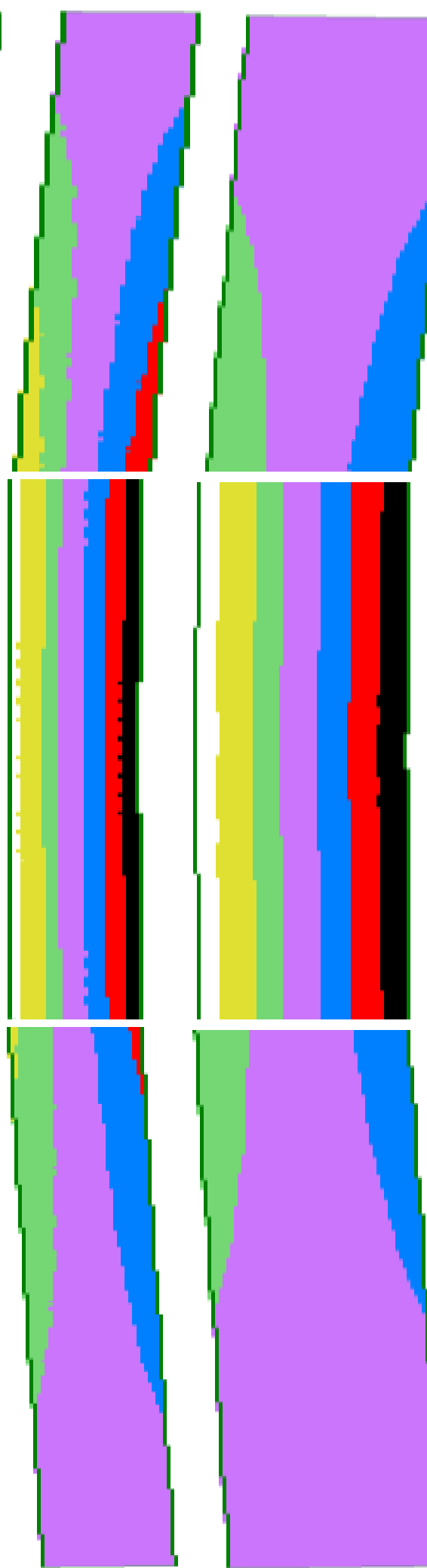
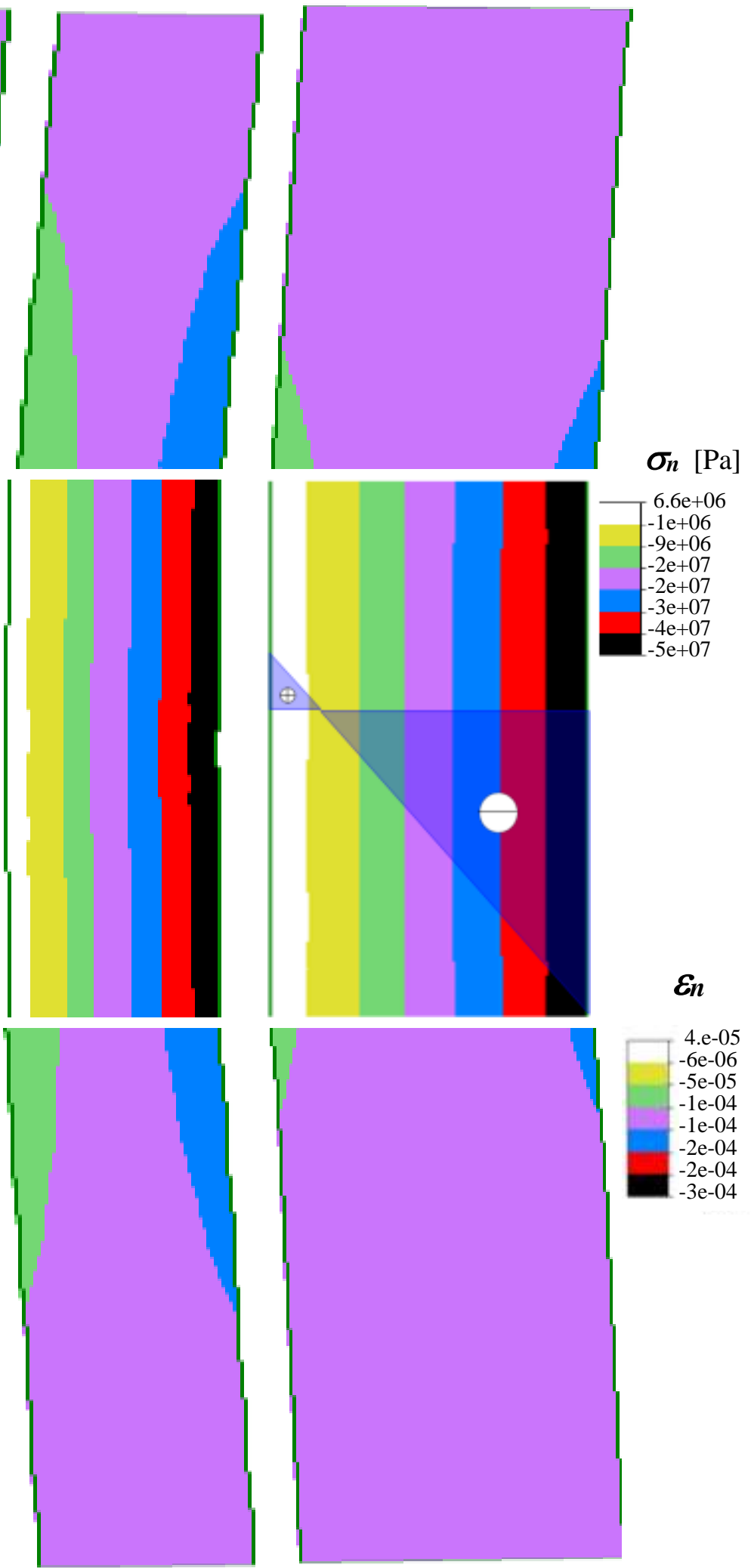

Fig. 11: Surface graphs of normal stresses $\sigma_{n}$ and strains $\varepsilon_{n}$ obtained from the post-buckling linear stress FEM analysis of the pinned box-section column with the dimensions $a=20 \mathrm{~mm}, b=28 \mathrm{~mm}, t=1 \mathrm{~mm}, L=2500 \mathrm{~mm}$ while the force line is getting out the critical cross-section. The side view. The top, middle and bottom parts of the column are shown in enlargements 


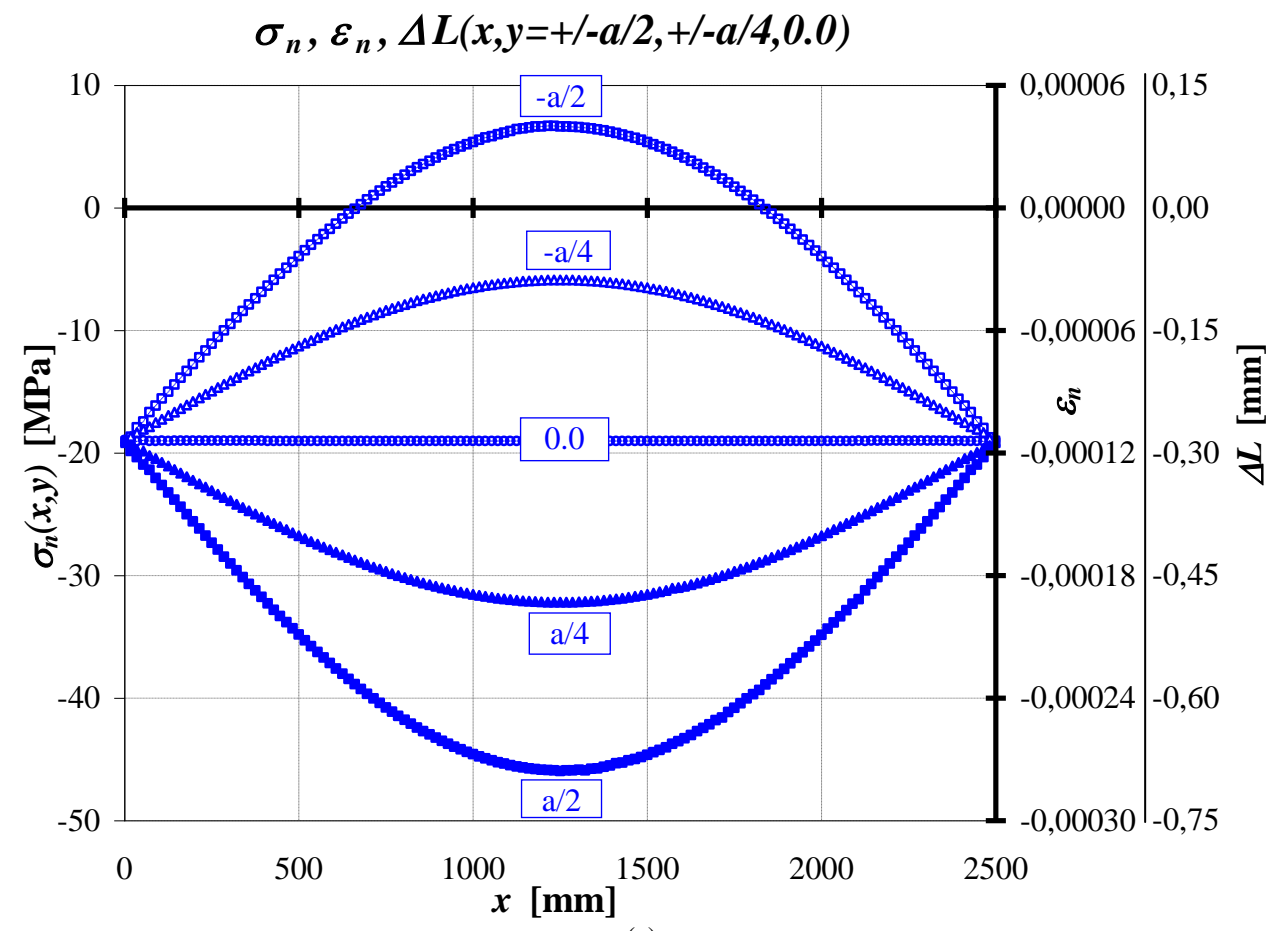

(a)
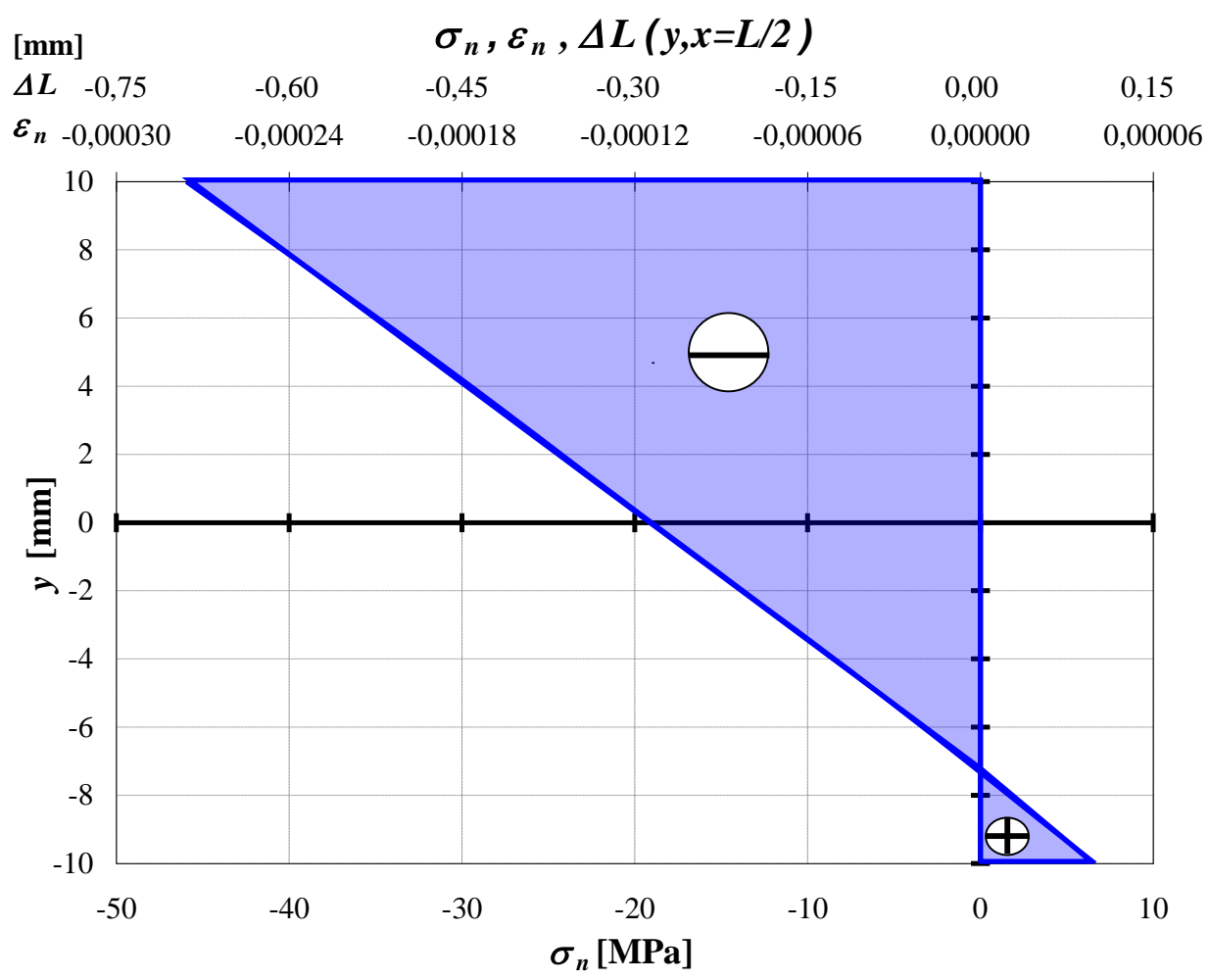

(b)

Fig. 12: Values obtained from the FEM post-buckling linear stress analysis (by the assumption that a maximal deflection equals the half of a side dimension, $a / 2=10 \mathrm{~mm}$, like in the TSTh, where the exit of a force line from a critical cross-section follows a loss of the (a) stability) of the stresses $\sigma_{n}(x, y)$, strains $\varepsilon_{n}(x, y)$ and elongations $\Delta L(x, y)$ for $x=0 \div L$ and $y= \pm a / 2, \pm a / 4,0.0$ in the axially loaded, pinned box-section column made of steel with dimensions: $a=20 \mathrm{~mm}, b=28 \mathrm{~mm}, t=1 \mathrm{~mm}, L=2500$ mm made of steel R35 in the longitudinal (a) and transverse (b) cross-section for $x=L / 2=1250 \mathrm{~mm}$ 


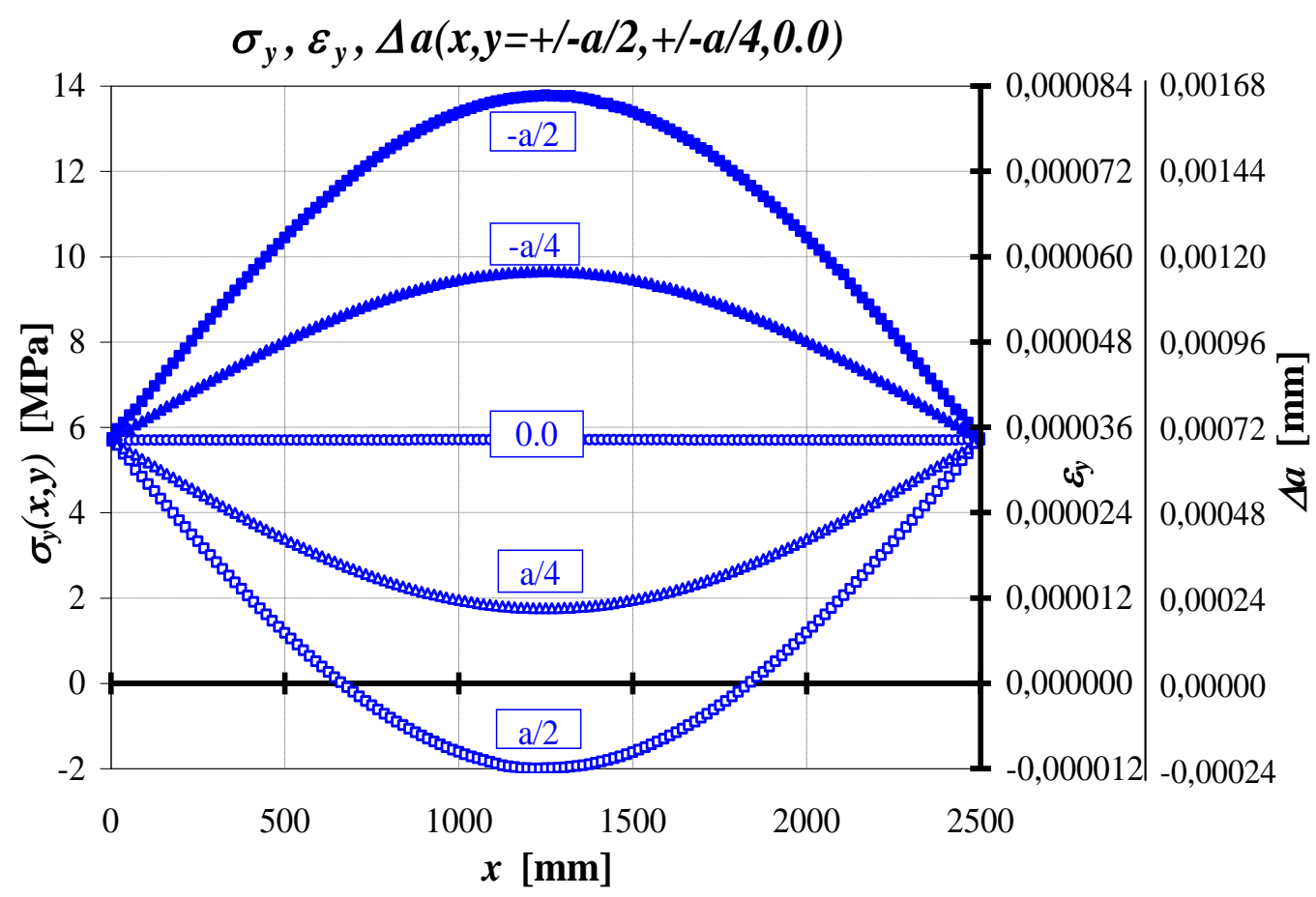

(a)

\begin{tabular}{|c|c|c|c|c|c|}
\hline \multirow{2}{*}{$\begin{array}{l}{[\mathbf{m m}]} \\
\Delta a-0,000240\end{array}$} & \multicolumn{4}{|c|}{$\sigma_{y}, \varepsilon_{y}, \Delta a(y, x=L / 2)$} & \multirow[b]{2}{*}{0,00168} \\
\hline & 0,00 & 0,000240 & 0,000720 & 0,00120 & \\
\hline$\varepsilon_{y}-0,000012$ & & 0,000012 & 0,000036 & 0,000060 & 0,000084 \\
\hline
\end{tabular}

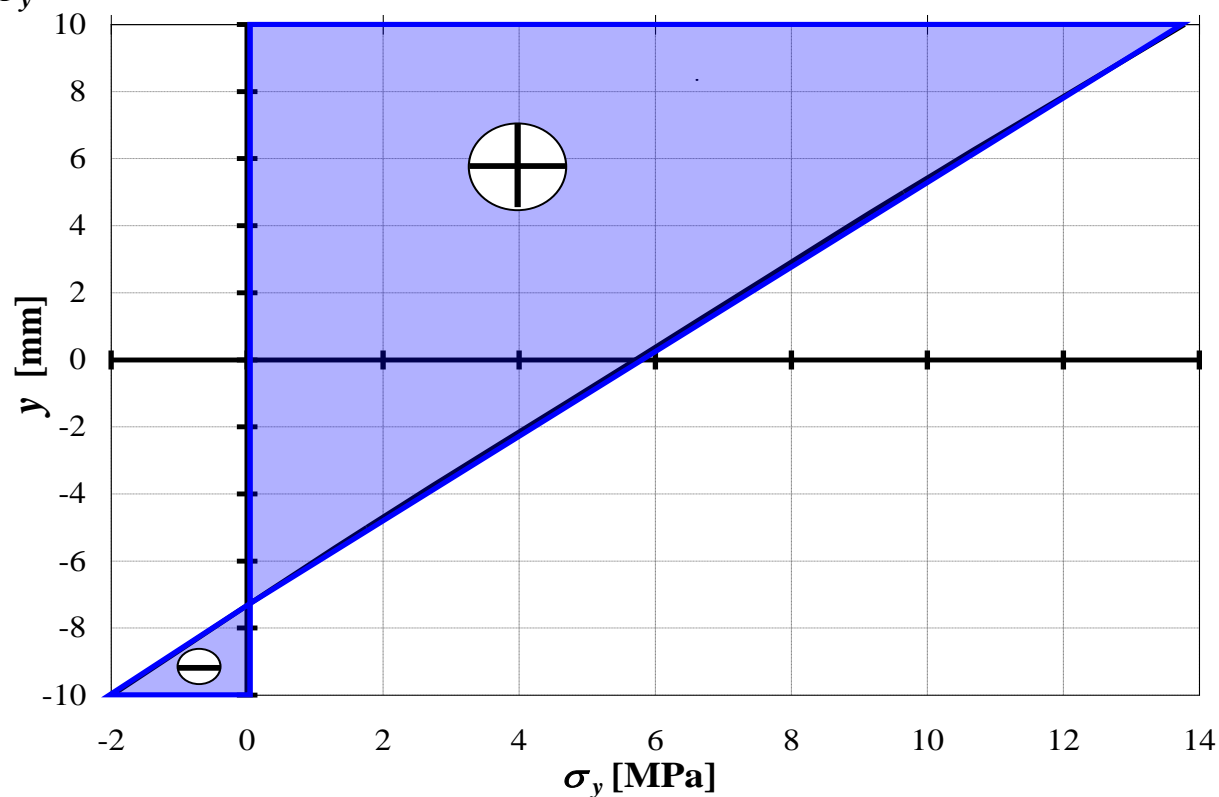

(b)

Fig. 13: Values obtained from the FEM post-buckling linear stress analysis (by the assumption that a maximal deflection equals the half of a side dimension, $a / 2=10 \mathrm{~mm}$, like in the TSTh, where the exit of a force line from a critical cross-section follows a loss of the stability) of the stresses $\sigma_{y}(x, y)$, strains $\varepsilon_{y}(x, y)$ and elongations $\Delta \mathrm{a}(x, y)$ for $x=0 \div L$ and $y= \pm a / 2, \pm a / 4,0.0$ in the axially loaded, pinned box-section column made of steel with dimensions: $a=20 \mathrm{~mm}, b=28 \mathrm{~mm}, t=1 \mathrm{~mm}, L=2500 \mathrm{~mm}$ made of steel R35 in the longitudinal (a) and transverse (b) cross-section for $x=L / 2=1250 \mathrm{~mm}$ 


\section{Discussion}

\section{Comparison of the FEM's and Euler's Results}

Figure 14a shows the comparison of the evolutions of function $y(x)$, Fig. 14b - elastic line slope $d y / d x$ and Fig. 14c - function $y_{L}(P)$, according to the FEM and to Euler by the assumption that a maximal deflection equals the half of a side dimension $(a / 2=10 \mathrm{~mm})$, like in the TSTh, where the exit of a force line from a critical transverse section follows a loss of the stability.

The maximal departures between functions $y(x)$ equal: $\Delta_{\max }=0.0073 \mathrm{~mm}$ and $\delta_{\max }=0.00073 \%$, between elastic line slopes $d y / d x$ equal: $\Delta_{\max }=0.029 \mathrm{deg}$ and $\delta_{\max }=$ $1.286 \%$ and between functions $y_{L}(P)$ equal: $\Delta_{\max }=230.86$ $\mathrm{N}$ and $\delta_{\max }=12.66 \%$.

In order to assess the FEM results they were compared with those obtained from Euler's Eq. (3) - presented in Table 4 and 5 and the differences are presented in Table 6 .

The departures between the FEM critical compressive stresses (Table 3) and the Euler's (Table 5) equal to values from -27.2 to $336.6 \%$.

Figure 15a shows the surface graphs of the critical compressive stresses $\sigma_{c r}{ }^{\text {Euler }}(\lambda, A, a / b=0.714, t / b=$ $0.0357)$ and Fig. $15 \mathrm{~b} \sigma_{c r}{ }^{\text {Euler }}(t, L / t, a / t=20, b / t=28)$ according to Euler.

\section{Comparison of the FEM's and TSTh's Results}

Figure 16a presents the comparison of the evolutions of the function $y(x)$, Fig. 16b - elastic line slope $d y / d x$ and Fig. 16c - function $y_{L}(P)$, for the compressed pinned box-section steel column with dimensions: $a=20 \mathrm{~mm}$, $b=28 \mathrm{~mm}, t=1 \mathrm{~mm}, L=2500 \mathrm{~mm}$, according to the FEM and to TSTh.

Table 4: Critical compressive forces $P_{c r}$ Euler obtained from the Euler's Eq. (3)

\begin{tabular}{|c|c|c|c|c|c|c|c|}
\hline & $P_{c r}^{\text {Euler }}[\mathrm{N}]$ & $a / b=$ & $b=0.03$ & & & & \\
\hline & $t[\mathrm{~mm}]=$ & 0.2 & 0.4 & 0.6 & 0.8 & 1.0 & 1.2 \\
\hline$\lambda:$ & 194,814 & 831,8 & 1663,7 & 2495,5 & 3327,3 & 4159,2 & 4991,0 \\
\hline & 234,814 & 572,6 & 1145,1 & 1717,7 & 2290,3 & 2862,8 & 3435,4 \\
\hline & 274,814 & 418,0 & 836,0 & 1254,1 & 1672,1 & 2090,1 & 2508,1 \\
\hline & 314,814 & 318,5 & 637,1 & 955,6 & 1274,2 & 1592,7 & 1911,3 \\
\hline & 354,814 & 250,8 & 501,5 & 752,3 & 1003,1 & 1253,8 & 1504,6 \\
\hline & 394,814 & 202,5 & 405,1 & 607,6 & 810,1 & 1012,7 & 1215,2 \\
\hline & $A\left[\mathrm{~mm}^{2}\right]=$ & 19.20 & 38.40 & 57.60 & 76.80 & 96.00 & 115.20 \\
\hline
\end{tabular}

Table 5: Critical compressive stresses $\sigma_{c r}$ Euler obtained from the Euler's Eq. (3)

\begin{tabular}{|c|c|c|c|c|c|c|c|}
\hline & \multirow{2}{*}{$\begin{array}{l}\sigma_{c r}^{\text {Euler }}[\mathrm{MPa}] \\
t[\mathrm{~mm}]=\end{array}$} & \multicolumn{6}{|c|}{$a / b=0.714, t / b=0.0357$} \\
\hline & & 0.2 & 0.4 & 0.6 & 0.8 & 1.0 & 1.2 \\
\hline \multirow[t]{7}{*}{$\lambda:$} & 194,814 & 43,325 & 43,325 & 43,325 & 43,325 & 43,325 & 43,325 \\
\hline & 234,814 & 29,821 & 29,821 & 29,821 & 29,821 & 29,821 & 29,821 \\
\hline & 274,814 & 21,772 & 21,772 & 21,772 & 21,772 & 21,772 & 21,772 \\
\hline & 314,814 & 16,591 & 16,591 & 16,591 & 16,591 & 16,591 & 16,591 \\
\hline & 354,814 & 13,061 & 13,061 & 13,061 & 13,061 & 13,061 & 13,061 \\
\hline & 394,814 & 10,548 & 10,548 & 10,548 & 10,548 & 10,548 & 10,548 \\
\hline & $A\left[\mathrm{~mm}^{2}\right]=$ & 19.20 & 38.40 & 57.60 & 76.80 & 96.00 & 115.20 \\
\hline
\end{tabular}

Table 6: Departures $\Delta[\%]$ of the Euler's critical loads from the FEM results

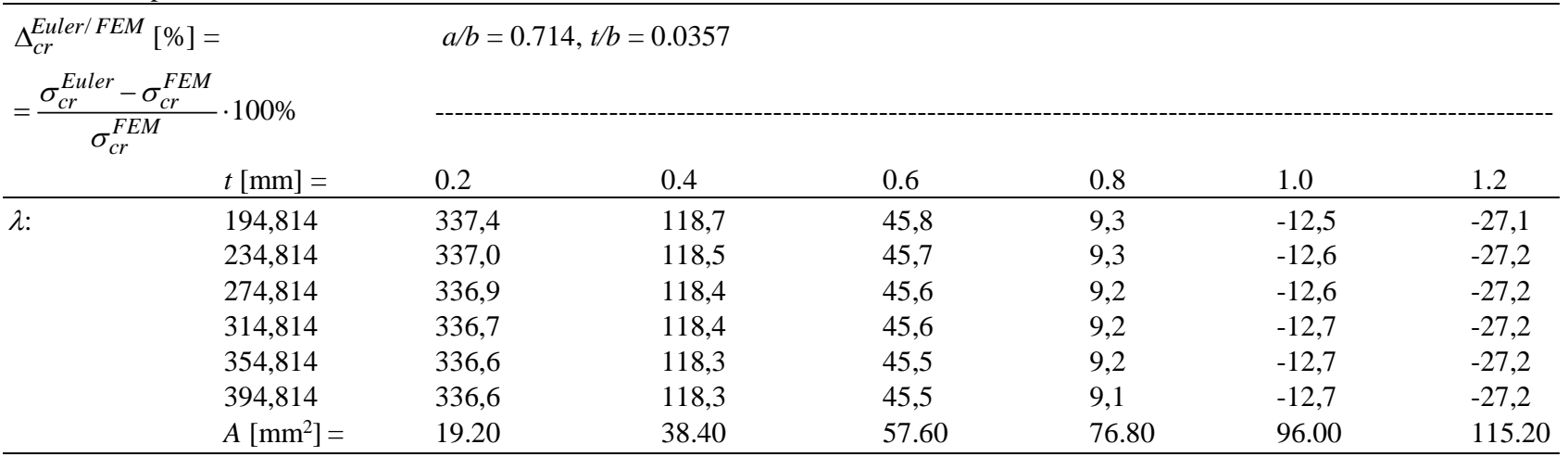




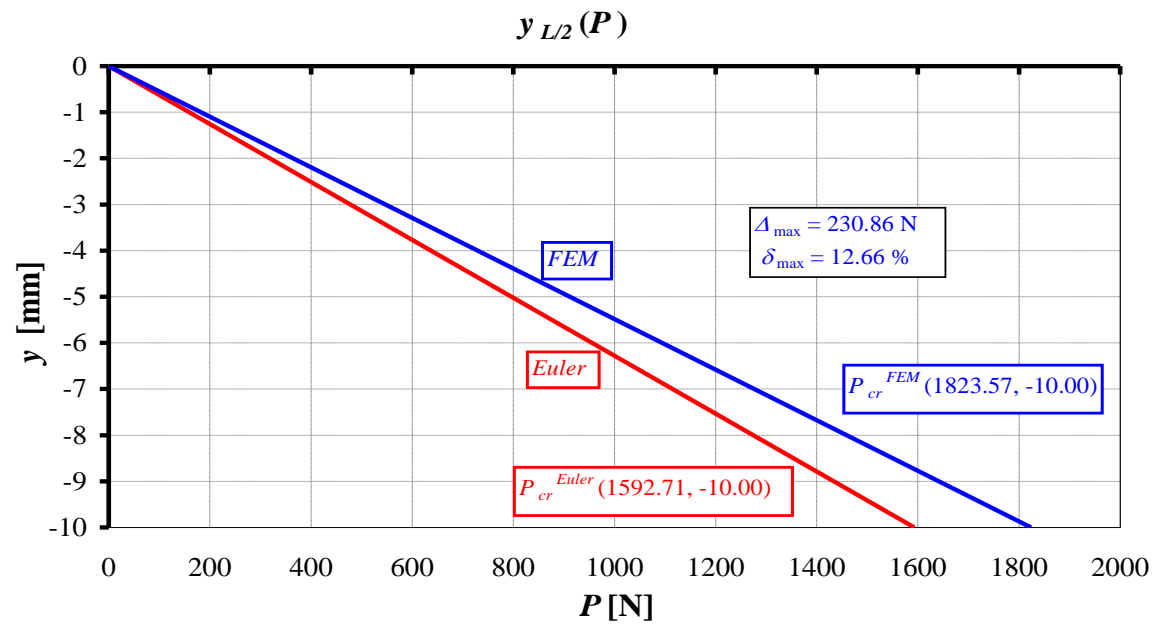

(a)

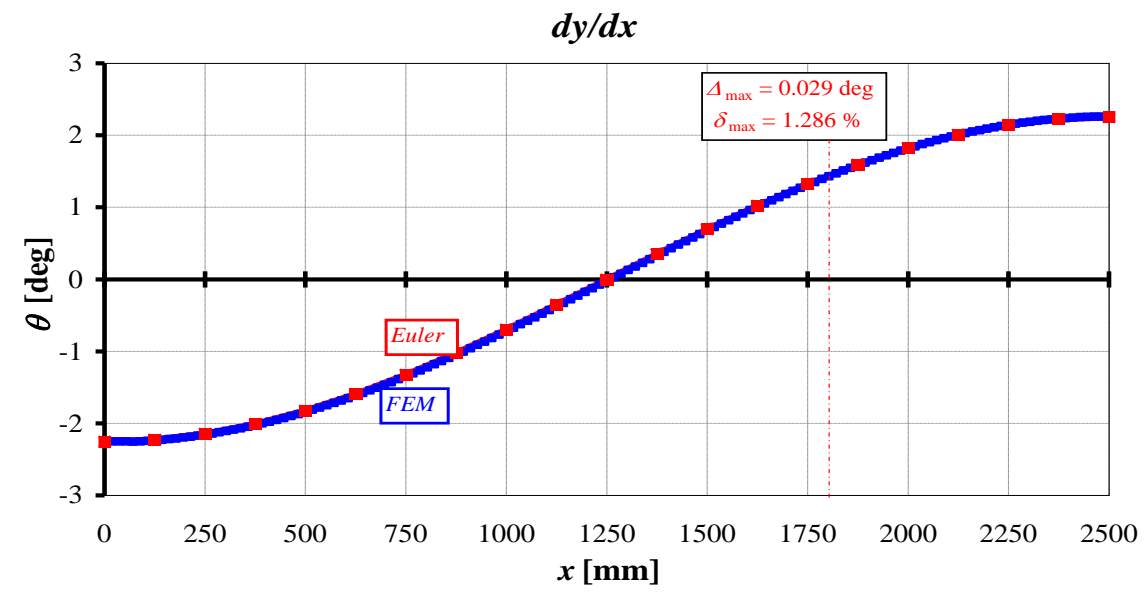

(b)

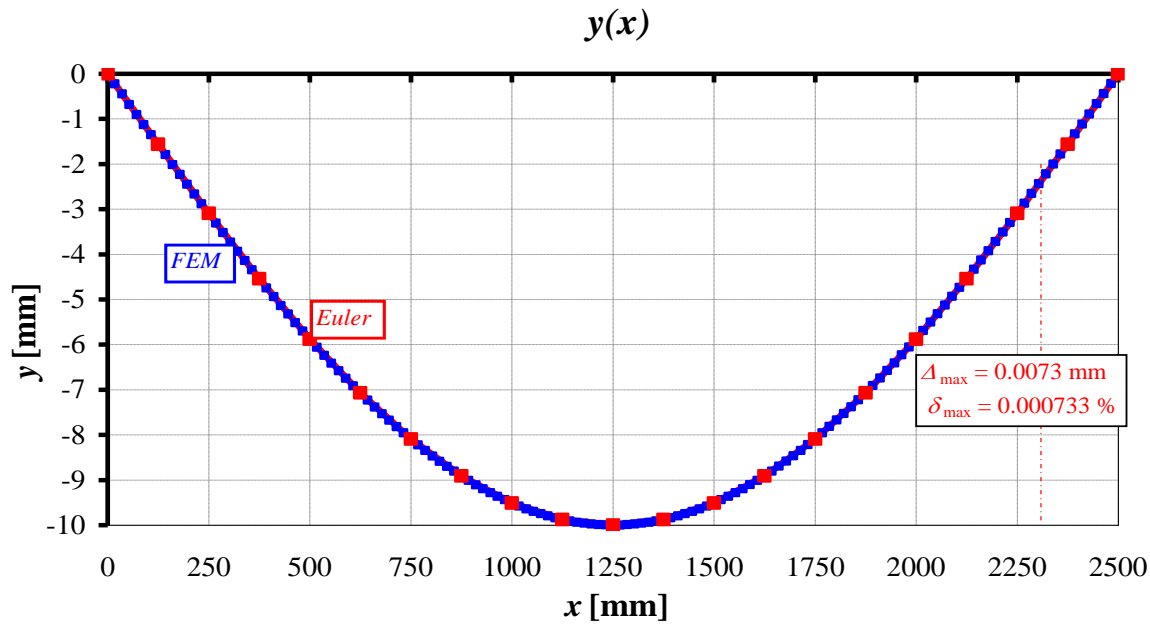

(c)

Fig. 14: Comparison of the evolutions of (a) elastic line $y(x)$, (b) elastic line slope $d y / d x$ and (c) function $y L(P)$ for the compressed pinned box-section steel column with dimensions: $a=20 \mathrm{~mm}, b=28 \mathrm{~mm}, t=1 \mathrm{~mm}, L=2500 \mathrm{~mm}$ made of steel R35, according to the results obtained from the FEM buckling linear stress computing and Euler's formulas by the assumption that a maximal deflection equals the half of a side dimension $(a / 2=10 \mathrm{~mm})$, like in the TSTh, where the exit of a force line from a critical cross-section follows a loss of the stability 


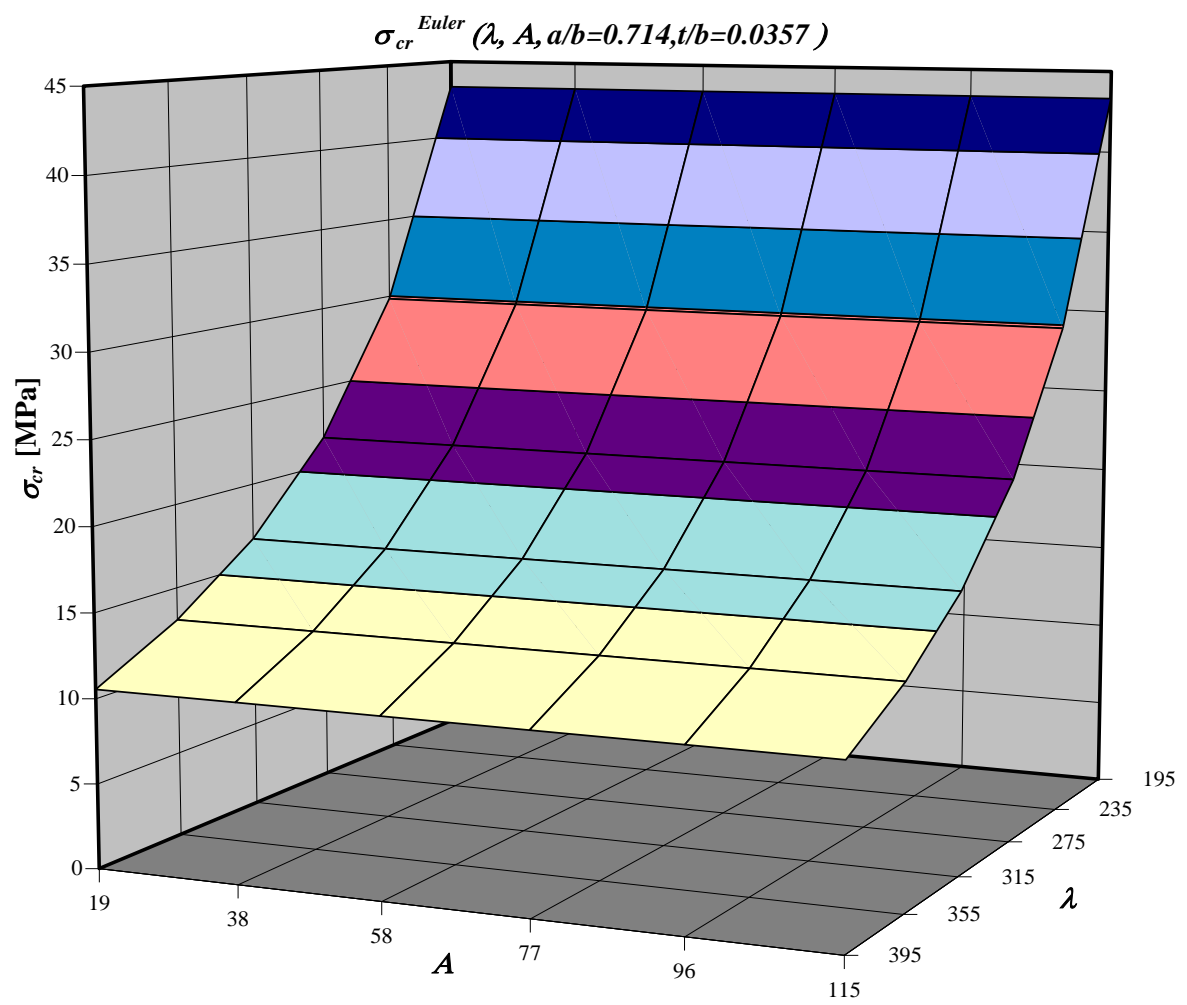

(a)

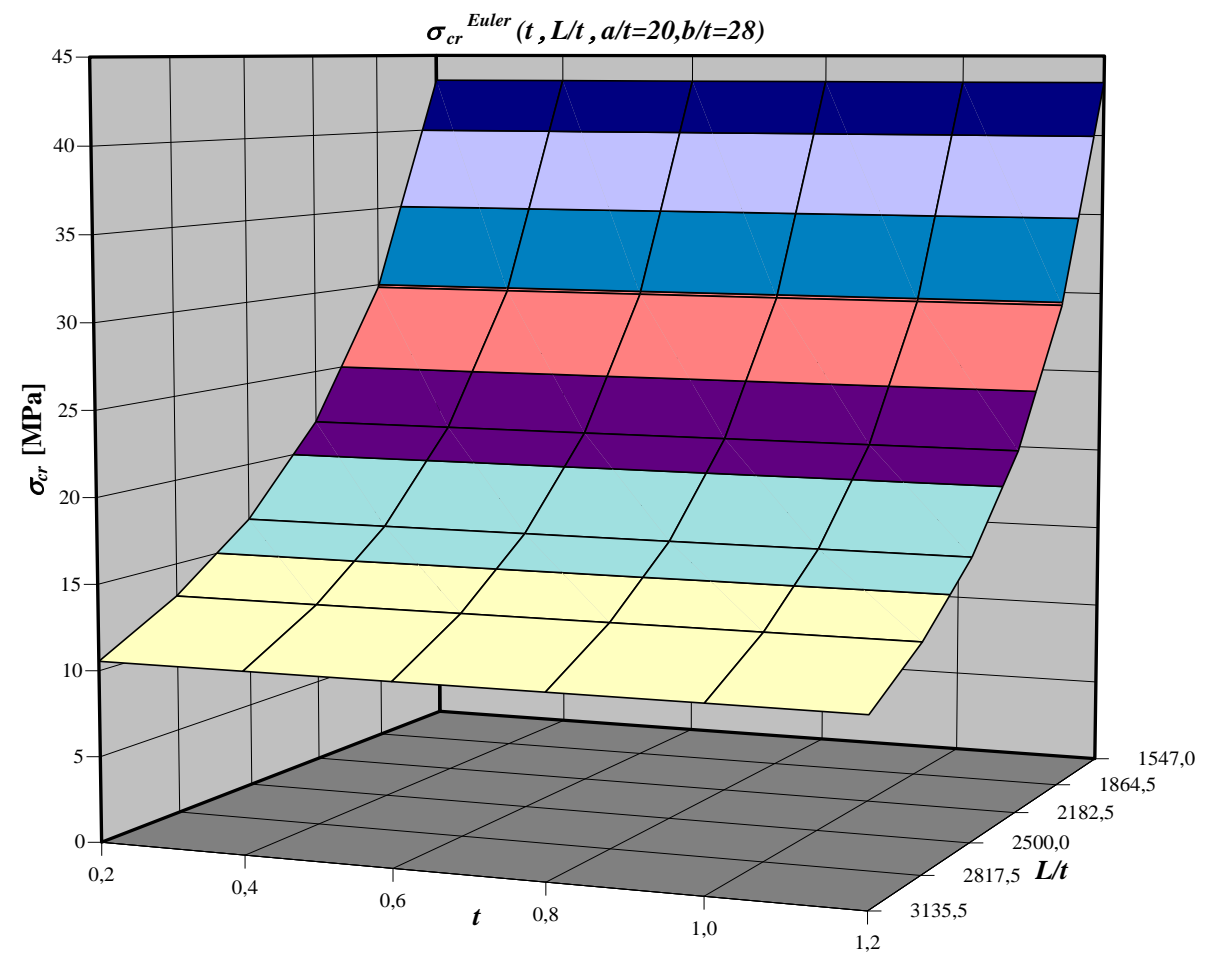

(b)

Fig. 15: Stresses Surface functions of critical compressive stresses: (a) $\sigma_{c r}{ }^{\text {Euler }}(\lambda, \mathrm{A}, a / b=0.714, t / b=0.0357)$, (b) $\sigma_{c r}{ }^{\text {Euler }}(t, L / t, a / t=$ $20, b / t=28$ ) for pinned without friction box-section columns made of steel R35 and axially compressed by force through, according to the results obtained from the Euler's formula 


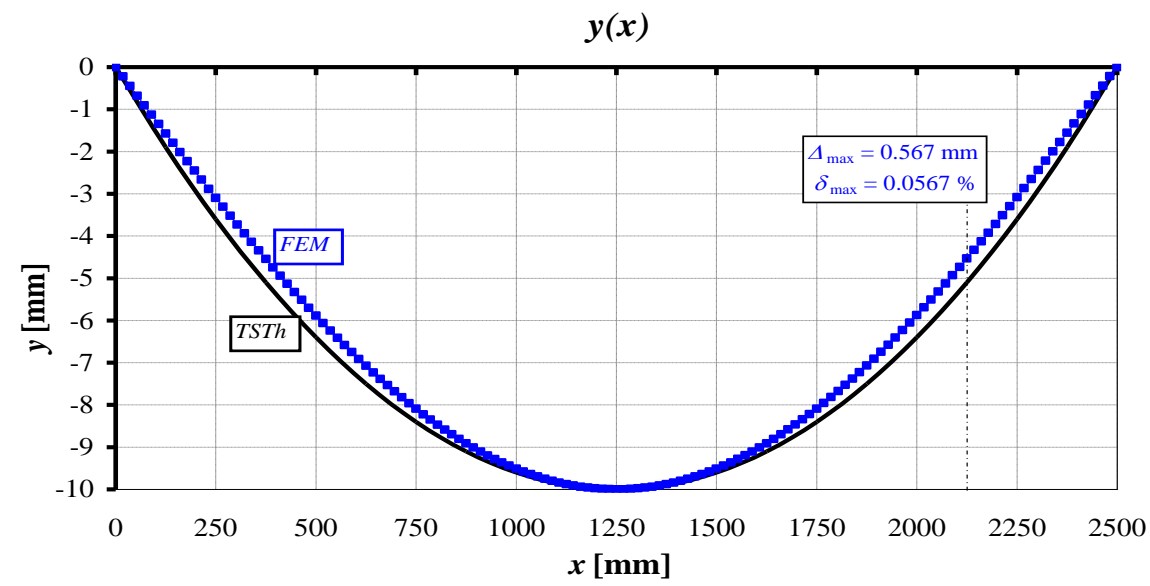

(a)

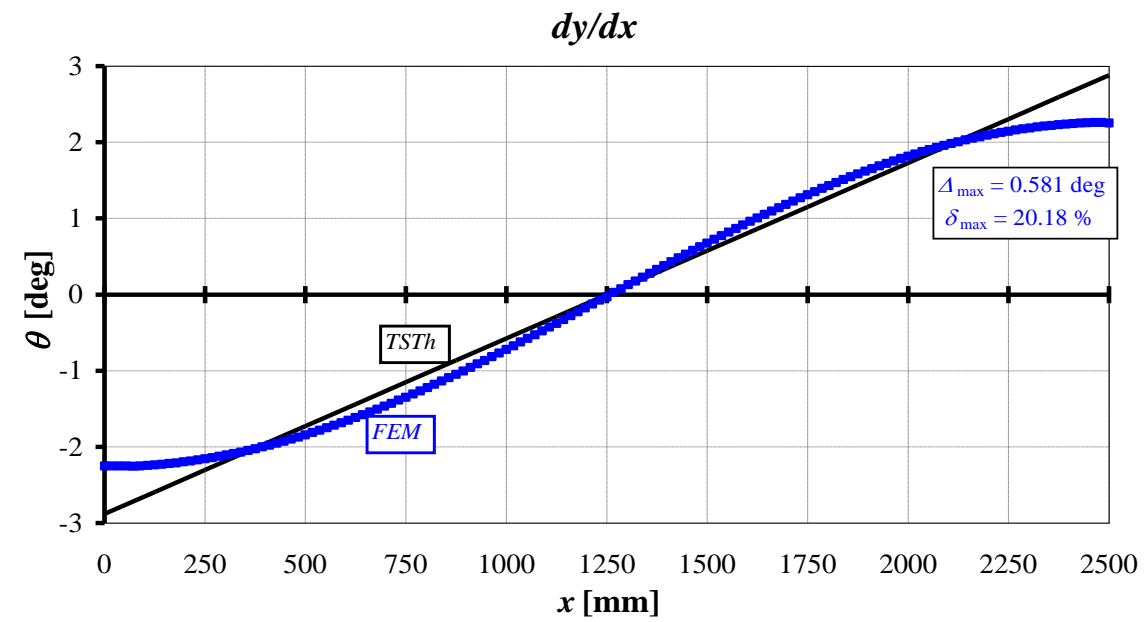

(b)

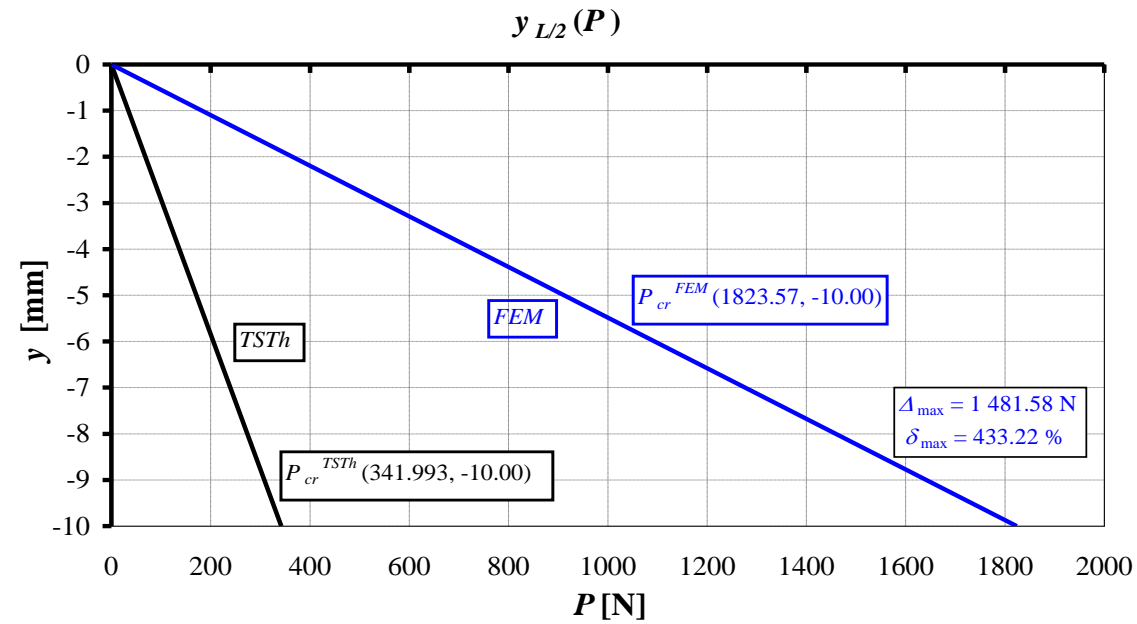

(c)

Fig. 16: Comparison of the evolutions of (a) elastic line $y(x)$, (b) elastic line slope $d y / d x$ and (c) function $y_{L}(P)$ for the compressed pinned box-section steel column with dimensions: $a=20 \mathrm{~mm}, b=28 \mathrm{~mm}, t=1 \mathrm{~mm}, L=2500 \mathrm{~mm}$ made of steel R35, according to the results obtained from the FEM buckling linear stress computing and TSTh by the assumption that a maximal deflection equals the half of a side dimension $(a / 2=10 \mathrm{~mm})$ and the exit of a force line from a critical cross-section follows a loss of the stability 
The maximal departures between functions $y(x)$ equal: $\Delta_{\max }=0.567 \mathrm{~mm}$ and $\delta_{\max }=0.567 \%$, between elastic line slopes $d y / d x$ equal: $\Delta_{\max }=0.581 \mathrm{deg}$ and $\delta_{\max }=20.18 \%$ and between functions $y_{L}(P)$ equal: $\Delta_{\max }$ $=1481.58 \mathrm{~N}$ and $\delta_{\max }=433.22 \%$.

In order to assess the FEM results they were compared with those obtained from the TSTh - presented in Table 7 and 8 and the differences are presented in Table 9.

The departures between the FEM critical compressive stresses (Table 3) and the TSTh stresses - Table 7 and Table 8 equal to values from -85.0 to $45.1 \%$ (Table 9).

Figure $17 \mathrm{a}$ shows the surface graphs of the critical stresses $\sigma_{c r N}{ }^{T S T h}(\lambda, A, a / b=0.714, t / b=0.0357)$ and Fig. $17 \mathrm{~b} \sigma_{c r N}{ }^{T S T h}(t, L / t, a / t=20, b / t=28)$ according to the TSTh.
Figure 18 shows the graphs of the FEM values and the TSTh (by the assumption that a maximal deflection equals the half of a side dimension, $a / 2=10 \mathrm{~mm}$, where the exit of a force line from a critical transverse section follows a loss of the stability) of the $\sigma_{n}(x, y), \varepsilon_{n}(x, y)$ and $\Delta L(x, y)$ for $x=0 \div L$ and $y= \pm \mathrm{a} / 2, \pm \mathrm{a} / 4,0.0$ in the longitudinal (Fig. 18a) and transverse section (Fig. 18b) for $x=L / 2=1250 \mathrm{~mm}$ in the axially loaded, pinned boxsection column made of steel with dimensions: $a=20$ $\mathrm{mm}, b=28 \mathrm{~mm}, t=1 \mathrm{~mm}, L=2500 \mathrm{~mm}$.

Figure 19 shows the graphs of the FEM values and the TSTh of the $\sigma_{y}(x, y), \varepsilon_{y}(x, y)$ and $\Delta 2 \mathrm{a}(x, y)$ for the same column. The maximal departures between stresses equal: $\Delta_{\max }=36.679 \mathrm{MPa}$ and $\delta_{\max }=398.26 \%$.

Table 7: Critical compressive forces $P^{T S T h}{ }_{c r}$ obtained from the TSTh

\begin{tabular}{|c|c|c|c|c|c|c|c|}
\hline & $P_{c r}^{T S T h}[\mathrm{~N}]$ & $a / b=0$ & 0.0357 & & & & \\
\hline & $t[\mathrm{~mm}]=$ & 0.2 & 0.4 & 0.6 & 0.8 & 1.0 & 1.2 \\
\hline$\lambda:$ & 194,814 & 275,90 & 446,95 & 603,37 & 751,18 & 893,07 & 1030,52 \\
\hline & 234,814 & 189,91 & 307,65 & 415,31 & 517,05 & 614,72 & 709,33 \\
\hline & 274,814 & 138,65 & 224,61 & 303,21 & 377,49 & 448,80 & 517,87 \\
\hline & 314,814 & 105,65 & 171,16 & 231,06 & 287,66 & 341,99 & 394,63 \\
\hline & 354,814 & 83,17 & 134,74 & 181,90 & 226,46 & 269,23 & 310,67 \\
\hline & 394,814 & 67,17 & 108,82 & 146,91 & 182,89 & 217,44 & 250,91 \\
\hline & $A\left[\mathrm{~mm}^{2}\right]=$ & 19.20 & 38.40 & 57.60 & 76.80 & 96.00 & 115.20 \\
\hline
\end{tabular}

Table 8 Critical compressive stresses $\sigma^{T S T h}{ }_{c r}$ obtained from the TSTh

\begin{tabular}{|c|c|c|c|c|c|c|c|}
\hline & \multirow{2}{*}{$\begin{array}{l}\sigma_{c r}^{T S T h}[\mathrm{MPa}] \\
t[\mathrm{~mm}]=\end{array}$} & \multicolumn{6}{|c|}{$a / b=0.714, t / b=0.0357$} \\
\hline & & 0.2 & 0.4 & 0.6 & 0.8 & 1.0 & 1.2 \\
\hline \multirow[t]{7}{*}{$\lambda:$} & 194,814 & 14,37 & 11,64 & 10,48 & 9,78 & 9,30 & 8,95 \\
\hline & 234,814 & 9,89 & 8,01 & 7,21 & 6,73 & 6,40 & 6,16 \\
\hline & 274,814 & 7,22 & 5,85 & 5,26 & 4,92 & 4,67 & 4,50 \\
\hline & 314,814 & 5,50 & 4,46 & 4,01 & 3,75 & 3,56 & 3,43 \\
\hline & 354,814 & 4,33 & 3,51 & 3,16 & 2,95 & 2,80 & 2,70 \\
\hline & 394,814 & 3,50 & 2,83 & 2,55 & 2,38 & 2,27 & 2,18 \\
\hline & $A\left[\mathrm{~mm}^{2}\right]=$ & 19.20 & 38.40 & 57.60 & 76.80 & 96.00 & 115.20 \\
\hline
\end{tabular}

Table 9: Departures $\Delta[\%]$ of the TSTh critical loads from the FEM results

\begin{tabular}{|c|c|c|c|c|c|c|c|}
\hline \multirow{3}{*}{\multicolumn{2}{|c|}{$\begin{array}{l}\Delta_{c r}^{T S T h / F E M} \quad[\%]= \\
=\frac{\sigma_{c r}^{T S T h}-\sigma_{c r}^{F E M}}{\sigma_{c r}^{F E M}} \cdot 100 \%\end{array}$}} & \multicolumn{6}{|c|}{$a / b=0.714, t / b=0.0357$} \\
\hline & & \multirow{2}{*}{\multicolumn{6}{|c|}{ 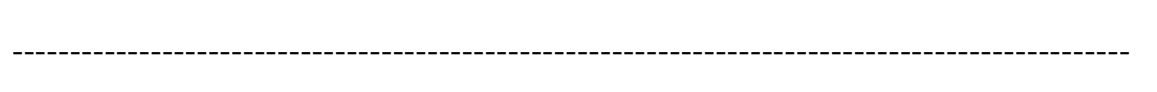 }} \\
\hline & & & & & & & \\
\hline & $t[\mathrm{~mm}]=$ & 0.2 & 0.4 & 0.6 & 0.8 & 1.0 & 1.2 \\
\hline \multirow[t]{7}{*}{$\lambda:$} & 194,814 & 45,1 & $-41,3$ & $-64,8$ & $-75,3$ & $-81,2$ & $-84,9$ \\
\hline & 234,814 & 44,9 & $-41,3$ & $-64,8$ & $-75,3$ & $-81,2$ & $-85,0$ \\
\hline & 274,814 & 44,9 & $-41,3$ & $-64,8$ & $-75,3$ & $-81,2$ & $-85,0$ \\
\hline & 314,814 & 44,9 & $-41,3$ & $-64,8$ & $-75,4$ & $-81,2$ & $-85,0$ \\
\hline & 354,814 & 44,8 & $-41,3$ & $-64,8$ & $-75,4$ & $-81,2$ & $-85,0$ \\
\hline & 394,814 & 44,8 & $-41,4$ & $-64,8$ & $-75,4$ & $-81,3$ & $-85,0$ \\
\hline & $A\left[\mathrm{~mm}^{2}\right]=$ & 19.20 & 38.40 & 57.60 & 76.80 & 96.00 & 115.20 \\
\hline
\end{tabular}




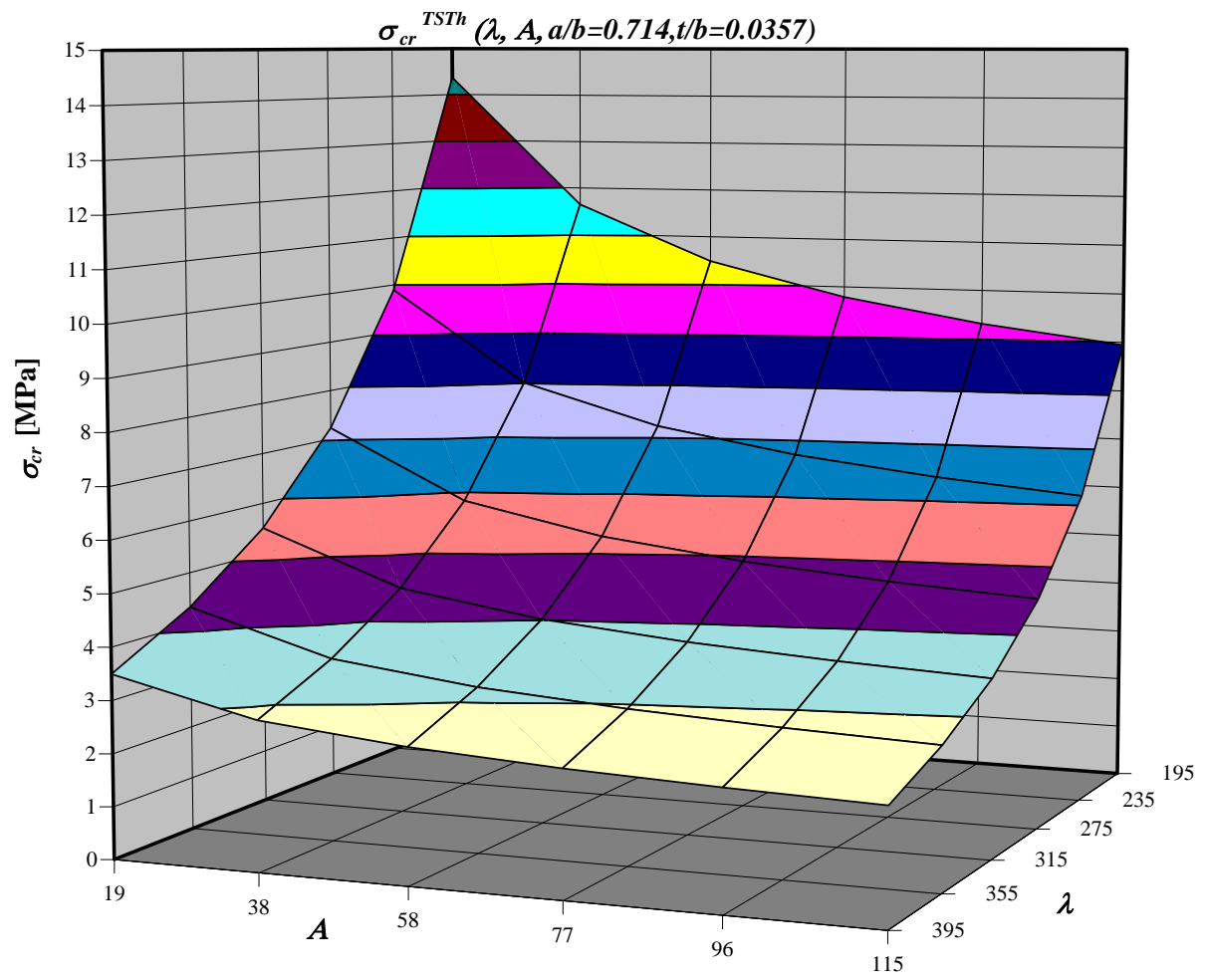

(a)

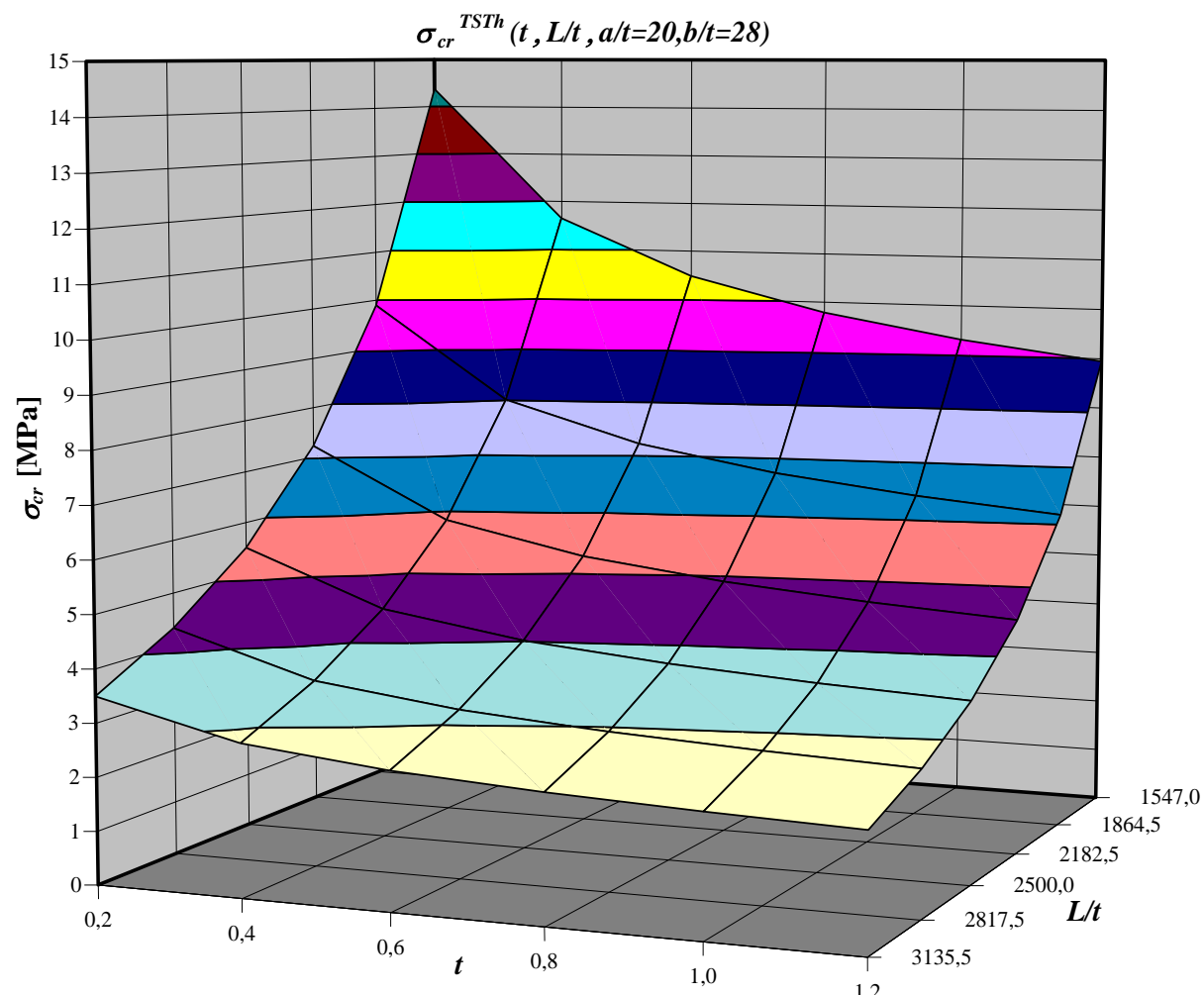

(b)

Fig. 17: Surface functions of critical compressive stresses: (a) $\sigma_{c r}{ }^{E u l e r}(\lambda, A, a / b=0.714, t / b=0.0357)$, (b) $\sigma_{c r}{ }^{\text {Euler }}(t, L / t, a / t=20, b / t=$ 28) for pinned without friction box-section columns made of steel R35 and axially compressed by force, according to the results obtained from the TSTh 

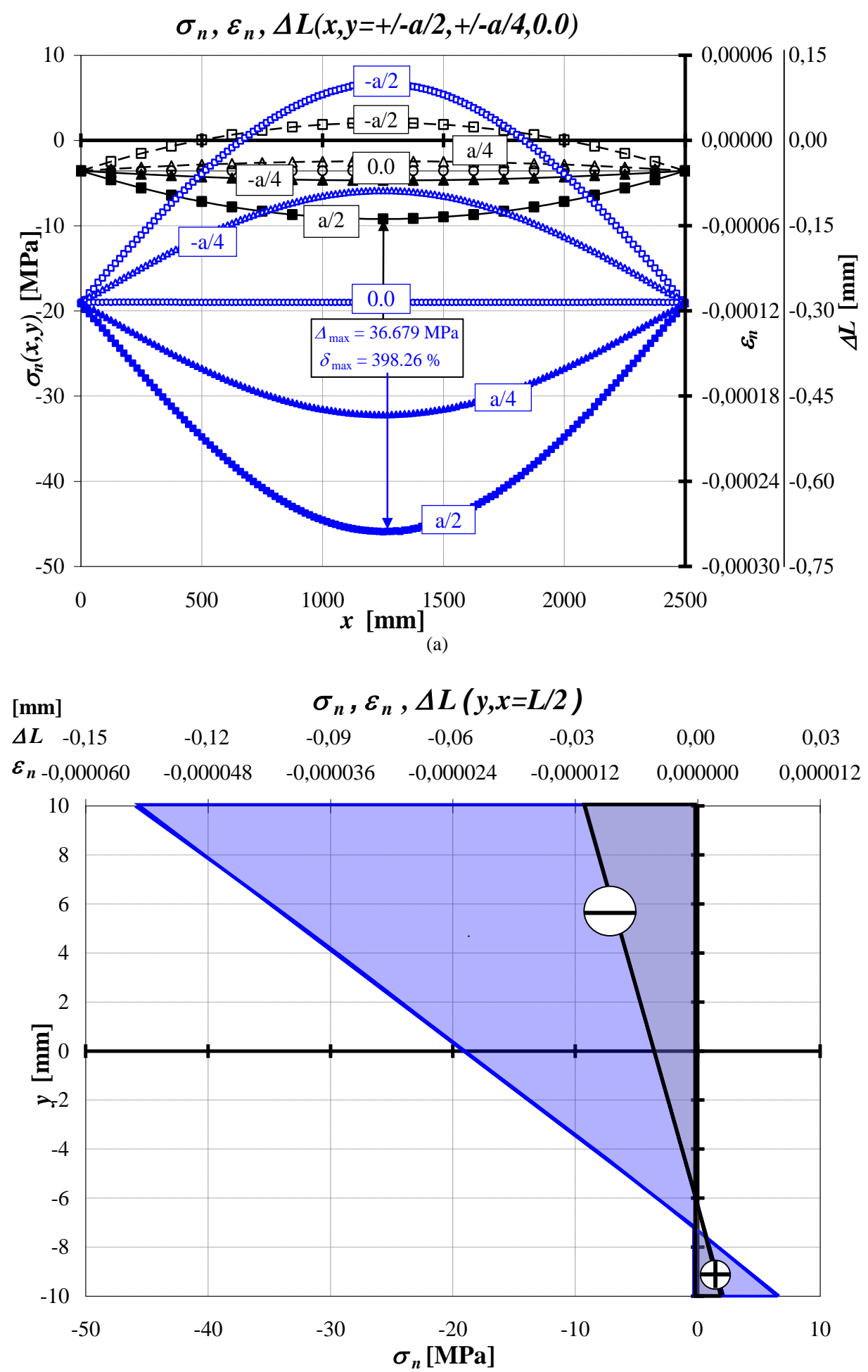

(b)

Fig. 18: Comparison of the values obtained from the FEM post-buckling linear stress analysis and the TSTh (by the assumption that a maximal deflection equals the half of a side dimension, $a / 2=10 \mathrm{~mm}$, where the exit of a force line from a critical cross-section follows a loss of the stability) of the $\sigma_{n}(x, y), \varepsilon_{n}(x, y)$ and $\Delta L(x, y)$ for $x=0 \div L$ and $y= \pm a / 2, \pm a / 4,0.0$ in the axially loaded, pinned box-section column made of steel with dimensions: $a=20 \mathrm{~mm}, b=28 \mathrm{~mm}, t=1 \mathrm{~mm}, L=2500 \mathrm{~mm}$ made of steel R35 in the longitudinal (a) and transverse (b) cross-section for $x=L / 2=1250 \mathrm{~mm}$ 


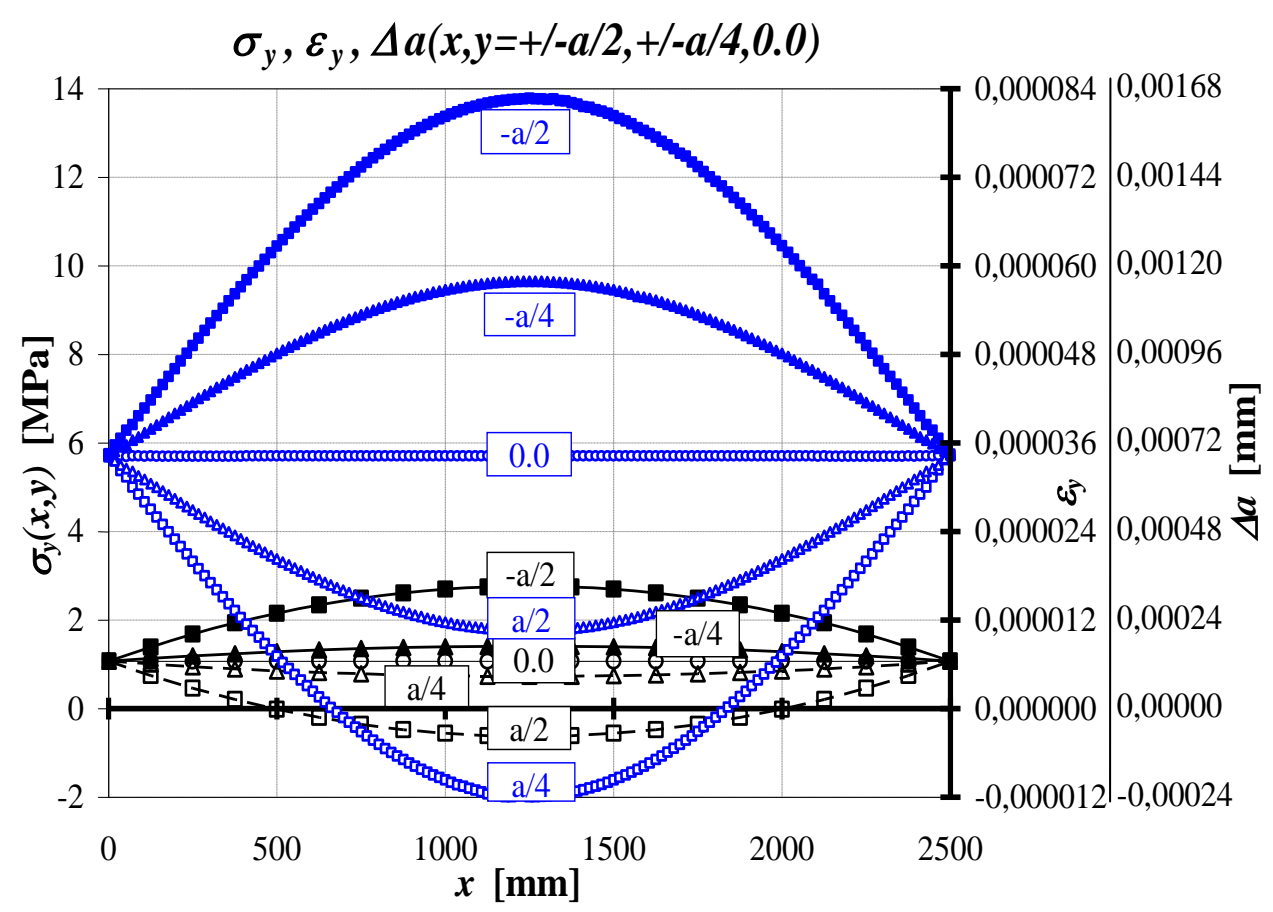

(a)
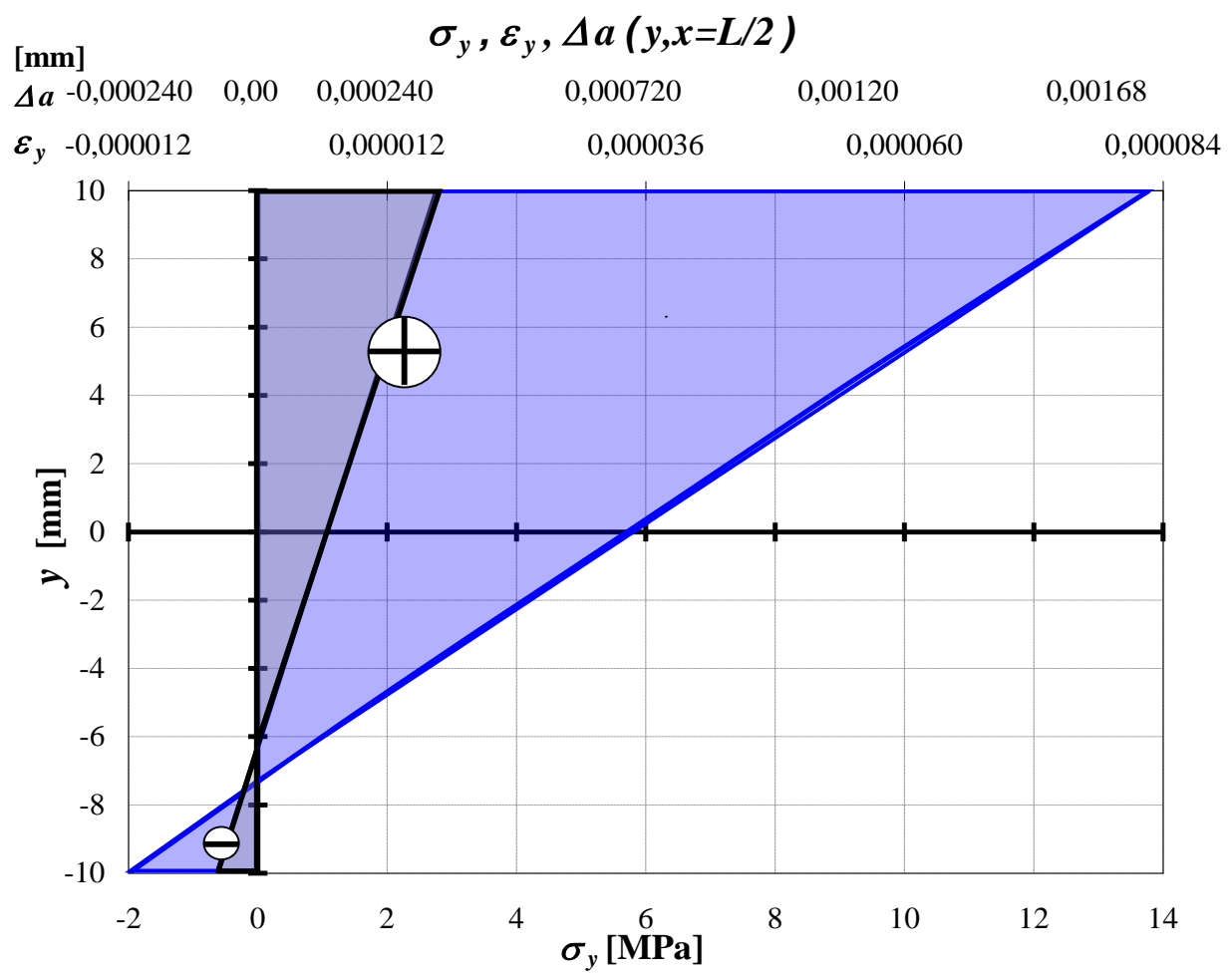

(b)

Fig. 19: Comparison of the values obtained from the FEM post-buckling linear stress analysis and the TSTh (by the assumption that a maximal deflection equals the half of a side dimension, $a / 2=10 \mathrm{~mm}$, where the exit of a force line from a critical cross-section follows a loss of the stability) of the $\sigma_{y}(x, y), \varepsilon_{y}(x, y)$ and $\Delta a(x, y)$ for $x=0 \div L$ and $y= \pm a / 2, \pm a / 4,0.0$ in the axially loaded, pinned box-section column made of steel with dimensions: $a=20 \mathrm{~mm}, b=28 \mathrm{~mm}, t=1 \mathrm{~mm}, L=2500 \mathrm{~mm}$ made of steel R35 in the longitudinal (a) and transverse (b) cross-section for $x=L / 2=1250 \mathrm{~mm}$ 
Figure 18 and 19 show that the courses of the normal stresses $\sigma_{n}{ }^{F E M}(x, y)$, strains $\varepsilon_{n}{ }^{F E M}(x, y)$ and extensions $\Delta L^{F E M}(x, y)$ are not symmetrical in relation to the layer with the geometrical axis $(y=0)$. In this layer, the stress $\sigma_{n}{ }^{F E M}(x$, $0)=19.020 \mathrm{MPa}$ is numerically equal to the pure critical stresses $\sigma_{c r}{ }^{F E M}(\lambda=314,814, a / b=0.714, t / b=0.0357, t=$ 1.0) $=19.000 \mathrm{MPa}$.

Because in the internal fibers on the concave side the values are negative, i.e., have the minus signs, so fibers are compressed and because of that they are shortened. On the opposite convex side, the values are positive, i.e., they have the plus signs, so the fibers are tensed and because of that, they are extended.

The courses of the $\sigma_{y}^{F E M}(x, y), \varepsilon_{y}{ }^{F E M}(x, y)$ and $\triangle 2 a^{F E M}(x, y)$, also are not symmetrical in relation to the layer with geometrical axis $(y=0)$.

The values are bigger on the concave side but are positive, i.e., they have the plus signs, i.e., the fibers are tensed and extended in the transverse direction.

The fibers on the opposite convex side are negative and they have the minus signs, so the fibers are compressed and shortened. The values are bigger on the concave side.

The normal stresses $\sigma_{n}{ }^{F E M}(x, y)$ are in the range: $6.638 \div-45.940 \mathrm{MPa}$ and $\sigma_{y}{ }^{F E M}(x, y):-1.991 \div 13.782 \mathrm{MPa}$. The strains $\varepsilon_{n}{ }^{F E M}(x, y)$ are in the range: $0.0000398 \div$ -0.0002758 and $\varepsilon_{y}{ }^{F E M}(x, y):-0.0000120 \div 0.0000826$.

The extensions $\Delta L^{F E M}(x, y)$ are in the range: $0.0996098 \div-0.6893758 \mathrm{~mm}$ and $\Delta 2 a^{F E M}(x, y):-0.00002406$ $\div 0.00016527 \mathrm{~mm}$.

The courses of the TSTh stresses, strains and extensions are similar to the FEM values. In the layer with geometrical axis $(y=0)$, the stress $\sigma_{n}^{T S T h}(\mathrm{x}, 0)=3.560$ $\mathrm{MPa}$ is equal to the pure critical compressive stresses $\sigma_{c r}{ }^{T S T h}(\lambda=314,814, a / b=0.714, t / b=0.0357, t=1.0)=$ 3.560 MPa.

The normal stresses $\sigma_{n}^{T S T h}(x, y)$ are in the range: $2.087 \div-9,211 \mathrm{MPa}$ and $\sigma_{y}{ }^{T S T h}(x, y):-0,626 \div 2.763 \mathrm{MPa}$.

The strains $\sigma_{n}{ }^{T S T h}(x, y)$ are in the range: $0.000013 \div$ -0.000055 and $\sigma_{y}{ }^{T S T h}(x, y):-0.0000038 \div 0.0000166$.

The extensions $\Delta \operatorname{LTSTh}(x, y)$ are in the range: $0.0313118 \div-0.1382273 \mathrm{~mm}$ and $\Delta 2 \operatorname{aTSTh}(x, y):-$ $0.0000075 \div 0.0000332 \mathrm{~mm}$.

Comparison of the FEM's Results under Load Determined from TSTh $\left(P_{c r}=341.99 N\right)$ and the TSTh's Results

In order to estimate the values obtained from the FEM computing under load determined from TSTh $\left(P_{c r}\right.$ $=341.99 \mathrm{~N})$ the results were compared with those obtained from the TSTh.
Figure 20-22 show the surface graphs of the $\sigma_{n}$ and $\varepsilon_{n}$ obtained from the post-buckling linear stress FEM analysis under load determined from TSTh $\left(P_{c r}=\right.$ $341.99 \mathrm{~N}$ ) of the box-section column pinned at both ends with the dimensions $a=20 \mathrm{~mm}, b=28 \mathrm{~mm}, t=1$ $\mathrm{mm}, L=2500 \mathrm{~mm}$ while the force line is leaving the critical cross-section.

Figure 23 shows the graphs of the FEM values under load determined from TSTh $\left(P_{c r}=341.99 \mathrm{~N}\right)$ and the TSTh (by the assumption that the maximal deflection equals the half of a side dimension, $a / 2=10 \mathrm{~mm}$, where the exit of the force line from a critical cross-section follows a loss of the stability) of the $\sigma_{n}(x, y), \varepsilon_{n}(x, y)$ and $\Delta L(x, y)$ for $x=0 \div L$ and $y= \pm a / 2, \pm a / 4,0.0$ in the longitudinal (Fig. 23a) and transverse section (Fig. 23b) for $x=L / 2=1250 \mathrm{~mm}$ in the pinned box-section column with dimensions: $a=20 \mathrm{~mm}, b=28 \mathrm{~mm}, t=1 \mathrm{~mm}, L=$ $2500 \mathrm{~mm}$ made of steel, axially loaded.

Figure 23 shows that the courses of the $\sigma_{n}{ }^{F E M}(x, y)$, $\varepsilon_{n}{ }^{F E M}(x, y)$ and $\Delta L^{F E M}(x, y)$ are not symmetrical in relation to the layer with geometrical axis $(y=0)$. In this layer, the stress $\sigma_{n}{ }^{F E M(P c r=341.99 \mathrm{~N}, x, 0)}=3.564 \mathrm{MPa}$ is numerically equal to the pure critical stresses $\sigma_{c r}{ }^{F E M}(\lambda=314,814, a / b$ $=0.714, t / b=0.0357, t=1.0)=3.560 \mathrm{MPa}$.

Figure 24 shows the graphs of the FEM values under load determined from TSTh $\left(P_{c r}=341.99 \mathrm{~N}\right)$ and the TSTh of the $\sigma_{y}(x, y), \varepsilon_{y}(x, y)$ and $\Delta 2 \mathrm{a}(x, y)$ for the same column. The maximal departures between stresses equal: $\Delta_{\max }=0.605 \mathrm{MPa}$ and $\delta_{\max }=6.6 \%$.

Figure 23 and 24 show that the stresses $\sigma_{n}{ }^{F E M_{-} P c r}=$ $341.99 \mathrm{~N}(x, y)$ are in the range: $1.245 \div-8.606 \mathrm{MPa}$ and $\sigma_{y}{ }^{F E M_{-} P c r=341.99 \mathrm{~N}}(x, y): \quad-0.376 \div 2.582 \mathrm{MPa}$. The strains $\varepsilon_{n}{ }^{F E M_{-} P c r=341.99 \mathrm{~N}}(x, y)$ are in the range: $0.0000075 \div-0.0000517$ and $\varepsilon_{y}{ }^{F E M_{-} P c r=341.99 \mathrm{~N}}(x, y):-0.0000022 \div 0.0000155$.

The extensions $\Delta L^{F E M \_P c r=341.99 \mathrm{~N}}(x, y)$ are in the range: $0.0186825 \div-0.1291417 \mathrm{~mm}$ and $\Delta 2 a^{F E M_{-} P_{c r}=341.99 \mathrm{~N}}(x, y)$ : $-0.00000448 \div 0.00003099 \mathrm{~mm}$.

The courses of the TSTh stresses, strains and extensions are similar to the FEM values under load determined from TSTh $\left(P_{c r}=341.99 \mathrm{~N}\right)$.

In the layer with geometrical axis $(y=0)$, the stress $\sigma_{n}{ }^{T S T h}(x, 0)=3.560 \mathrm{MPa}$ is equal to the pure critical stresses $\sigma_{c r}^{T S T h}(\lambda=314,814, a / b=0.714, t / b=0.0357, t$ $=1.0)=3.560 \mathrm{MPa}$.

The stresses $\sigma_{n}{ }^{T S T h}(x, y)$ are in the range: $2.087 \div-9,211$ MPa and $\sigma_{y}{ }^{T S T h}(x, y):-0,626 \div 2.763 \mathrm{MPa}$.

The strains $\varepsilon_{n}^{\text {TSTh }}(x, y)$ are in the range: $0.000013 \div$ -0.000055 and $\varepsilon_{y}{ }^{T S T h}(x, y):-0.0000038 \div 0.0000166$.

The extensions $\Delta L^{T S T h}(x, y)$ are in the range: $0.0313118 \div-0.1382273 \mathrm{~mm}$ and $\Delta 2 a^{T S T h}(x, y):-0.0000075$ $\div 0.0000332 \mathrm{~mm}$. 


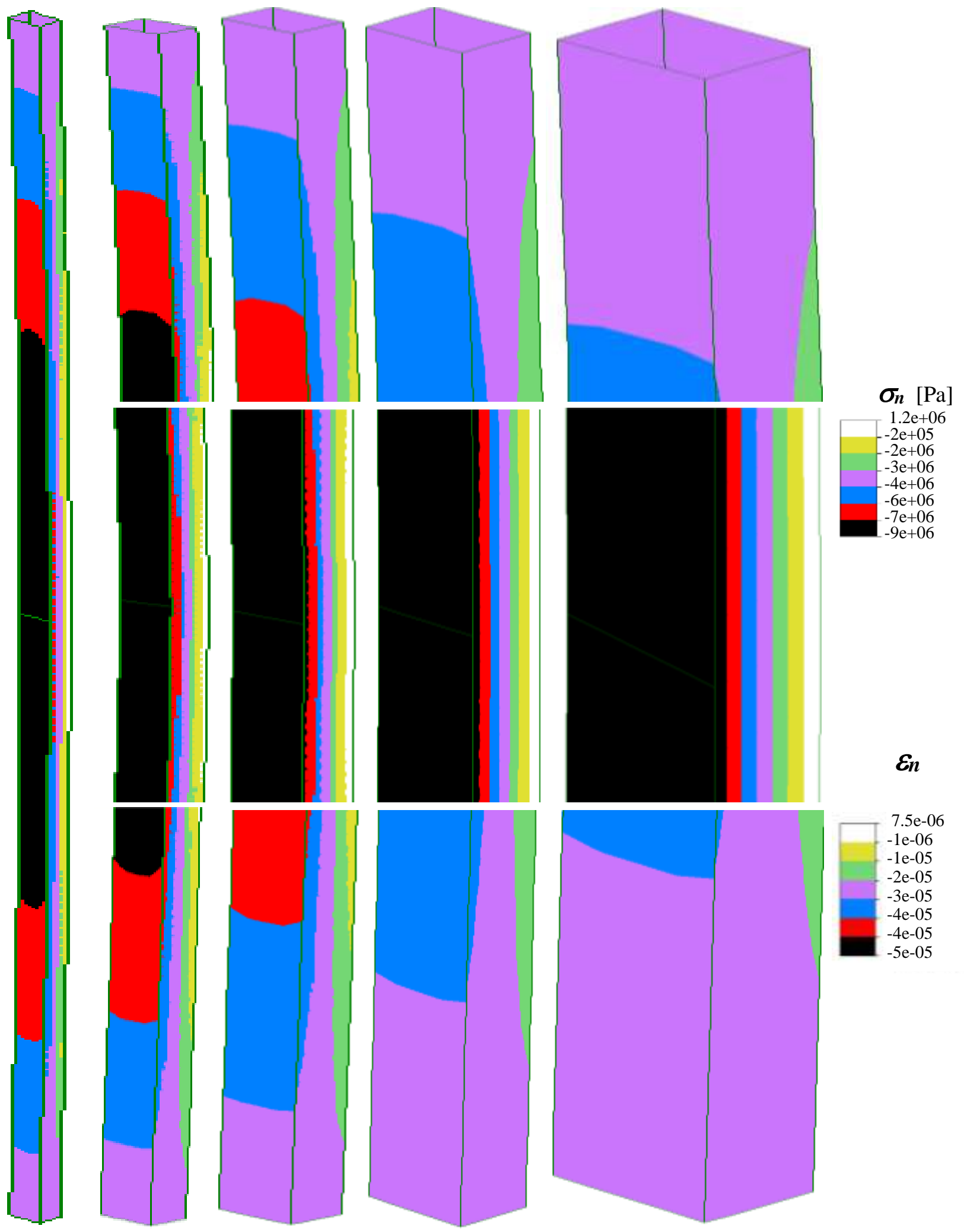

Fig. 20: Surface graphs of the $\sigma_{n}$ and $\varepsilon_{n}$ obtained from the post-buckling linear stress FEM analysis under load determined from TSTh $\left(P_{c r}=341.99 \mathrm{~N}\right)$ of the pinned box-section column, with the dimensions $a=20 \mathrm{~mm}, b=28 \mathrm{~mm}, t=1 \mathrm{~mm}, L=2500 \mathrm{~mm}$ made of steel R35, while the force line is leaving the critical cross-section. View on the concave wall. The top, middle and bottom parts of the column are shown in the enlargements 


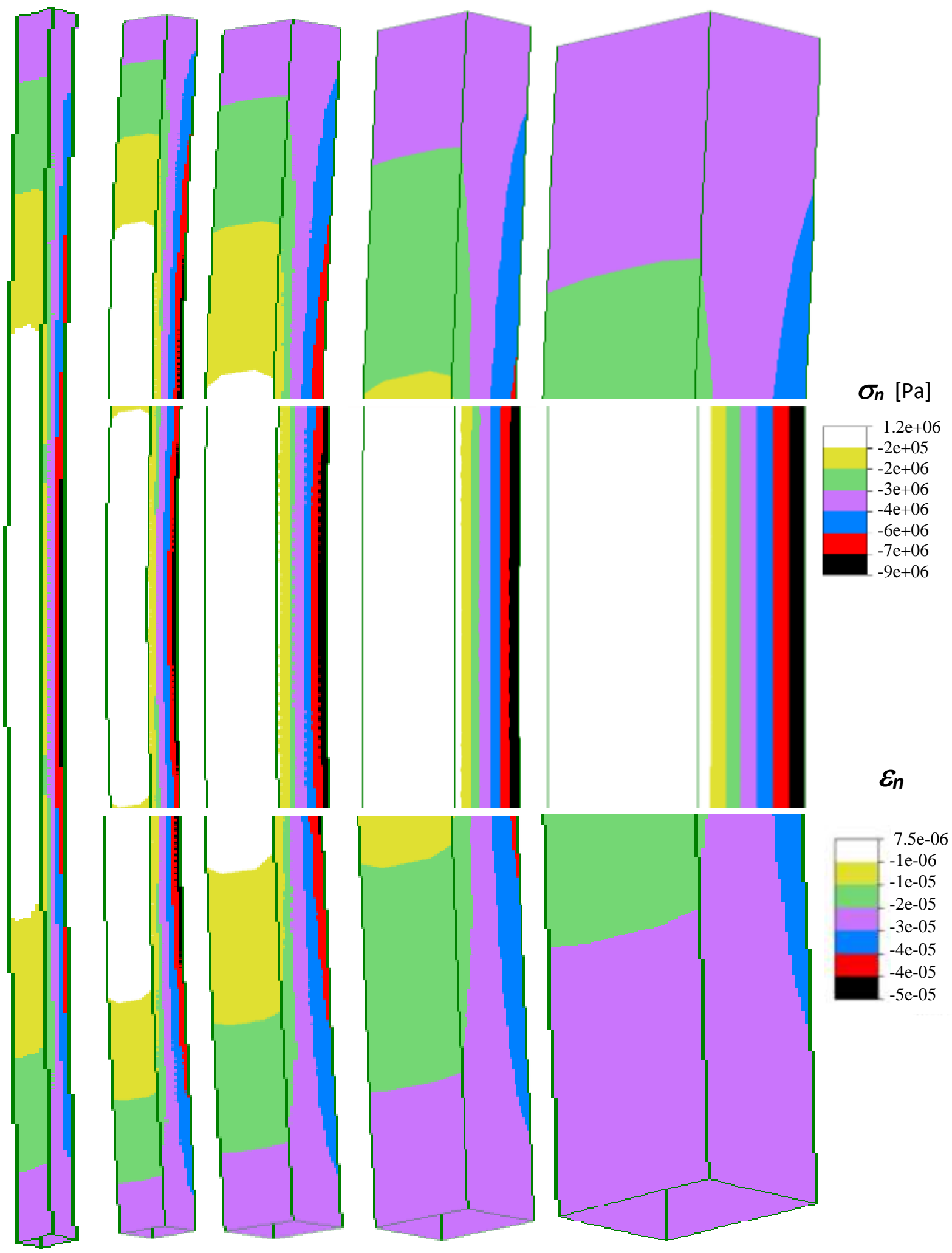

Fig. 21: Surface graphs of the $\sigma_{n}$ and $\varepsilon_{n}$ obtained from the post-buckling linear stress FEM analysis under load determined from TSTh $\left(P_{c r}=341.99 \mathrm{~N}\right)$ of the pinned box-section column, with the dimensions $a=20 \mathrm{~mm}, b=28 \mathrm{~mm}, t=1 \mathrm{~mm}, L=2500 \mathrm{~mm}$ made of steel R35, while the force line is getting out the critical cross-section. View on the convex wall. The top, middle and bottom parts of the column are shown in the enlargements 


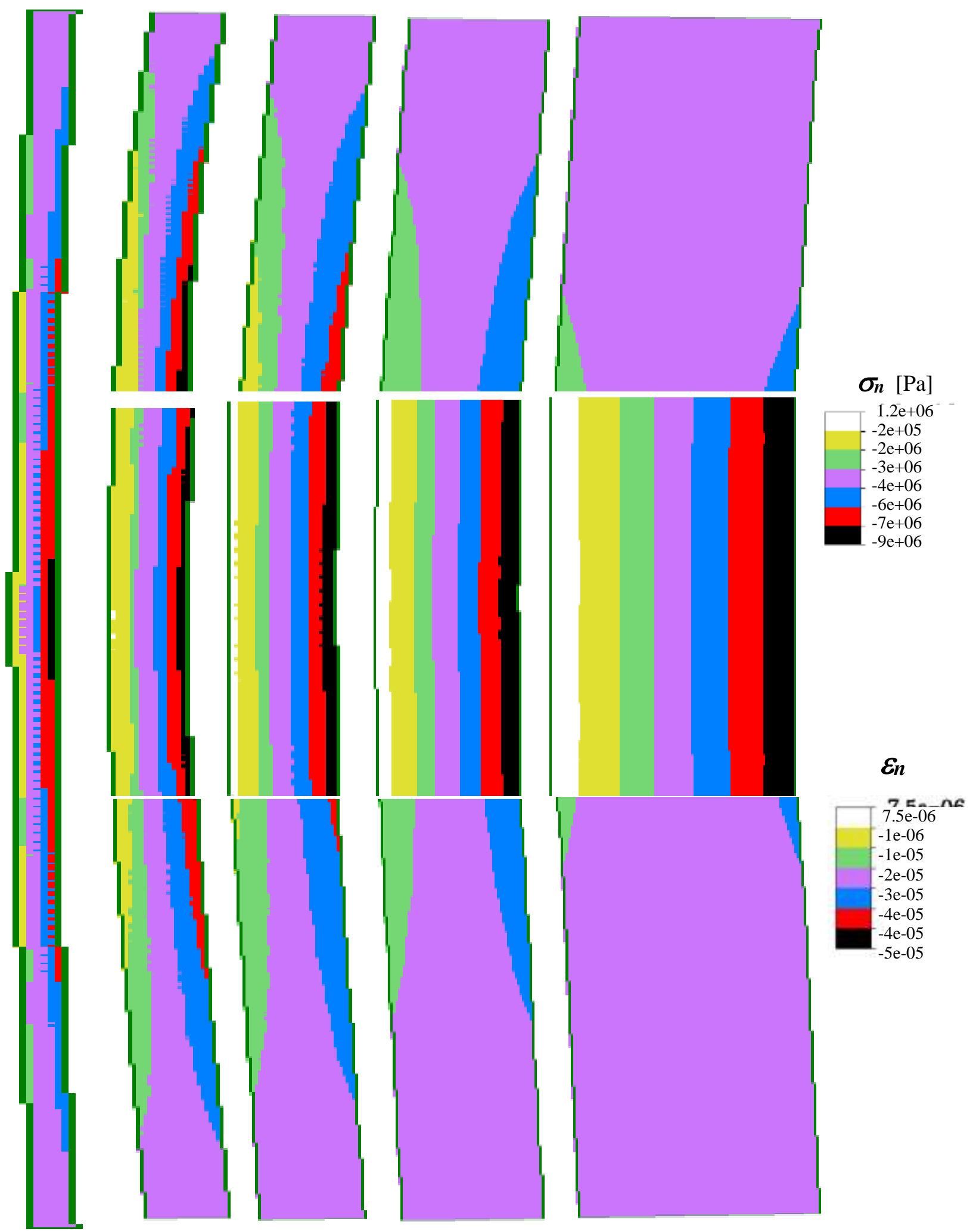

Fig. 22: Surface graphs of the $\sigma_{n}$ and $\varepsilon_{n}$ obtained from the post-buckling linear stress FEM analysis under load determined from TSTh $\left(P_{c r}=341.99 \mathrm{~N}\right)$ of the pinned box-section column, with the dimensions $a=20 \mathrm{~mm}, b=28 \mathrm{~mm}, t=1 \mathrm{~mm}, L=2500 \mathrm{~mm}$ made of steel R35, while the force line is getting out the critical cross-section. The side view. The top, middle and bottom parts of the column are shown in the enlargements 


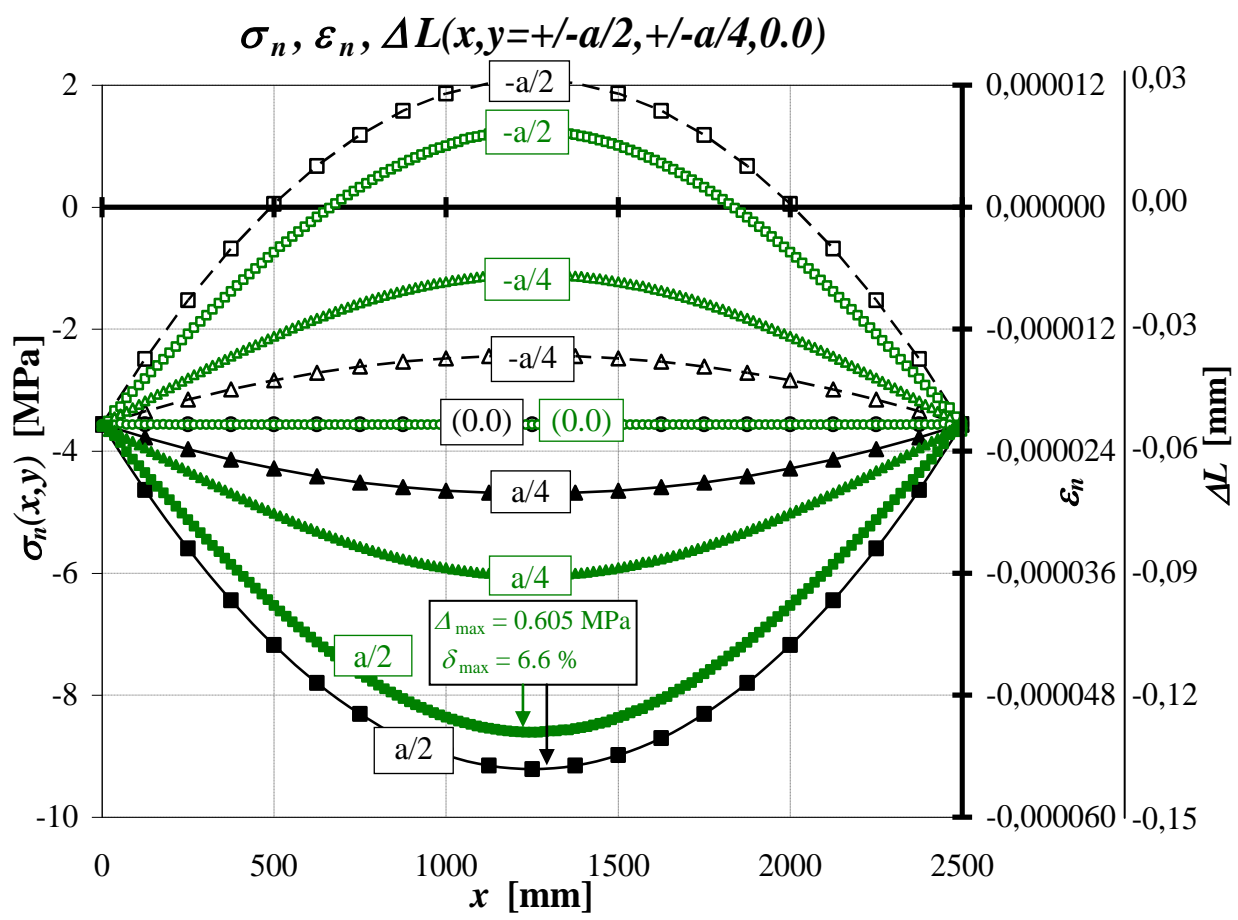

(a)

\begin{tabular}{|c|c|c|c|c|c|c|}
\hline$[\mathrm{mm}]$ & & $\sigma_{n}, \varepsilon$ &,$\Delta L(y, x$ & $L / 2)$ & & \\
\hline$\Delta \boldsymbol{L} \quad-0,15$ & $-0,12$ & $-0,09$ & $-0,06$ & $-0,03$ & 0,00 & 0,03 \\
\hline $\boldsymbol{\varepsilon}_{\boldsymbol{n}-0,000060}$ & $-0,000048$ & $-0,000036$ & $-0,000024$ & $-0,000012$ & 0,000000 & 0,000012 \\
\hline
\end{tabular}

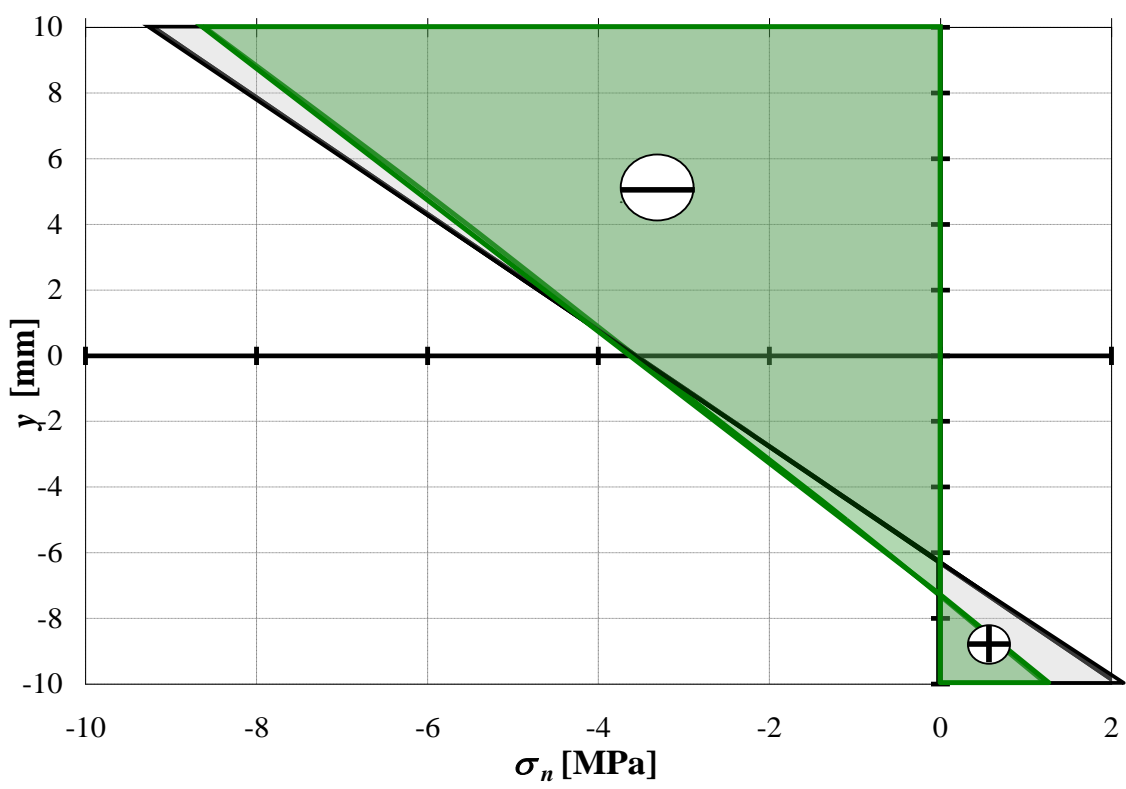

(b)

Fig. 23: Comparison of the values obtained from the FEM post-buckling linear stress analysis under load determined from TSTh $\left(P_{c r}\right.$ $=341.99 \mathrm{~N}$ ) and the TSTh (by the assumption that a maximal deflection equals the half of a side dimension, $a / 2=10 \mathrm{~mm}$, where the exit of a force line from a critical transverse section follows a loss of the stability) of the stresses $\sigma_{n}(x, y)$, strains $\varepsilon_{n}(x, y)$ and elongations $\Delta L(x, y)$ for $x=0 \div L$ and $y= \pm a / 2, \pm a / 4,0.0$ in the axially loaded, pinned box-section column made of steel R35 with dimensions $a=20 \mathrm{~mm}, b=28 \mathrm{~mm}, t=1 \mathrm{~mm}, L=2500 \mathrm{~mm}$ in the longitudinal (a) and transverse (b) crosssection for $x=L / 2=1250 \mathrm{~mm}$ 


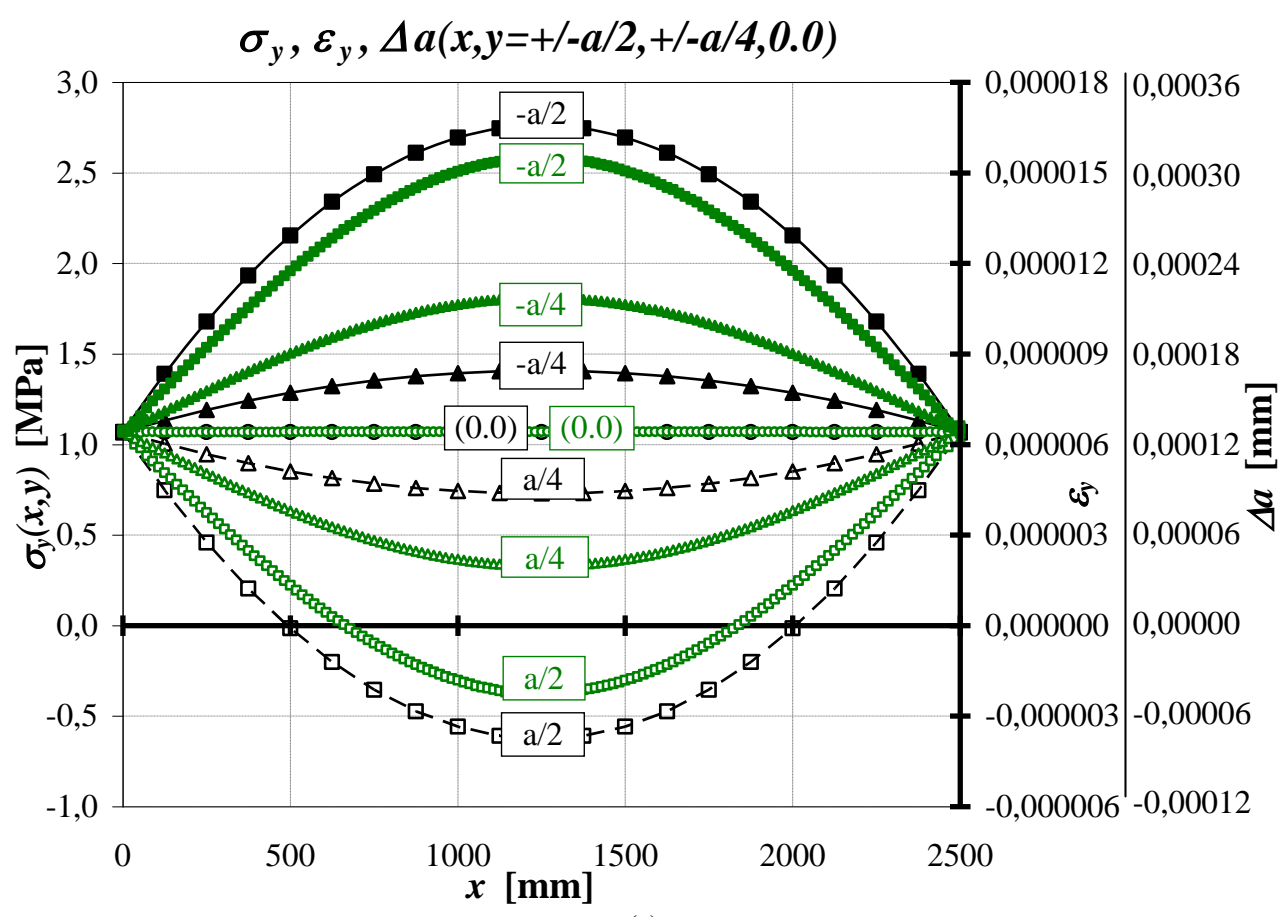

(a)

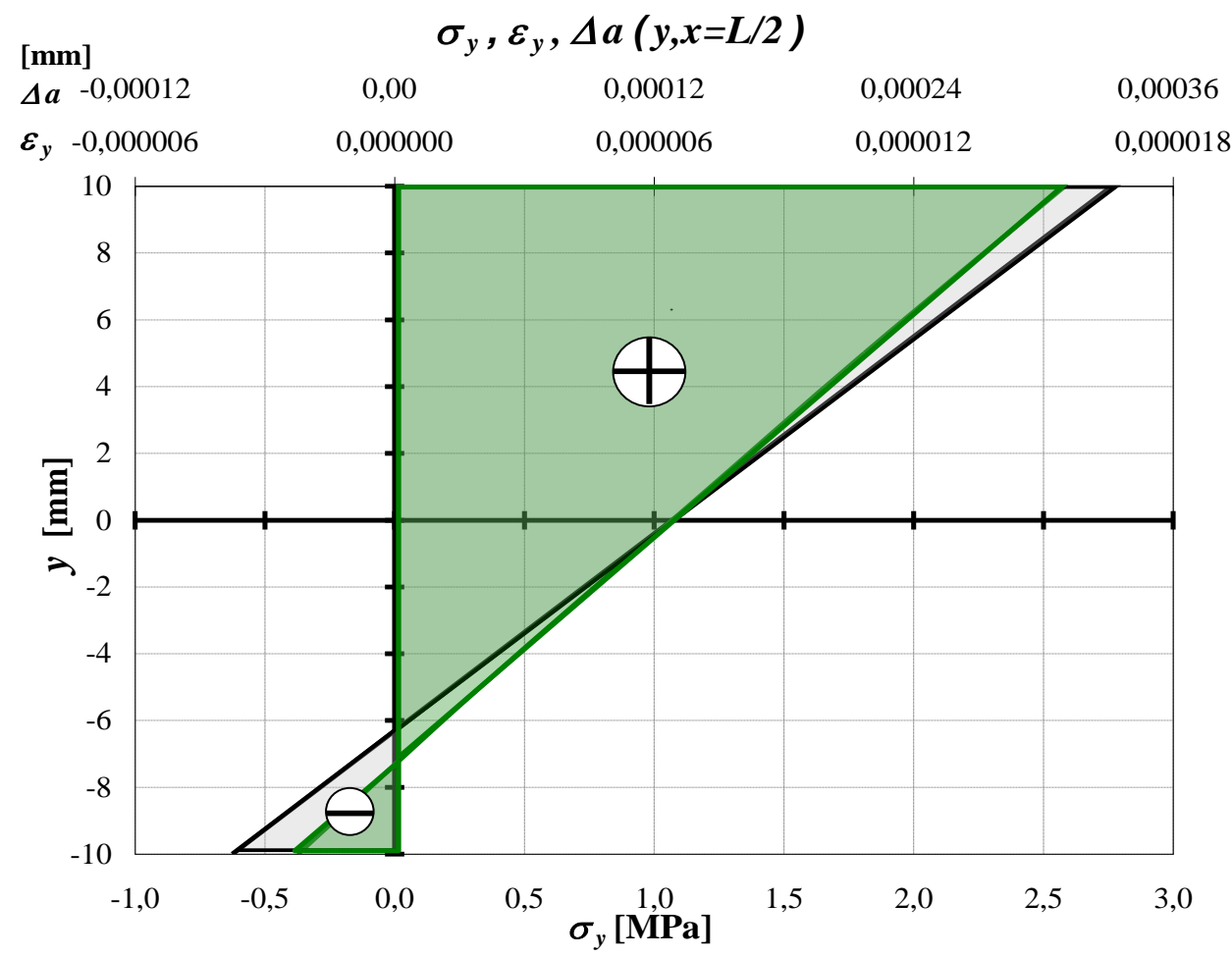

(b)

Fig. 24: Comparison of the values obtained from the FEM post-buckling linear stress analysis under load determined from TSTh $\left(P_{c r}\right.$ $=341.99 \mathrm{~N}$ ) and the TSTh (by the assumption that a maximal deflection equals the half of a side dimension, $a / 2=10 \mathrm{~mm}$, where the exit of a force line from a critical cross-section follows a loss of the stability) of the $\sigma_{y}(x, y), \varepsilon_{y}(x, y)$ and $\Delta a(x, y)$ for $x=0 \div L$ and $y= \pm a / 2, \pm a / 4,0.0$ in the axially loaded, pinned box-section column made of steel R35 with dimensions $a=$ $20 \mathrm{~mm}, b=28 \mathrm{~mm}, t=1 \mathrm{~mm}, L=2500 \mathrm{~mm}$ in the longitudinal (a) and transverse (b) cross-section for $x=L / 2=1250 \mathrm{~mm}$ 


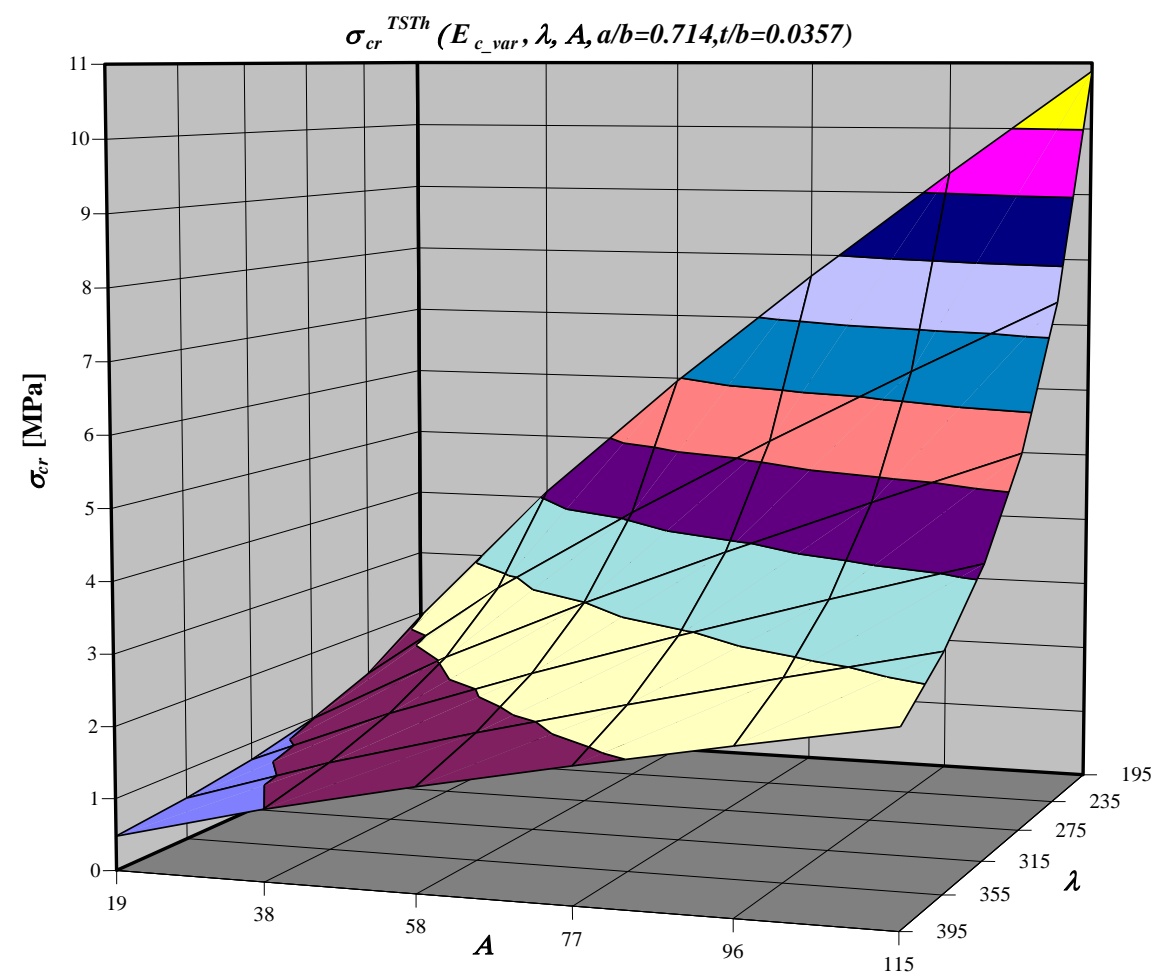

(a)

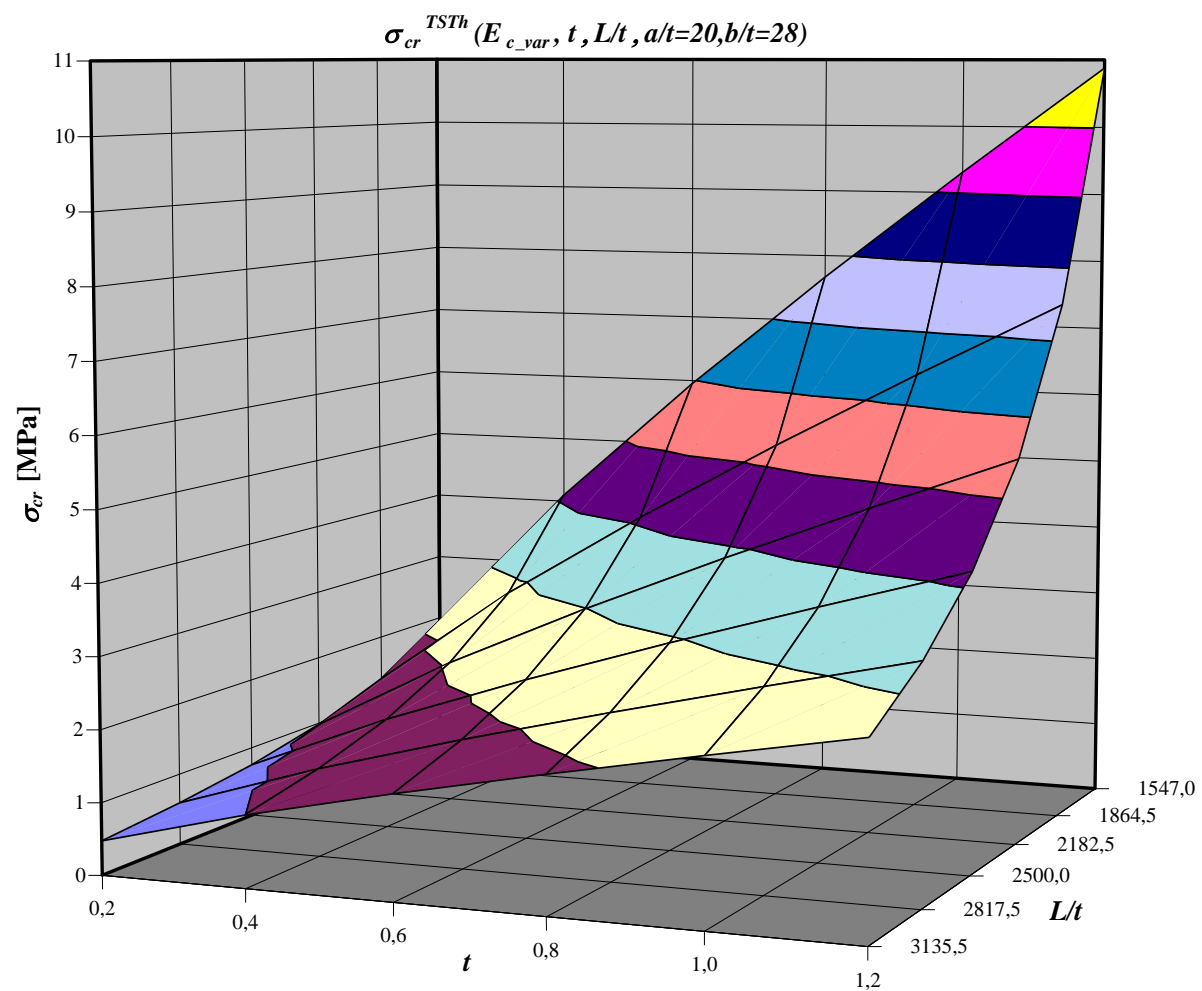

(b)

Fig. 25: Surface functions of critical compressive stresses: (a) $\sigma_{c r}{ }^{T S T h-E c_{-} v a r}(\lambda, \mathrm{A}, a / b=0.714, t / b=0.0357)$, (b) $\sigma_{c r}{ }^{T S T h-E c_{-} v a r}(t, L / t, a / t$ $=20, b / t=28)$ for box-section columns made of steel R35 and axially compressed by force through ball-and-socket joints without friction, according to the results obtained from the TSTh with varying $E_{c}$ 
Table 10: Critical compressive forces $P^{T S T h}{ }_{c r_{-} E c_{-} v a r}$ obtained from the TSTh with varying $E_{c}$ $P^{T S T C_{\text {crE Ec_var }}[\mathrm{N}] \quad a / b=0.714, t / b=0.0357}$

\begin{tabular}{|c|c|c|c|c|c|c|c|}
\hline & & & & & & & \\
\hline & $\mathrm{t}[\mathrm{mm}]=$ & 0.2 & 0.4 & 0.6 & 0.8 & 1.0 & 1.2 \\
\hline$\lambda:$ & 194,814 & 37,43 & 157,21 & 342,61 & 588,86 & 893,07 & 1253,20 \\
\hline & 234,814 & 25,76 & 108,21 & 235,83 & 405,33 & 614,72 & 862,61 \\
\hline & 274,814 & 18,81 & 79,00 & 172,17 & 295,92 & 448,80 & 629,77 \\
\hline & 314,814 & 14,33 & 60,20 & 131,20 & 225,50 & 341,99 & 479,90 \\
\hline & 354,814 & 11,28 & 47,39 & 103,29 & 177,52 & 269,23 & 377,80 \\
\hline & 394,814 & 9,11 & 38,28 & 83,42 & 143,37 & 217,44 & 305,12 \\
\hline & $A\left[\mathrm{~mm}^{2}\right]=$ & 19.20 & 38.40 & 57.60 & 76.80 & 96.00 & 115.20 \\
\hline & $E_{c}[\mathrm{MPa} * \mathrm{e} 6]=$ & 22600 & 58600 & 94600 & 130600 & 166600 & 202600 \\
\hline
\end{tabular}

Table 11: Critical compressive stresses $\sigma^{T S T h r_{-} E c_{-} v a r}$ obtained from the TSTh with varying $E_{c}$

\begin{tabular}{|c|c|c|c|c|c|c|c|}
\hline \multicolumn{2}{|c|}{$\sigma^{T S T h}{ }_{c r_{-} E c_{-} v a r}[\mathrm{MPa}]$} & \multicolumn{6}{|c|}{$a / b=0.714, t / b=0.0357$} \\
\hline & $t[\mathrm{~mm}]=$ & 0.2 & 0.4 & 0.6 & 0.8 & 1.0 & 1.2 \\
\hline \multirow[t]{8}{*}{$\lambda:$} & 194,814 & 1,95 & 4,09 & 5,95 & 7,67 & 9,30 & 10,88 \\
\hline & 234,814 & 1,34 & 2,82 & 4,09 & 5,28 & 6,40 & 7,49 \\
\hline & 274,814 & 0,98 & 2,06 & 2,99 & 3,85 & 4,67 & 5,47 \\
\hline & 314,814 & 0,75 & 1,57 & 2,28 & 2,94 & 3,56 & 4,17 \\
\hline & 354,814 & 0,59 & 1,23 & 1,79 & 2,31 & 2,80 & 3,28 \\
\hline & 394,814 & 0,47 & 1,00 & 1,45 & 1,87 & 2,27 & 2,65 \\
\hline & $A\left[\mathrm{~mm}^{2}\right]=$ & 19.20 & 38.40 & 57.60 & 76.80 & 96.00 & 115.20 \\
\hline & $E_{c}[\mathrm{MPa} * \mathrm{e} 6]=$ & 22600 & 58600 & 94600 & 130600 & 166600 & 202600 \\
\hline
\end{tabular}

Table 12: Departures $\Delta[\%]$ of the TSTh- $E_{c_{-} v a r}$ critical loads from the FEM results

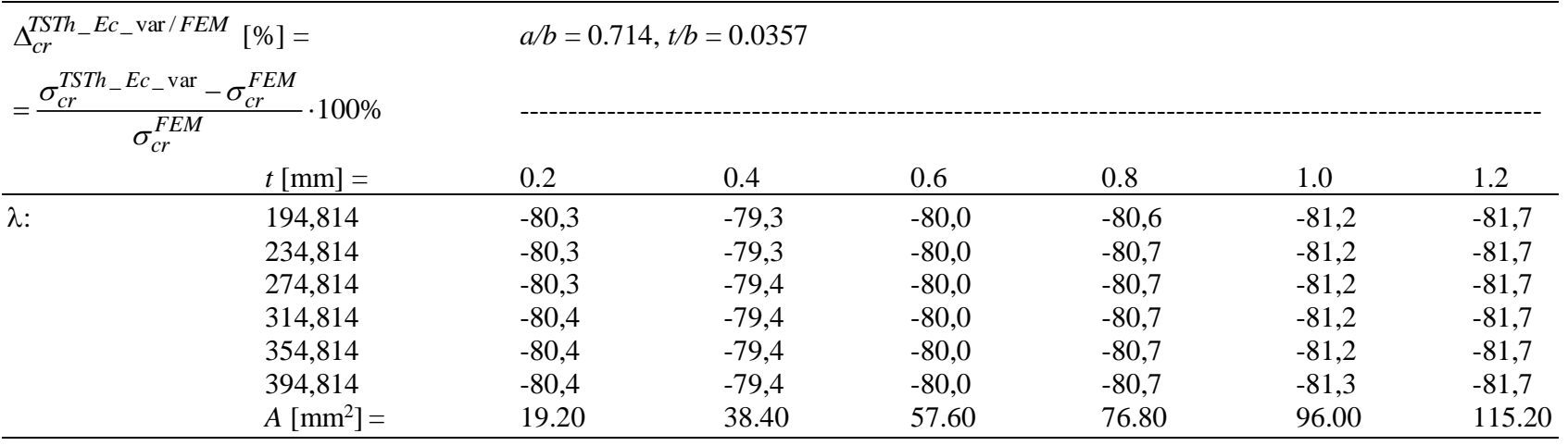

\section{Comparison of FEM's and TSTH's Results with Varying $E_{c}$}

As it was found from the experimental researches and was presented in the paper (Murawski 2020a, Fig. 25) the compress modulus $E_{c}$ is changing with slenderness ratio $\lambda$ and critical transverse cross-section $A$.

In order to find similar results obtained from the FEM computing to the results from the TSTh were taken under consideration the results with varying $E_{c}$ presented in Table 10 and 11 - and they were compared.

The differences are presented in Table 12.

The relative departures between critical compressive stresses obtained from FEM (Table 3) and the TSTh with varying $E_{c}$ - Table 10 and 11 equal to values from -81.7 to $-79.3 \%$ (Table 12).
Figure 25a shows the surface graph of the critical compressive stresses $\sigma_{c r}{ }^{T S T h_{-} E c_{-} v a r}(\lambda, A, a / b=0.714, t / b=$

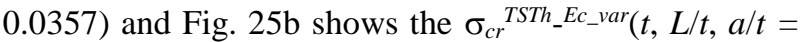
$20, b / t=28)$ according to the TSTh with varying $E_{c}$.

So it is seen that shapes of the surface functions in Fig. 7 and Fig. 25 are similar, however, they are different with values: $\sigma_{c r}{ }^{F E M}(\lambda, \mathrm{A}, a / b=0.714, t / b=0.0357)$ and $\sigma_{c r}{ }^{F E M}(t, L / t, a / t=20, b / t=28)$ have the values in the range: $0 \div 60 \mathrm{MPa}$, but $\sigma_{c r}{ }^{T S T h} E_{c_{-} \text {var }}(\lambda, A, a / b=0.714, t / b$ $=0.0357)$ and $\sigma_{c r}{ }^{T S T h_{-} E c_{-} v a r}(t, L / t, a / t=20, b / t=28)$ have the values in the range: $0 \div 11 \mathrm{MPa}$.

\section{Conclusion}

In the paper, there are discussed three different methods for determining the critical compressive load of the pinned box-section thin-walled column: FEM, Euler's 
and TSTh. Based on the presented results the following important remarks can be concluded:

1. The evolutions of the function $y(x)$ and elastic line slope $d y / d x$, according to the FEM and to Euler (by the assumption that a maximal deflection equals the half of a side dimension, like in the TSTh, where the exit of a force line from a critical cross-section follows a loss of the stability) are almost the same

2. The maximal departures between functions $y_{L}(P)$, according to the FEM and to Euler, equal: $\Delta_{\max }=$ $230.86 \mathrm{~N}$ and $\delta_{\max }=12.66 \%$ but still are small

3. The evolutions of the function $y(x)$ and elastic line slope $d y / d x$ according to the FEM and to TSTh are clearly different, but functions $y_{L}(P)$ are strongly different and the maximal relative departures between them are $\delta_{\max }=0.0567 \%$ for the functions $y(x), \delta_{\max }=20.18 \%$ for the elastic line slope $d y / d x$ and $\delta_{\max }=433.22 \%$ for the functions $y_{L}(P)$

4. The surface function of critical compressive stresses according to Euler is not varying with transverse cross-section area $A$ unlike the surface function according to the FEM and to TSTh

5. The relative departures of the Euler's critical loads from the FEM critical loads are in the searched cases in the range: $-27.2 \div 337.4 \%$

6. The relative departures of the TSTh critical loads from the FEM critical loads are in the searched cases in the range: $-85.0 \div 45.1 \%$

7. There is no possibility to determine the values of the stresses and strains in the column shell directly from Euler's theory

8. The state of the stresses and strains according to the FEM and to TSTh is similar, i.e., the shapes of those functions are similar

9. The maximal relative departure of the TSTh stresses and strains from the FEM stresses and strains in the searched case is very big and equals: $398.26 \%$

10. The maximal relative departure of the TSTh stresses and strains from the FEM stresses and strains under the load obtained from the TSTh $\left(P_{c r}=341.99 \mathrm{~N}\right)$ in the searched case is very small and equals: $6.6 \%$

11. The relative departures of the TSTh with varying $E c$ critical loads from the FEM critical loads are in searched cases in the range: $-79.4 \div 81.7 \%$

12. The large maximal relative departures between the Euler/TSTh and FEM results are caused probably by simplifications of the theories, especially the oldest Euler's theory seems to be the most simplified

13. the surface function of critical compressive stresses according to the FEM is very similar to the surface function of the critical compressive stresses according to the TSTh with varying $E_{c}$, however, the values of the TSTh are about 5 times smaller

\section{Author's Contributions}

All authors equally contributed in this work.

\section{Ethics}

This article is original and contains unpublished material. The corresponding author confirms that all of the other authors have read and approved the manuscript and no ethical issues involved.

\section{References}

Abbas, R. M., \& Awazli, A. G. (2017). Behavior of Reinforced Concrete Columns Subjected to Axial Load and Cyclic Lateral Load. Journal of Engineering, 23(2), 21-40. https://joe.uobaghdad.edu.iq/index.php/main/article/ view/69

Abdel-Karim, M., Abdel-Rahman, G. T., Said, M., \& Shaaban, I. G. (2018). Proposed model for strength analysis of HSC eccentrically loaded slender columns. Magazine of Concrete Research, 70(7), 340-349. https://doi.org/10.1680/jmacr.17.00137

Abdel-Lateef, T. H., Dabaon, M. A., Abdel-Moez, O. M., \& Salama, M. I. (2001, April). Buckling loads of columns with gradually changing cross-section subjected to combined axial loading. In Fourth Alexandria International Conference on Structural and Geotechnical Engineering (pp. 2-4).

Abdulazeez, M. M., ElGawady, M. A., \& Abdelkarim, O. I. (2019). Bending and buckling behavior of hollowcore FRP-concrete-steel columns. Journal of Bridge Engineering, 24(8), 04019082. https://doi.org/10.1061/(ASCE)BE.19435592.0001419

Abed, F. H., AlHamaydeh, M. H., \& Barakat, S. A. (2013). Nonlinear finite-element analysis of buckling capacity of pretwisted steel bars. Journal of Engineering Mechanics, 139(7), 791-801. https://doi.org/10.1061/(ASCE)EM.19437889.0000528

Abedini, M., Mutalib, A. A., Zhang, C., Mehrmashhadi, J., Raman, S. N., Alipour, R., ... \& Mussa, M. H. (2020). Large deflection behavior effect in reinforced concrete columns exposed to extreme dynamic loads. Frontiers of Structural and Civil Engineering, 14(2), 532-553. https://doi.org/10.1007/s11709-020-0604-9

Ahiwale, D., Khartode, R., Bhapkar, A., Narule, G., \& Sharma, K. (2020). Influence of compressive load on concrete filled steel tubular column with variable thickness. Innovative Infrastructure Solutions, 6(1), 1-14. https://doi.org/10.1007/s41062-020-00390-z 
Ahmed, N., Xue, P., Kamran, M., Zafar, N., Mustafa, A., \& Zahran, M. S. (2017). Investigation of the energy absorption characteristics of metallic tubes with curvy stiffeners under dynamic axial crushing. Latin American Journal of Solids and Structures, $\quad 14(7)$, 1293-1313. https://doi.org/10.1590/1679-78253820

Algor®. (2001). Algor ® Version 12.08-WIN 15-OCT2001. Copyright (C 1984-2001 Algor, Inc. All rights reserved.

Al-Kamal, M. (2016). Design for prestressed concrete flexural members against progressive collapse. Thesis for $\mathrm{PhD}$.

Alomarah, A., Masood, S. H., \& Ruan, D. (2020). Out-ofplane and in-plane compression of additively manufactured auxetic structures. Aerospace Science and Technology, 106, 106107. https://doi.org/10.1016/j.ast.2020.106107

Alvarenga, A. R., \& Silveira, R. A. (2006). Considerations on advanced analysis of steel portal frames. In Proceedings of ECCM III European Conference on Computational Mechanics Solids, Structures and Coupled Problems in Engineering (p. 2119). https://doi.org/10.1007/1-4020-5370-3_103

Ammash, H. K. (2017). Shape optimization of innovation cold-formed steel columns under uniaxial compressive loading. Jordan Journal of Civil Engineering, 11(3).

Andreev, V. I., \& Tsybin, N. Y. (2015). On the stability of rod with variable cross-section. Procedia Engineering, $\quad 111, \quad 42-48$ https://doi.org/10.1016/j.proeng.2015.07.033

Anuntasena, W., Lenwari, A., \& Thepchatri, T. (2019). Finite element modelling of concrete-encased steel columns subjected to eccentric loadings. Engineering Journal, 23(6), 299-310 https://doi.org/10.4186/ej.2019.23.6.299

Ascione, L., \& Grimaldi, A. (1983). On the stability and postbuckling behaviour of elastic beams. ThinWalled Structures, 1(4), 325-351. https://doi.org/10.1016/0263-8231(83)90013-7

Atteya, M., Shaat, A., \& Sayed-Ahmed, E. (2017). Effect of CFRP Bonded Length on the Strength of Axially loaded HSS. Al-Azhar University Civil Engineering Research Magazine (CERM), 39(2), 89-96. http://www.azharcermjournal.com/CERMF1704/P1 7-04-08.pdf

Avci-Karatas, C., 2020. Time History Analysis of a Reinforced Concrete, RC Building in Hilly Terrain Subjected to Earthquake. $6^{\text {th }}$ International Congress on Engineering, Architecture and Design, Istanbul/Turkey.
Baru, A. (2017). An Investigation of Buckling Phenomenon in Steel Elements. Heriot Watt University, School of Energy, Geoscience, Infrastructure and Society. https://doi.org/10.13140/RG.2.2.36815.48803

Bedon, C., \& Amadio, C. (2017). Structural Glass Elements-Unified approach for the buckling verification. $\quad$ Structural, 212 http://www.structuralweb.it/cgibin/copertine/somma riostru212.pdf

Bedon, C., \& Amadio, C. (2018). Buckling analysis and design proposal for 2-side supported double Insulated Glass Units (IGUs) in compression. Engineering Structures, 168, 23-34. https://doi.org/10.1016/j.engstruct.2018.04.055

Brasil, R. M., \& Wahrhafitg, A. M. (2017, July). Experimental Evaluation of the Effect of Geometric Nonlinearities on Structural Resonances. In International Conference on Experimental Vibration Analysis for Civil Engineering Structures (pp. 611-618). Springer, Cham. https://doi.org/10.1007/978-3-319-67443-8_53

D’Aniello, M., Della Corte, G., \& Mazzolani, F. M. (2006, August). Seismic upgrading of RC buildings by buckling restrained braces: experimental results vs. numerical modeling. In Proceedings of Fifth International Conference on Behavior of Steel Structures in Seismic Areas (STESSA 2006).

Di Sarno, L., \& Manfredi, G. (2012). Experimental tests on full-scale RC unretrofitted frame and retrofitted with buckling-restrained braces. Earthquake Engineering \& Structural Dynamics, 41(2), 315-333. https://doi.org/10.1002/eqe.1131

Doan, Q. H., Thai, D. K., \& Tran, N. L. (2020). A numerical study of the effect of component dimensions on the critical buckling load of a GFRP composite strut under uniaxial compression. Materials, $13(4), \quad 931$. https://doi.org/10.3390/ma13040931

Euler, L. (1744). Methodus inveniendi lineas curvas maximi minimive proprietate gaudentes. apud Marcum-Michaelem Bousquet.

Euler, L. (1759). Sur la force des colonnes. Memoires de l'Academie des Sciences de Berlin, 252-282. https://scholarlycommons.pacific.edu/cgi/viewconte nt.cgi? article $=1237 \&$ context $=$ euler-works

Fraldi, M., Nunziante, L., Carannante, F., Prota, A., Manfredi, G., \& Cosenza, E. (2008). On the prediction of the collapse load of circular concrete columns confined by FRP. Engineering Structures, 30(11), 3247-3264. https://doi.org/10.1016/j.engstruct.2008.04.036 
Genoese, A., Genoese, A., Rizzi, N. L., \& Salerno, G. (2019). Buckling analysis of single-layer graphene sheets using molecular mechanics. Frontiers in Materials, 6 , 26. https://doi.org/10.3389/fmats.2019.00026

Naseri, R., Showkati, H., \& Firouzsalari, S. E. (2020). Buckling behaviour of GFRP cylindrical shells subjected to axial compression load. Composite Structures, 260, 113269 https://doi.org/10.1016/j.compstruct.2020.113269

Goroshko, A., Royzman, V., \& Petraschuk, S. (2020). Simulation of a thin long rod that does not have critical forces and does not lose stability to Euler. Problems of Tribology, 25(3/97), 25-31. https://doi.org/10.31891/2079-1372-2020-97-3-25-31

Gupta, N. K., Sekhon, G. S., \& Gupta, P. K. (2001). A study of lateral collapse of square and rectangular metallic tubes. Thin-walled structures, 39(9), 745-772. https://doi.org/10.1016/S02638231(01)00033-7

Hedayati, E., Hedayati, A., \& Vahedi, M. (2015). Critical buckling load analysis of truck chassis using arc-length method. Journal of Engg. Research, 3 , $129-140$ https://doi.org/10.7603/s40632-015-0018-3

Hooke, R. (1678). De Potentia Restitutiva, or of Spring. Explaining the Power of Springing Bodies, London.

Isleem, H. F., Wang, Z., Wang, D., \& Smith, S. T. (2018). Monotonic and cyclic axial compressive behavior of CFRP-confined rectangular RC columns. Journal of Composites for Construction, 22(4), 04018023. https://doi.org/10.1061/(ASCE)CC.19435614.0000860

Ismail, M. R. (2011). Evaluating the Dynamical Behavior and Stability of Pipes Conveying Fluid (Doctoral dissertation, Ph. D. Thesis AL-Nahrain University, mechanical engineering). https://doi.org/10.13140/RG.2.2.34510.87369

Ivanov, A. I., (2019a). Vibrations of Shaft Caused by Inertial Excitations. Journal of Mining and Geological Science, 62, 19-24.

Ivanov A. I., (2019b). Theoretical Study of Small Vibrations of Two Rigid Bodies with Damping. Сборник доклади от Годишна университетска научна конференция, 27-28 юни 2019. Велико Търново. Издателски комплекс на НВУ “Васил Левски", ISSN 2367-7481, 1555-1556.

Jakab, A., Nehme, K., \& Nehme, S. G. (2016, April). Fracture behaviour of glass columns experimental study of axial loaded glass columns. In IOP Conference Series: Materials Science and Engineering (Vol. 123, No. 1, p. 012056). IOP Publishing. https://doi.org/10.1088/1757-
Johnson, C. G., Jain, U., Hazel, A. L., Pihler-Puzović, D., \& Mullin, T. (2017). On the buckling of an elastic holey column. Proceedings of the Royal Society A: mathematical, physical and engineering sciences, 473(2207), https://doi.org/10.1098/rspa.2017.0477

Kalamar, R., Bedon, C., \& Eliášová, M. (2016). Experimental investigation for the structural performance assessment of square hollow glass columns. Engineering Structures, 113, 1-15. https://doi.org/10.1016/j.engstruct.2016.01.028

Kambe, W., Takahashi, S., Ito, T., \& Aoki, K. (2013). An experimental study on compression resistant performance of thick plywood as an axial member. Journal of Structural and Construction Engineering, 78(684), 355-361. https://doi.org/10.3130/aijs.78.355

Kiss, L. P. (2020a). Stability of fixed-fixed shallow arches under arbitrary radial and vertical forces. Magazine of Civil Engineering, 95(3). https://doi.org/10.18720/MCE.95.3

Kiss, L. (2020b). Stability of pinned-rotationally restrained arches. Theoretical and Applied Mechanics, $10-10$ https://doi.org/10.2298/TAM200402010K

Kudryavtsev, S. (2019). Buckling behavior of steel column with triangularly corrugated web. In MATEC Web of Conferences (Vol. 279, p. 02007). EDP

Sciences. https://doi.org/10.1051/matecconf/201927902007

Li, W., Song, Z., \& Chai, Y. (2015). Discrete singular convolution method for dynamic stability analysis of beams under periodic axial forces. Journal of Engineering Mechanics, 141(10), 04015033. https://doi.org/10.1061/(ASCE)EM.19437889.0000931

Li, Z., He, M., Tao, D., \& Li, M. (2016). Experimental buckling performance of scrimber composite columns under axial compression. Composites Part B: $\quad$ Engineering, 86, 203-213. https://doi.org/10.1016/j.compositesb.2015.10.023

Liang, M., Wu, Z. M., Ueda, T., Zheng, J. J., \& Akogbe, R. (2012). Experiment and modeling on axial behavior of carbon fiber reinforced polymer confined concrete cylinders with different sizes. Journal of Reinforced Plastics and Composites, 31(6), $389-403$ https://doi.org/10.1177/0731684412439347

Liu, Y. (2018). Axial and circumferential buckling of a hyperelastic tube under restricted compression. International Journal of Non-Linear Mechanics, 98, 145-153. https://doi.org/10.1016/j.ijnonlinmec.2017.10.016 
Lolov, D. S., \& Lilkova-Markova, S. V. (2006). Dynamic stability of a curved pipe bent in the arc of a circle on hinge supports at the ends. Sadhana, 31(5), 537-541. https://doi.org/10.1007/BF02715912

Lolov, D., \& Lilkova-Markova, S. (2005). A Plane Problem of the Dynamic Stability of Curved Pipes. Latvian Journal of Physics and Technical Sciences, 6, 24-28.

Łukowicz, A., Deniziak, P., Migda, W., GordziejZagórowska, M., \& Szczepański, M. (2016). Innovative cold formed GEB section under compression. In Proceedings of the XIII International Conference on Metal Structures-ICMS 2016 Zielona Góra, Recent Progress in Steel and Composite Structures (pp. 76-77). Balkema: CRC Press. https://doi.org/10.1201/b21417-14

Malikan, M., Tornabene, F., \& Dimitri, R. (2018). Nonlocal three-dimensional theory of elasticity for buckling behavior of functionally graded porous nanoplates using volume integrals. Materials Research Express, 5(9), 095006. https://doi.org/10.1088/2053-1591/aad4c3

Marante, M. E., Picon, R. A., Guerrero, N., \& Flã3rezLã ${ }^{3}$ pez, J. U. L. I. O. (2012). Local buckling in threedimensional frames: experimentation and simplified analysis. Latin American Journal of Solids and Structures, 9(6), 691-691. http://www2.lajss.org/index.php/LAJSS/article/view 1443

Megahed, K. (2016). Experimental and Theoretical Analysis of Concrete Encased Cold Formed Steel Composite Column. Doctoral dissertation, Thesis for master degree, Mansoura University, Faculty of Engineering, Structural Eng. Department. https://doi.org/10.13140/RG.2.2.20548.48005

Mehrabi, P., Honarbari, S., Rafiei, S., Jahandari, S., \& Bidgoli, M. A. (2021). Seismic response prediction of FRC rectangular columns using intelligent fuzzy-based hybrid metaheuristic techniques. Journal of Ambient Intelligence and Humanized Computing, 1-19. https://doi.org/10.1007/s12652020-02776-4

Melissianos, V. E., Lignos, X. A., Bachas, K. K., \& Gantes, C. J. (2017). Experimental investigation of pipes with flexible joints under fault rupture. Journal of Constructional Steel Research, 128, 633-648. https://doi.org/10.1016/j.jcsr.2016.09.026

Milašinović, D. D., Vlajić, L. M., \& Miličić, I. M. (2003). Prediction of buckling curves of steel columns using by rheological analogy. Materijali i konstrukcije, 46(3-4),

8-13. http://scindeks.ceon.rs/article.aspx $?$ artid=054307980304008M
Mohammadi, F. S., Rahimi, Z., Sumelka, W., \& Xiao-Jun, Y. A. N. G. (2019). Investigation of free vibration and buckling of Timoshenko nano-beam based on a general form of eringen theory using conformable fractional derivative and Galerkin method. Engineering Transactions, 67(3), 347-367. http://et.ippt.pan.pl/index.php/et/article/viewFile/10 01/801

Moita, J. S., Araújo, A. L., Correia, V. F., Soares, C. M. M., \& Herskovits, J. (2018). Buckling and nonlinear response of functionally graded plates under thermo-mechanical loading. Composite Structures, 202, 719-730. https://doi.org/10.1016/j.compstruct.2018.03.082

Monsalve-Cano, J. F., \& Aristizábal-Ochoa, J. D. (2016). Stability and free vibration analyses of orthotropic 3d beam-columns with singly symmetric section including shear effects. Engineering Structures, 113, 315-327. https://doi.org/10.1016/j.engstruct.2016.01.036

Moradi-Dastjerdi, R., \& Malek-Mohammadi, H. (2017). Free vibration and buckling analyses of functionally graded nanocomposite plates reinforced by carbon nanotube. Mechanics of Advanced Composite Structures, 4(1), 59-73. https://doi.org/10.22075/MACS.2016.496

Moustabchir, H., Arbaoui, J., El Moussaid, M., Azari, Z., \& Pruncu, C. I. (2018). Characterization of fracture toughness properties of aluminium alloy for pipelines. Experimental Techniques, 42(6), 593-604. https://doi.org/10.1007/s40799-018-0280-z

Mozafari, H., Lin, S., Tsui, G. C., \& Gu, L. (2018). Controllable energy absorption of double sided corrugated tubes under axial crushing. Composites Part B: Engineering, 134, 9-17. https://doi.org/10.1016/j.compositesb.2017.09.042

Murawski, K. (1992). Stability of thin shell columns in elasto-plastic states. 14 Międzynarodowe Sympozjum Naukowe Studentów i Młodych Pracowników Nauki. Mechanika, Zielona Góra, 38-43.

Murawski, K. (1999). The Modelling of Energy Consuming Process in Layered Vehicles Bumper (Doctoral dissertation, Doctor's thesis. Poznan University of Technology, Faculty of Hardworking Machines and Vehicles). https://www.researchgate.net/publication/32455776 5_Modelowanie_procesu_pochlaniania_energii_w_ warstwowych_zderzakach

Murawski, K. (2002). Stability analysis of a thinwalled plywood cylindrically shaped element. Annals of Warsaw Agricultural University, Forestry and Wood Technology, Special Number I, Warsaw Agricultural University Press, Warsaw, 230-234. 
Murawski, K. (2003a). Theory of stability of layered cylindrical rods in elasto-plastic states exemplified by steel R35. Electronic Journal of Polish Agricultural Universities. Civil Engineering, 2(6).

Murawski, K. (2003b). Stability analysis in elastic states of very slender cylindrical shaped plywood compressed by balls. Annals of Warsaw Agricultural University, Forestry and Wood Technology, 53, 257-260.

Murawski, K. (2003c). Stability analysis of layered cylindrical plywood shaped element. Annals of Warsaw Agricultural University, Forestry and Wood Technology, (53), 252-256.

Murawski, K. (2003d). Stresses and strains analysis in elastic states of very slender cylindrical shaped plywood compressed by balls. Ann. Warsaw Agric. Univ. SGGW-AR, For Wood Technol, 53, 247-251.

Murawski, K. (2004a). Stability analysis in elastic states of very slender rods fixed by one end with stresses and strains analysis as examplified by cylindrical shaped plywood made of birch. Acta Scientiarum Polonorum, Silvarum Colendarum Ratio et Industria Lignaria 3, 85-95. ISSN 1644-0722.

Murawski, K. (2004b). The Euler's modified theory of stability with stresses and strains analysis on example of very slender cylindrical shells made of steel. Acta Scientiarum Polonorum, Architectura, 3(1), 2004.

Murawski, K. (2004c). Stresses and strains analysis in elastic states of very slender square shaped plywood compressed by balls. Annals of Warsaw Agricultural University, Forestry and Wood Technology, (55), 387-391.

Murawski, K. (2004d). Finite Element Method Analysis of stability in elastic states of very slender cylindrical shaped plywood compressed by balls. Annals of Warsaw Agricultural University, Forestry and Wood Technology, (55), 373-377.

Murawski, K. (2005). Stability analysis in elastic states of compressed very slender square shaped plywood tube fixed by one end. Roczniki Akademii Rolniczej w Poznaniu CCCLXVIII, Technol. Drewn, 40, 51-59.

Murawski, K. (2007). Movement of the neutral layer during lose of stability in the critical cross section of very slender cylindrical shaped plywood compressed by ball-and-socket joints. Annals of Warsaw University of Life Sciences-SGGW. Forestry and Wood Technology, 62. http://yadda.icm.edu.pl/yadda/element/bwmeta1.ele ment.agro-8624ebb7-e627-41f4-a23f-a1e64c1394c9

Murawski, K. (2011a). Teoria technicznej stateczności smukłych prętów sklejkowych. Oficyna Wydawnicza Politechniki Warszawskiej.. ISBN 978-83-7207-959-6

Murawski, K. (2011b). Theory of Technical Stability of Slender Plywood Rods. Publishing House of Warsaw University of Technology. ISBN 978-837207-968-8
Murawski, K. (2011c). Modelowanie procesu pochłaniania energii w warstwowych zderzakach. Oficyna Wydawnicza Politechniki Warszawskiej. ISBN: 978-83-7207-973-2

Murawski, K. (2017a). Modelling of the Energyabsorptive Process in Layered Bumpers. Lulu Press, Inc. ISBN 978-1-387-37333-8.

Murawski, K. (2017b). Technical stability of continuously loaded thin-walled slender columns. ISBN 978-1-387-36762-7.

Murawski, K. (2018). Technical stability of very slender thin-walled orthotropic columns. ISBN 978-0-35901937-3.

Murawski, K. (2020a). Lateral buckling in elastic-plastic states of thin-walled semi-slender columns made of steel R35 according to known hypotheses.

Murawski, K. (2020b). Experimental results of lateral buckling of thin-walled semi-slender columns with pinned ends made of steel R35 in the elastic-plastic states in comparison to the known hypotheses.

Murawski, K. (2020c). Technical stability of very slender rectangular columns compressed by ball-and-socket joints without friction. International Journal of Structural Glass and Advanced Materials Research 4(1), 186-208. https://doi.org/10.3844/sgamrsp.2020.186.208

Murawski, K., \& Kłos, R., (2007). Experimental determining of extensions during test of stability of the rode $870 \times \varphi 12 \mathrm{~mm}$ made of pine compressed by ball-and-socket joints. Ann. Warsaw Agricult. Univ.SGGW, For and Wood Technol, 62, 70-72.

Naderpour, H., Nagai, K., Haji, M., \& Mirrashid, M. (2019). Adaptive neuro-fuzzy inference modelling and sensitivity analysis for capacity estimation of fiber reinforced polymer-strengthened circular reinforced concrete columns. Expert Systems, 36(4), e12410. https://doi.org/10.1111/exsy.12410

Nazarimofrad, E., \& Shokrgozar, A. (2019). Seismic performance of steel braced frames with selfcentering buckling-restrained brace utilizing superelastic shape memory alloys. The Structural Design of Tall and Special Buildings, 28(16), e1666. https://doi.org/10.1002/tal.1666

Nguyen, N. D., Nguyen, T. K., Vo, T. P., \& Thai, H. T. (2018). Ritz-based analytical solutions for bending, buckling and vibration behavior of laminated composite beams. International Journal of Structural Stability and Dynamics, 18(11), 1850130. https://doi.org/10.1142/S0219455418501304

Nouri, M. D., Hatami, H., \& Jahromi, A. G. (2015). Experimental and numerical investigation of expanded metal tube absorber under axial impact loading. Structural Engineering and Mechanics, 54,

1245-1266 https://doi.org/10.12989/sem.2015.54.6.1245 
Oleiwi, J. K., Al-hassani, E. S., \& Abd Mohammed, A. (2014). Modeling and Buckling Analysis of Polymeric Composite Columns. Engineering and Technology Journal, 32(5 Part (A) Engineering). https://www.iasj.net/iasj/article/99864

Oliveira, T. V., Dias, C. A. C., Sousa, R. A., Pasquetti, E., \& Souza, R. M. D. (2017). Analytical study of the shear effect on the buckling of columns on elastic medium. XXXVIII Ibero-Latin American Congress on Computational Methods in Engineering, Florianopolis - $\quad$ SC, https://doi.org/10.20906/CPS/CILAMCE2017-0274

Osmani, A., \& Meftah, S. A. (2018). Lateral buckling of tapered thin walled bi-symmetric beams under combined axial and bending loads with shear deformations allowed. Engineering Structures, 165, 76-87. https://doi.org/10.1016/j.engstruct.2018.03.009

Ozbasaran, H., Aydin, R., \& Dogan, M. (2015). An alternative design procedure for lateral-torsional buckling of cantilever I-beams. Thin-Walled Structures, 90, 235-242. https://doi.org/10.1016/j.tws.2015.01.021

Psyrras, N., Kwon, O., Gerasimidis, S., \& Sextos, A. (2019). Can a buried gas pipeline experience local buckling during earthquake ground shaking?. Soil Dynamics and Earthquake Engineering, 116, 511-529. https://doi.org/10.1016/j.soildyn.2018.10.027

Qays, S., \& Al-Zuhairi, A. (2020). Structural Performance of Slender RC Columns with Cross and Square-Shaped under Compression Load. IOP Conference Series: Materials Science and Engineering, 881, 012040. https://doi.org/10.1088/1757-899X/881/1/012040

Qi, Y., Xie, L., Bai, Y., Liu, W., \& Fang, H. (2019). Axial compression behaviours of pultruded GFRP-wood composite columns. Sensors, 19(4), 755. https://doi.org/10.3390/s19040755

Rahmani, O., Refaeinejad, V., \& Hosseini, S. A. H. (2017). Assessment of various nonlocal higher order theories for the bending and buckling behavior of functionally graded nanobeams. Steel and Composite Structures, 23(3), 339-350. https://doi.org/10.12989/scs.2017.23.3.339

Rahnavard, R., Naghavi, M., Aboudi, M., \& Suleiman, M. (2018). Investigating modeling approaches of buckling-restrained braces under cyclic loads. Case Studies in Construction Materials, 8, 476-488. https://doi.org/10.1016/j.cscm.2018.04.002

Rajkannu, J. S., \& Jayachandran, S. A. (2020). Flexuraltorsional buckling strength of thin-walled channel sections with warping restraint. Journal of Constructional Steel Research, 169, 106041. https://doi.org/10.1016/j.jcsr.2020.106041

Rao, L. B., \& Ra, C. K. (2009). Buckling of circular plates with a ring support and elastically restrained edge. Advances in Vibration Engineering, 8(1), 59-67.
Razdolsky, A. G. (2018). Determination of slenderness ratio for laced and battened columns. Practice Periodical on Structural Design and Construction, 23(4), 04018019 . https://doi.org/10.1061/(ASCE)SC.19435576.0000383

Riahi, F., Zirakian, T., Ghaderi, V. M., \& Arya, S. (2018). Buckling stability assessment of plates under uniaxial compression. Advances in Science and Technology Research Journal, 12, 97-105. https://doi.org/10.12913/22998624/90789

Roy, K., Ting, T. C. H., Lau, H. H., \& Lim, J. B. (2019). Experimental and numerical investigations on the axial capacity of cold-formed steel built-up box sections. Journal of Constructional Steel Research, 160 , 411-427. https://doi.org/10.1016/j.jcsr.2019.05.038

Saberi, H., Kolmi Zade, V., Mokhtari, A., \& Saberi, V. (2020). Investigating of the Effect of Concrete Confinement on the Axial Performance of Circular Concrete Filled Double-Skin Steel Tubular (CFDST) Long Columns. Journal of Rehabilitation in Civil Engineering, 8(3), 43-59. https://doi.org/10.22075/JRCE.2020.19167.1362

Sabouri-Ghomi, S., Kharrazi, M. H., Mam-Azizi, S. E. D., \& Sajadi, R. A. (2008). Buckling behavior improvement of steel plate shear wall systems. The Structural Design of Tall and Special Buildings, 17(4), 823-837. https://doi.org/10.1002/tal.394

Sadath, A., Vinu, V., \& Vyasarayani, C. P. (2017). Vibrations of a simply supported cross flow heat exchanger tube with axial load and loose supports. Journal of Computational and Nonlinear Dynamics, $\quad 12(5), \quad 051001$. https://doi.org/10.1115/1.4035880

Saingam, P., Sutcu, F., Terazawa, Y., Fujishita, K., Lin, P. C., Celik, O. C., \& Takeuchi, T. (2020). Composite behavior in $\mathrm{RC}$ buildings retrofitted using bucklingrestrained braces with elastic steel frames. Engineering Structures, 219, 110896. https://doi.org/10.1016/j.engstruct.2020.110896

Sanchez, H. C. A., \& Corte's Salas, C. (2008, January). Deformation of steel straight pipes with internal pressure under axial compression and bending load by seismic action. In International Conference on Offshore Mechanics and Arctic Engineering OMAE, 3, (pp. 447-455). https://doi.org/10.1115/OMAE2008-57491

Schnabl, S., Planinc, I., \& Turk, G. (2013). Buckling loads of two-layer composite columns with interlayer slip and stochastic material properties. Journal of Engineering Mechanics, 139, 961-966. https://doi.org/10.1061/(ASCE)EM.19437889.0000478 
Seyranian, A. P., \& Privalova, O. G. (2003). The Lagrange problem on an optimal column: old and new results. Structural and Multidisciplinary Optimization, 25(5-6), 393-410 https://doi.org/10.1007/s00158-003-0333-4

Singh, S. J., \& Harsha, S. P. (2019). Buckling analysis of FGM plates under uniform, linear and non-linear inplane loading. Journal of Mechanical Science and Technology, 33(4), 1761-1767. https://doi.org/10.1007/s12206-019-0328-8

Slimani, A., Ammari, F., \& Adman, R. (2018). The effective length factor of columns in unsymmetrical frames asymmetrically loaded. Asian Journal of Civil Engineering, 19(4), 487-499. https://doi.org/10.1007/s42107-018-0038-z

Sun, G., Li, S., Li, G., \& Li, Q. (2018). On crashing behaviors of aluminium/CFRP tubes subjected to axial and oblique loading: an experimental study. Composites Part B: Engineering, 145, 47-56. https://doi.org/10.1016/j.compositesb.2018.02.001

Thermou, G. E., Katakalos, K., \& Manos, G. (2018). Experimental investigation of substandard RC columns confined with SRG jackets under compression. Composite Structures, 184, 56-65. https://doi.org/10.1016/j.compstruct.2017.09.082

Thumrongvut, J., \& Tiwjantuk, P. (2018). Strength and axial behavior of cellular lightweight concrete-filled steel rectangular tube columns under axial compression. Materials Science Forum, 941, 2417-2422. https://doi.org/10.4028/www.scientific.net/MSF.941 .2417

Toufik, B., Ammari, F., \& Adman, R. (2018). Influence of load position on critical lateral torsional buckling moment of laterally restrained beam at tense flange. Asian Journal of Civil Engineering, 19(7), 839-848. https://doi.org/10.1007/s42107018-0067-7

Vu, Q. V., Papazafeiropoulos, G., Graciano, C., \& Kim, S. E. (2019). Optimum linear buckling analysis of longitudinally multi-stiffened steel plates subjected to combined bending and shear. Thin-Walled Structures, $\quad 136,235-245$. https://doi.org/10.1016/j.tws.2018.12.008

Wahrhaftig, A. M., Brasil R. M. L. R. F., \& Machado, M. A. S. (2008). Evaluation of the Buckling Critical Load of Bars Subjected to their SelfWeight. In The Ninth International Conference on Computational Structures Technology. https://doi.org/10.4203/ccp.88.13

Wahrhaftig, A. M., Brasil, R. M. L. R. D. F., \& César, S. F. (2016). Creep in the fundamental frequency and stability of a slender wooden column of composite section. Revista Árvore, 40(6), 1129-1140. https://doi.org/10.1590/010067622016000600018
Wahrhaftig, A. M., Silva, M. A. D., \& Brasil, R. M. L. R. D. F. (2019). Analytical determination of the vibration frequencies and buckling loads of slender reinforced concrete towers. Latin American Journal of Solids and Structures, 16(5), e196. https://doi.org/10.1590/1679-78255374

Wahrhaftig, A. M., Magalhães, K. M. M., \& Siqueira, G. H. (2020a). Evaluation of limit state of stress and strain of free-fixed columns with variable geometry according to criteria from the Brazilian code for concrete structures. Latin American Journal of Solids and Structures, 17(1), e244. https://doi.org/10.1590/1679-78255780

Wahrhaftig, A. M., Magalhães, K. M., Brasil, R. M. L. R. D. F., \& Murawski, K. (2020b). Evaluation of Mathematical Solutions for the Determination of Buckling of Columns Under Self-weight. Journal of Vibration Engineering \& Technologies, 1-17. https://doi.org/10.1007/s42417-020-00258-7

Wahrhaftig, A. M. (2020c). Time-dependent analysis of slender, tapered reinforced concrete columns. Steel and Composite Structures, 36(2), 229-247. https://doi.org/10.12989/SCS.2020.36.2.229

Wahrhaftig, A. M., Magalhães, K. M. M., \& Nascimento, L. S. M. S. C. (2021). Stress assessment in reinforcement for columns with concrete creep and shrinkage through Brazilian technical normative. Journal of the Brazilian Society of Mechanical Sciences and Engineering 43, 6. https://doi.org/10.1007/s40430-020-02731-6

Wang, J., Shen, Q., Jiang, H., \& Pan, X. (2018). Analysis and design of elliptical concrete-filled thin-walled steel stub columns under axial compression. International journal of steel structures, $\quad 18(2)$, 365-380. https://doi.org/10.1007/s13296-018-0002-5

Wikipedia. (2021). Wikipedia. https://en.wikipedia.org/wiki/Finite_element_method

$\mathrm{Xu}$, D., Zhao, Z., \& Zhou, J. (2013). Design and Characteristic Analysis of a Buckling Plate Vibration Isolator with Quasi zero-stiffness. Journal of Hunan University (Natural Sciences), 40(6), 47-52.

Ye, J., Mojtabaei, S. M., \& Hajirasouliha, I. (2018). Local-flexural interactive buckling of standard and optimised cold-formed steel columns. Journal of constructional steel research, 144, 106-118. https://doi.org/10.1016/j.jcsr.2018.01.012

Yiotis, A., Katsikadelis, J. T., \& Kounadis, A. (1982). Stability Analysis of Box-Shaped Structures of Rectangular Cross-Section. Revue Roumaine des Sciences Techniques. Serie Mecanique Appliquee, 27, 681-695. 
Zhou, L., Tang, J., Wang, W., Zhao, E., Ren, S., Zhang, Q., \& Liu, P. (2019). An accurate method for the calculation of ultimate load in lattice boom. Advances in Mechanical Engineering, 11(11), 1687814019886774.

https://doi.org/10.1177/1687814019886774

Zhou, T., Lu, Y., Li, W., \& Wu, H. (2017). End condition effect on distortional buckling of cold-formed steel columns with arbitrary length. Thin-Walled Structures, $\quad 117, \quad 282-293$. https://doi.org/10.1016/j.tws.2017.04.029
Zucco, G., Oliveri, V., Rouhi, M., Telford, R., Clancy, G., McHale, C., ... \& Peeters, D. (2020). Static test of a variable stiffness thermoplastic composite wingbox under shear, bending and torsion. The Aeronautical Journal, 124(1275), 635-666. https://doi.org/10.1017/aer.2019.161 